University of South Florida

DIGITAL COMMONS

@ UNIVERSITY OF SOUTH FLORIDA
Digital Commons @ University of

South Florida

$5-1-2006$

\title{
Transit Use Viability Among Older Drivers Losing Driving \\ Privileges
}

CUTR

Follow this and additional works at: https://digitalcommons.usf.edu/cutr_nctr

\section{Recommended Citation}

"Transit Use Viability Among Older Drivers Losing Driving Privileges," National Center for Transit Research (NCTR) Report No. CUTR-NCTR-RR-2005-04, Center for Urban Transportation Research, University of South Florida, 2006.

DOI: https://doi.org/10.5038/CUTR-NCTR-RR-2005-04

Available at: https://scholarcommons.usf.edu/cutr_nctr/179

This Technical Report is brought to you for free and open access by the National Center for Transit Research (NCTR) Archive (2000-2020) at Digital Commons @ University of South Florida. It has been accepted for inclusion in Research Reports by an authorized administrator of Digital Commons @ University of South Florida. For more information, please contact digitalcommons@usf.edu. 


\section{Transit Use Viability Among Older Drivers Losing Driving Privileges}

National Center Transit Resear

\author{
Center for Urban \\ Transportation Research \\ University of South Florida, Tampa
}

May 2006

National Center for

Transit Research

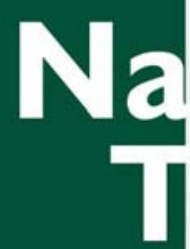

National Center

for Transit Research

Center for Urban Transportation Research

University of South Florida

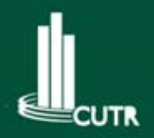

BC549-17 



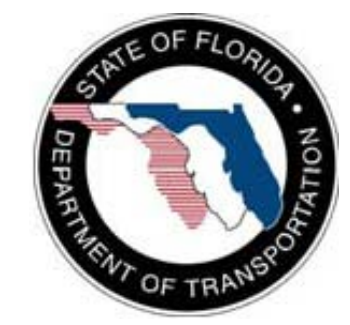

State of Florida Department of Transportation

Public Transit Office 605 Suwannee Street

Tallahassee, FL 32399-0450

(850) 414-4500

Project Manager: Amy Datz

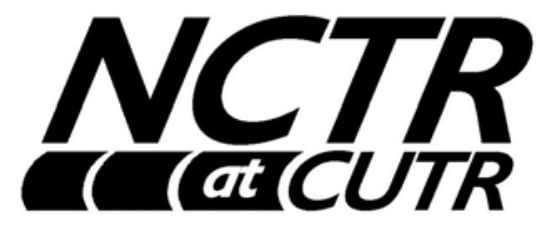

National Center for Transit Research Center for Urban Transportation Research

University of South Florida

4202 E. Fowler Avenue, CUT100

Tampa, FL 33620-5375

(813) $974-3120$

Principal Investigator: $\quad$ Steve Polzin, Ph.D., P.E.

Director, Public Transportation Research Program 


\section{Disclaimer}

"The opinions, findings, and conclusions expressed in this publication are those of the authors and not necessarily those of the State of Florida Department of Transportation." 
TECHNICAL REPORT STANDARD TITLE PAGE

\begin{tabular}{|c|c|c|c|}
\hline $\begin{array}{l}\text { 1. Report No. } \\
\text { NCTR 776-01 } \\
\text { FDOT BC 549-17 }\end{array}$ & 2. Government Accession No. & \multicolumn{2}{|c|}{ 3. Recipient's Catalog No. } \\
\hline \multirow{2}{*}{\multicolumn{2}{|c|}{$\begin{array}{l}\text { 4. Title and Subtitle } \\
\text { Transit Use Viability Among Older Drivers Losing Driving Privileges }\end{array}$}} & \multicolumn{2}{|l|}{$\begin{array}{l}\text { 5. Report Date } \\
\text { May } 2006\end{array}$} \\
\hline & & \multicolumn{2}{|c|}{ 6. Performing Organization Code } \\
\hline \multicolumn{2}{|l|}{ 7. Author(s) } & \multicolumn{2}{|c|}{ 8. Performing Organization Report No. } \\
\hline \multirow{2}{*}{\multicolumn{2}{|c|}{$\begin{array}{l}\text { 9. Performing Organization Name and Address } \\
\text { National Center For Transit Research (NCTR) } \\
\text { University of South Florida CUT } 100 \\
4202 \text { East Fowler Avenue, Tampa, FL } 33620\end{array}$}} & \multicolumn{2}{|l|}{ 10. Work Unit No. } \\
\hline & & \multicolumn{2}{|c|}{$\begin{array}{l}\text { 11. Contract or Grant No. } \\
\text { DTRS98-G-0032 }\end{array}$} \\
\hline \multicolumn{2}{|c|}{$\begin{array}{l}\text { 12. Sponsoring Agency Name and Address } \\
\text { Office of Research and Special Programs (RSPA) } \\
\text { U.S. Department of Transportation, Washington, D.C. } 20590\end{array}$} & \multicolumn{2}{|c|}{ 13. Type of Report and Period Covered } \\
\hline \multicolumn{2}{|c|}{$\begin{array}{l}\text { Florida Department of Transportation } \\
605 \text { Suwannee Street, MS 26, Tallahassee, FL } 32399\end{array}$} & \multicolumn{2}{|c|}{ 14. Sponsoring Agency Code } \\
\hline \multicolumn{4}{|c|}{$\begin{array}{l}\text { 15. Supplementary Notes } \\
\text { Supported by a grant from the USDOT Research and Special Programs Administration, and the Florida } \\
\text { Department of Transportation }\end{array}$} \\
\hline \multicolumn{4}{|c|}{$\begin{array}{l}\text { 16. Abstract } \\
\text { Effective January } 1,2004, \text { Florida Statute } 322.18 \text {, subsection } 5 \text {, requires drivers } 79 \text { years or older to pass vision tests when } \\
\text { renewing their six-year licenses. Such a mandate is part of an "age-based" testing regime that several U.S. states have } \\
\text { implemented in recent years with respect to enhancing the safety environment afforded to road users. Implementation of "age-based } \\
\text { testing" produces a group of travelers who could provide a resource in understanding travel behavior changes and mode choice } \\
\text { after driving cessation. The objective of this study is to provide additional insight into travel behavior changes for persons who lose } \\
\text { their driving privileges, particularly their interest in, ability to, and subsequent use of public transit. First, a literature review of } \\
\text { developments that have impacted senior travel behavior is presented. Developments such as the changing demographics of } \\
\text { seniors, senior socio-economic status and the process of driving retirement (i.e., driving reduction ultimately resulting in driving } \\
\text { cessation) are then discussed. A descriptive overview of senior travel behavior as derived from analyses of publicly available } \\
\text { datasets is complemented by findings from focus group discussions on senior travel behavior. Recommendations originating from } \\
\text { this study are as follows: increase the provision of information to seniors regarding their mobility options; continue the adaptation of } \\
\text { vehicles to accommodate older travelers; explore additional roles for local transit providers and monitor trends in driving cessation } \\
\text { and senior mobility as part of local public transportation planning functions. Knowledge gaps in our understanding of senior travel } \\
\text { needs before and after driving cessation are also presented. In conclusion, there is, no doubt, a strong consensus on the desire to } \\
\text { find more efficient and cost effective ways to serve the travel needs of older persons, but there is far less consensus regarding the } \\
\text { extent of public resources that should be spent to attract more trips into the realm of public responsibility. }\end{array}$} \\
\hline $\begin{array}{l}\text { 17. Key Words } \\
\text { Elderly Mobility, Driving Cessation, } \\
\text { Transit }\end{array}$ & $\begin{array}{l}\text { 18. Distribution Statement } \\
\text { Available to the public through } \\
\text { Service (NTIS), } 5285 \text { Port Ro } \\
\text { 487-4650, http://www.ntis.gov } \\
\text { http://www.nctr.usf.edu/. }\end{array}$ & $\begin{array}{l}\text { National } \\
\text { Road, Spr } \\
\text { nd through }\end{array}$ & $\begin{array}{l}\text { Information } \\
22161,(703) \\
\text { web site at }\end{array}$ \\
\hline $\begin{array}{l}\text { 19. Security Classif. (of this report) } \\
\text { Unclassified }\end{array}$ & $\begin{array}{l}\text { 20. Security Classif. (of this page) } \\
\text { Unclassified }\end{array}$ & $\begin{array}{l}\text { 21. No. of pages } \\
131\end{array}$ & $\begin{array}{l}\text { 22. Price } \\
\text { none }\end{array}$ \\
\hline
\end{tabular}

Form DOT F 1700 
[This page left blank intentionally] 


\section{ACKNOWLEDGEMENTS}

The authors are grateful to the following organizations for their assistance in the execution of this project:

Department of Aging Services Hillsborough County (FL) Florida Department of Highway Safety and Motor Vehicles Focus Group participants and facilitators, Hillsborough County (FL) 
[This page left blank intentionally] 


\section{EXECUTIVE SUMMARY}

Effective January 1, 2004, Florida Statute 322.18, subsection 5, requires drivers 79 years or older to pass vision tests when renewing their six-year licenses. Several U.S. states have implemented similar mandates in recent years to enhance road safety. This action is one of many that acknowledges the impending boom in population belonging to age brackets in which driving risks are known to increase. Many older members of these populations will no longer be able to drive. Meeting the mobility needs of those for whom driving is no longer an option will be a challenge for Florida and, indeed, the rest of the nation. Determining an appropriate role for public transportation will be part of addressing this challenge.

The objective of this project is to study the travel behavior changes of persons ( 55 years and older) who lose their driving privileges. Researchers will investigate subjects' interest in and ability to use public transit, as well as their actual use of public transit. While it is extremely challenging to determine the magnitude of the role that public transportation might play in meeting the travel needs of elder baby boomers, it is possible for the public transportation research community to begin to explore the nature of the travel demand that may arise and how the industry might position itself to respond. Towards that end, this research effort will explore opportunities and challenges for public transportation in meeting the travel needs of ceased drivers.

The issues surrounding driving cessation and its impact on public transportation, particularly in the future, are quite complex and involve subjects beyond the traditional areas of interest of transportation planners. For example, progress in medical care, improvements in technologies to mitigate the impacts of physical and mental decline, and changes in the social and cultural environment are all likely to influence travel needs of the elderly population in the future.

The baby boomer generation has been characterized as suburban in concentration, and the historic tendency has been for elders to retire in place. This suggests that the next generation of elders will be concentrated in suburban locations where traditional fixed-route public transportation will less likely be in place to provide the quality of service that most of these customers will demand. Fewer of the next-generation of elders will have grown up in locations with good public transportation service or have themselves been regular users of public transportation, both as a result of population migrations to the south and the west, and a general decline in public transportation use in the past several decades. Despite the strong growth of public transportation services in some of the western and southern areas that have experienced rapid population increases, the majority of the future elder population will not be very familiar with public transportation.

Perhaps the most important issue with regard to public transportation demand will be the ability of future seniors to rely upon family, household members, or friends as mobility 
providers. Indeed, focus groups revealed that the extent of family and friend support to meet mobility needs strongly influences how successfully elders who discontinue driving adapt. The presence of such support will be critical in determining the extent to which public transportation is desired or necessary. The focus groups addressed household relocation in order to have greater access to public transportation (which would impact transit demand), as an option for both elder drivers and those no longer able to drive. Proximity to public transportation does not appear to be a high-priority strategic consideration in household location.

Currently, transit plays a modest overall role, although it is very important to those who rely on it. Public transportation is not necessarily the logical successor to driving as a means of travel; it certainly is not the substitute of choice. Most often, the conditions that lead one to cease driving result in the person preferring to travel as an auto passenger, providing someone or some entity can provide driving services. While seniors who have ceased driving are frequently reluctant to be burdensome to others, the practical reality remains that few find themselves in a situation where fixed-route transit services are a viable option.

Among the strategies that can support improved mobility for persons no longer able to drive are the following:

- Explore opportunities to provide mobility information through a single group or entity in an urban area, going beyond the current coordination of mobility providers towards a standardized information resource.

- Continue adapting vehicles and facilities to more readily accommodate older travelers.

- Explore and support additional roles for the local transit providers in terms of meeting overall mobility needs of older travelers (e.g., hosting or coordinating ride sharing initiatives).

- Monitor trends in driving cessation and senior mobility as part of local public transportation planning functions.

The study concludes that while there is certainly political will to ensure safety-net services to provide for medical and sustenance trips for those in need, this level of service falls well short of providing quality-of-life enhancing services or increasing the prospect that high quality public transit services can begin to attract a larger share of trips from persons who might otherwise rely on family or friends for mobility. There is a strong desire to find more effective and cost-efficient ways to serve the travel needs of older persons, but there is far less consensus regarding the extent to which public resources and facilities should be applied to attract and absorb the increase of trips occasioned by driving cessation.

The research will be of interest to Florida-based mobility providers and will benefit public transportation operators by providing a better understanding of the potential size and mobility needs of the market of individuals who may be ceasing and/or have ceased to drive. Public transportation service providers can both shape and market their services to this 
audience. Dissemination of the findings will enhance the urgency of developing and implementing strategies to accommodate ceasing drivers, either through driver training programs or public transit provision. This is of particular concern to states with significant senior populations.

Overall potential benefits, thus, would include enhanced road safety for all road users and continuance of healthy lifestyles for seniors who, without having to operate vehicles, are able to meet their traveling needs in a state that is known to be and that strives to continue to be welcoming and supportive of its seniors. 
[This page left blank intentionally] 


\section{TABLE OF CONTENTS}

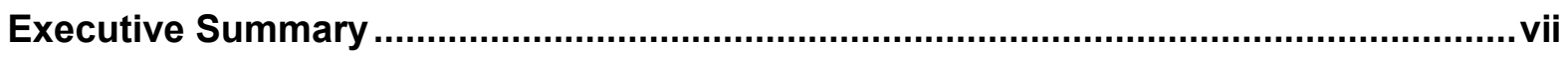

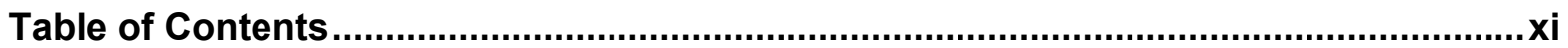

List of Figures

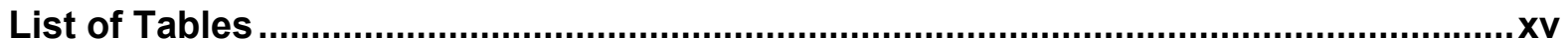

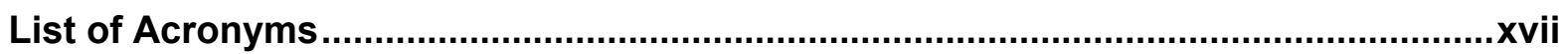

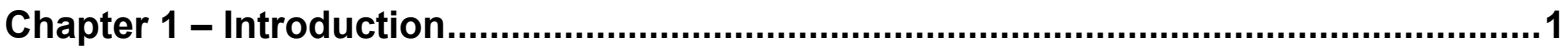

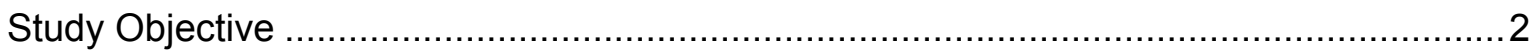

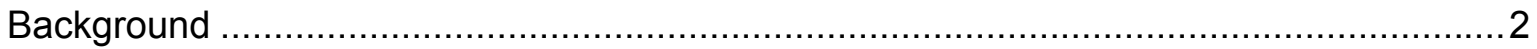

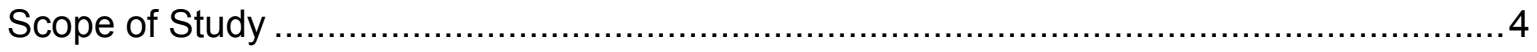

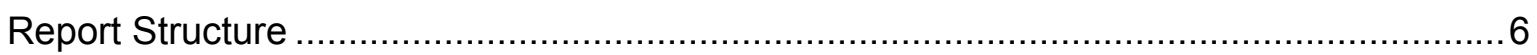

Chapter 2 - Recent Developments Impacting Senior Travel Behavior............................

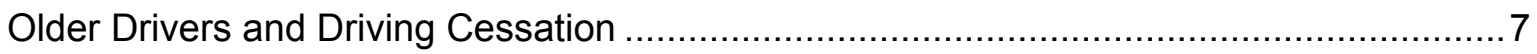

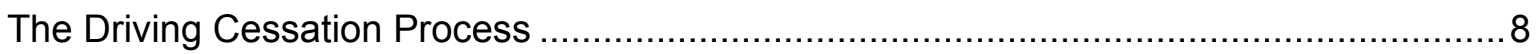

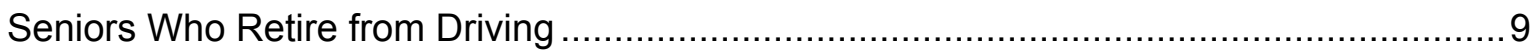

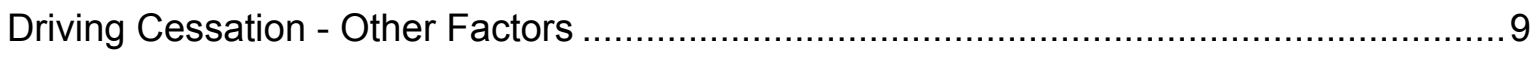

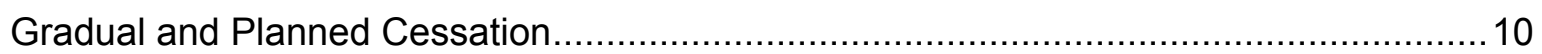

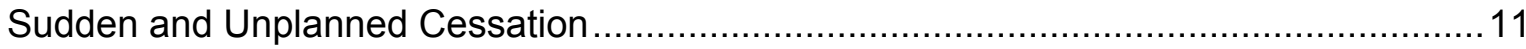

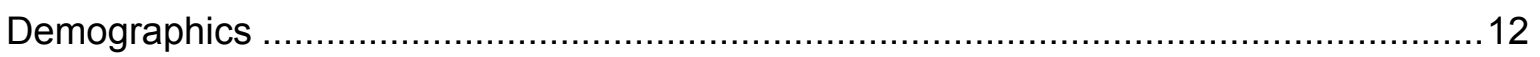

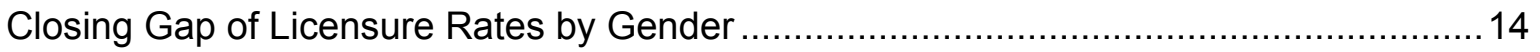

Moves Toward Age-Based Driver Testing by State Licensing Authorities ......................15

Increased Susceptibility to Injury Arising from Motor Vehicle Crashes ...........................18

Seniors Potential to be More Dependent on Outside Resources for Mobility...................19

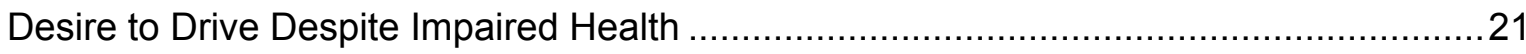

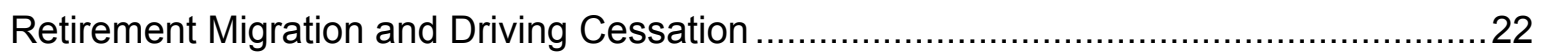

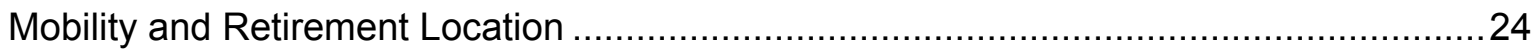

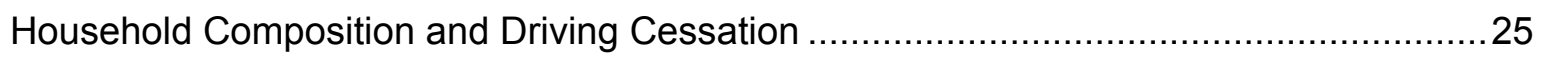

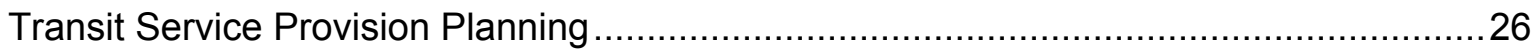

Chapter 3 - An Overview of Senior Driver and Travel Behavior in Florida ..................27

National Household Travel Survey $2001 \ldots \ldots \ldots \ldots \ldots \ldots \ldots \ldots \ldots \ldots \ldots \ldots \ldots \ldots \ldots \ldots \ldots \ldots \ldots \ldots \ldots \ldots \ldots \ldots \ldots \ldots \ldots \ldots \ldots \ldots \ldots \ldots . . .27$

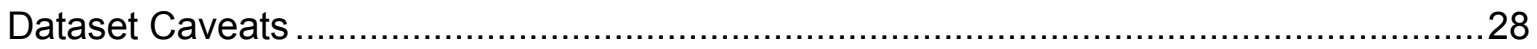

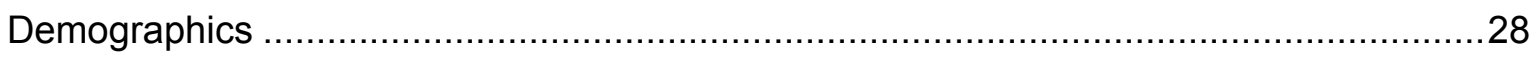

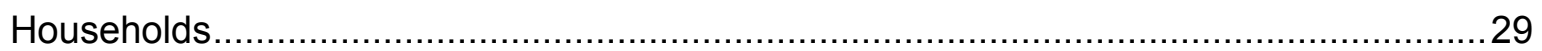

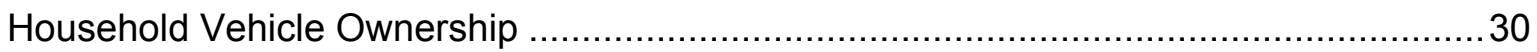

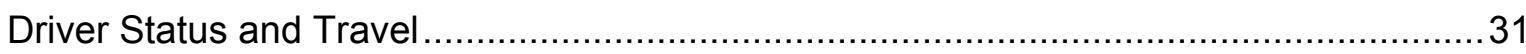

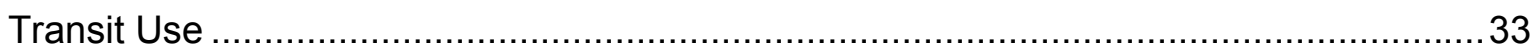

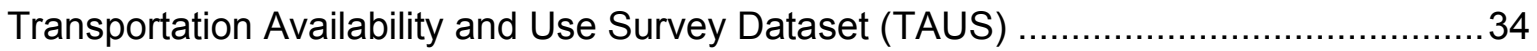

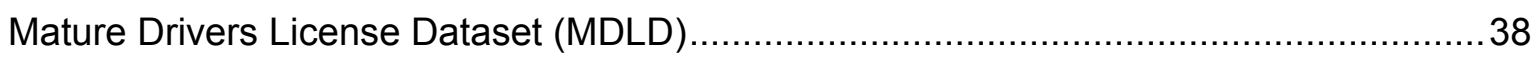


Mature Drivers License Dataset Caveats ..................................................... 39

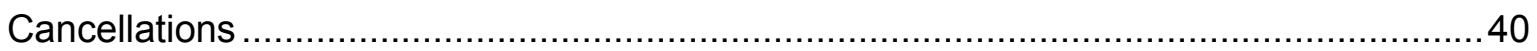

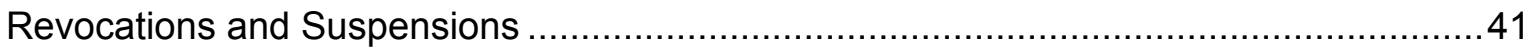

Estimates of Former Drivers Needing Alternative Transportation Options ......................42

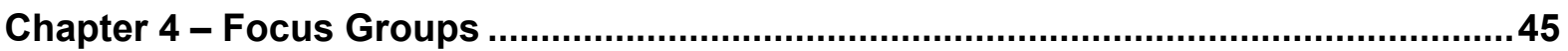

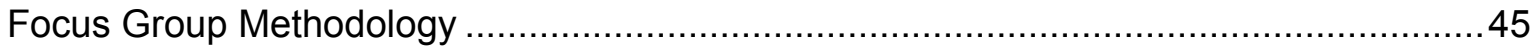

Socio-Economic and Demographic Profile of Focus Group Participants ........................46

Current Driving Status of Focus Group Participants ............................................. 47

Current Licensure Status of Focus Group Participants .........................................48

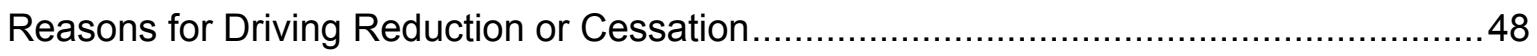

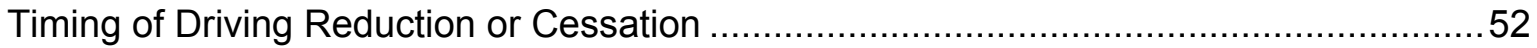

Consequences of Driving Cessation or Reduction ...............................................52

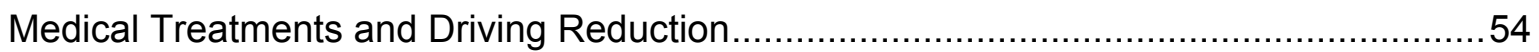

Feelings/Emotions when Driving Less or Not Driving .........................................55

Transportation Mode Currently Used .............................................................. 56

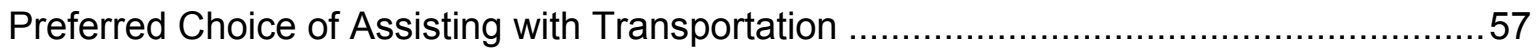

Role of Public Transportation During Driving Reduction or After Driving Cessation .........59

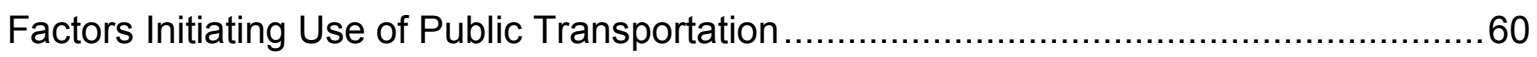

Fears or Concerns in Using Public Transit .............................................................. 62

Retirement Relocation and Public Transit Accessibility ...........................................6 62

Viability of Using Public Transit in the Future ............................................................64

Chapter 5 - Conclusions and Recommendations ..................................................65

The Demand for Publicly Provided Elder Transportation .........................................6 65

The Size of the Elder Market that may be Served by Public Transit ..............................67

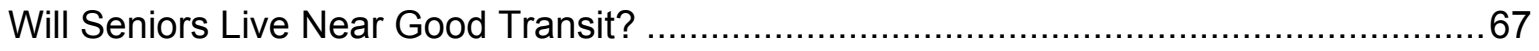

To What Extent Will Family Mobility Options Exist? .................................................69

Will Alternative Public Transit Services Help? ............................................................ 70

Will Seniors Move to be Near Transit? ................................................................... 70

Will Changing Elder Health Impact the Transit Market? .......................................... 71

Will Travel Rates Influence Overall Transit Demand? ............................................... 72

Tactics and Strategies for Providing Transportation for the Elderly ...............................72

Information and Knowledge Needs to Support Improved Transportation for the Elderly ..76

Public Transportation's Role in Meeting Travel Needs for Ceased-Driving Seniors..........80

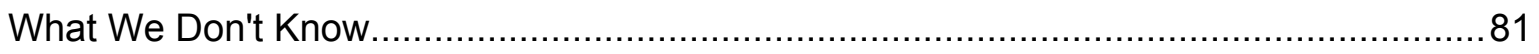

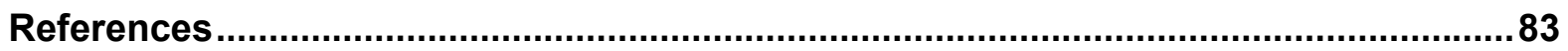

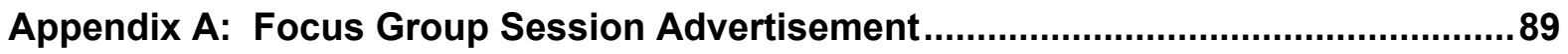

Appendix B: Focus Group Session Structure ........................................................... 93

Appendix C: Focus Group Questionnaire - Former Drivers.......................................97

Appendix D: Focus Group Questionnaire - Current Drivers ....................................105 


\section{LIST OF FIGURES}

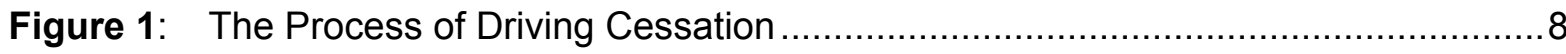

Figure 2: Percentage of Persons 65 Years or More of Total Population (20002030)

Figure 3: Percentage of Persons 65 Years or More of Florida Population (2000-2030). 13

Figure 4: Percentage of Population Licensed by Age Cohort and Gender in 2000 14

Figure 5: Predicted Percentage of National Population Licensed in the 75 to 84 Year Cohort by Gender 15

Figure 6: Passenger Vehicle Fatal Crash Involvements Rate per 100 Million Miles Traveled (April 2001-March 2002) ....................................................18

Figure 7: Living Arrangements of Adults 65 Years and Older 1990 and 2000 ................20

Figure 8: Persons Who Needed Assistance with Activities by Age ................................20

Figure 9: The Retirement Migratory Cycle............................................................ 23

Figure 10: Florida Population Estimates by Age Cohort (Year 2001).............................29

Figure 11: Percent of "Life Cycle" Households by Income (Year 2001) .............................30

Figure 12: Vehicles per "Life Cycle" Household (Year 2001) ............................................31

Figure 13: Licensure Rate by Age Cohort (Year 2001) ....................................................32

Figure 14: POV Travel (Driver/Passenger) Proportion by Age Cohort (Year

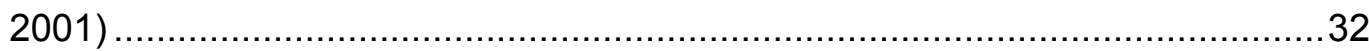

Figure 15: POV Driver Status of All Trips Made by Age Cohort (Year 2001) ....................33

Figure 16: Percent Transit Trips by Age Cohort (Year 2001) ........................................34

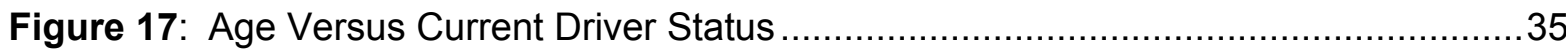

Figure 18: Age Versus Current Driver and Disability Status...........................................36

Figure 19: Responses of Seniors (55+ Yrs) to the Question: "Do you ever plan

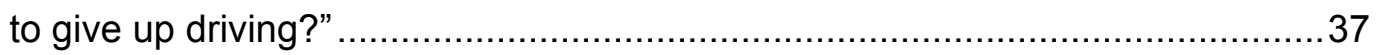

Figure 20: Licenses Revoked or Suspended 2002-2004 ........................................42

Figure 21: Age Breakdown of Focus Group Participants ............................................46

Figure 22: Years of Driving Experience at Point of Driving Cessation ..............................47

Figure 23: Factors Influencing Permanent Driving Cessation .....................................48

Figure 24: Self-Imposed Driving Restrictions on Seniors ............................................... 51

Figure 25: Preferred Choice in Assisting with Transportation ........................................57

Figure 26: Factors Enhancing Potential Use of Public Transportation ............................61

Figure 27: Factors Influencing Concerns About Using Public Transit ..............................62

Figure 28: Importance of Access to Public Transit if Having to Relocate..........................63

Figure 29: Characterization of the Public Transportation Market Potential of an

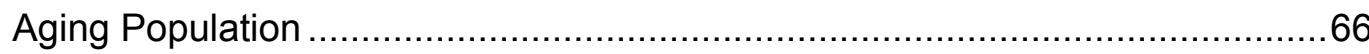


Figure 30: The Decision on Using Public Transportation for Ceased Driver (Schematic of Older Traveler Travel Decision-Making)...... 


\section{LIST OF TABLES}

Table 1: $\quad$ NHTS Data File Statistics...................................................................... 28

Table 2: $\quad$ Modal Split for Daily Travel in 2001 Florida and the U.S.A. ............................ 34

Table 3: $\quad$ Type of Transportation Used Most Frequently ...........................................37

Table 4: $\quad$ Florida Mature Drivers License Dataset File Types and Contents .....................39

Table 5: $\quad$ License Cancellation Statistics Voluntary Surrender of License .......................41

Table 6: 2004 License Cancellation Statistics Voluntary Surrender of License

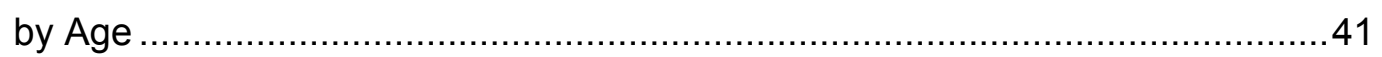

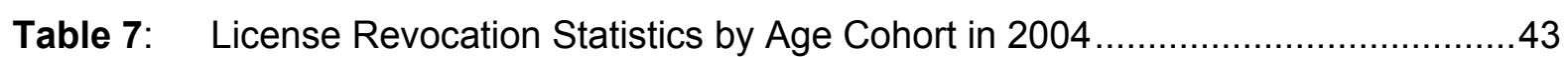

Table 8: Viability of Future Consideration of Public Transportation as a

Transportation Alternative ..................................................................64 
[This page left blank intentionally] 


\section{LIST OF ACRONYMS}

\begin{tabular}{ll} 
AAA & American Automobile Association \\
ASCII & American Standard Code for Information Interchange \\
BTS & Bureau of Transportation Statistics \\
CATI & Computer-Aided Telephone Interview \\
CUTR & Center for Urban Transportation Research \\
DL & Drivers License \\
DUI & Driving Under the Influence \\
FDOT & Florida Department of Transportation \\
FHWA & Federal Highway Administration \\
FTP & File Transfer Protocol \\
HSMV & Florida Department of Highway Safety and Motor Vehicles \\
IIHS & Insurance Institute of Highway Safety \\
MDLD & Mature Drivers License Dataset \\
NHTS & National Household Travel Survey \\
NHTSA & National Highway Traffic Safety Administration \\
NPTS & Nationwide Personal Travel Survey \\
OHPI & Office of Highway Policy Information \\
POV & Personally-Operated Motor Vehicle \\
RDD & Random Digit Dialing \\
RV & Recreational Vehicle \\
SIPP & Survey of Income and Program Participation \\
SUV & Sport Utility Vehicle \\
TAUS & Transportation Availability and Use Survey \\
TRB & Transportation Research Board \\
TRIS & Transportation Research Information Services \\
USDOT & U.S. Department of Transportation \\
\hline
\end{tabular}


[This page left blank intentionally] 


\section{CHAPTER 1 - INTRODUCTION}

Effective January 1, 2004, Florida Statute 322.18, subsection 5, required drivers 79 years or older to pass vision tests when renewing their six-year licenses. Such a mandate is part of an "age-based" testing regime that several U.S. states have implemented in recent years with respect to enhancing the safety environment afforded to road users. ${ }^{1}$ Age-based license renewal testing is defined as a situation where "the nature or schedule of renewal testing changes with age" (Lange \& McKnight 1996, p. 81). This action is one of many taking place that signal recognition of the impending boom in population that will reach age brackets where driving risks are known to increase. Perhaps more so than prior generations, the next generation of elders are individuals who, for the most part, have a long history of driving; are independent-minded; have grown accustomed to high levels of mobility, which they cherish; and are less likely to have spouses, siblings, and children who are able to provide for their mobility. Thus, the role of government in regulating driver licensing and in providing mobility alternatives promises to be a challenge over the next several decades.

Florida, long known as a Mecca for retirees, currently has an estimated 710,000 drivers 80 years or older who have a class A, B, C, D, E or O license. ${ }^{2}$ Currently, as the fourth most populous state, with an estimated 18 million persons, and one with the second highest median age of 38.7 years in the U.S., Florida has a strong interest in gaining a full understanding of the mobility needs of the older population and the implications of driving cessation/retirement. If one percent of older drivers were to fail the vision test annually, about 7,000 drivers would need to look for alternative modes of transportation to remain active in their communities. However, it should be noted that "the literature has not yet provided estimates of the current or future incidence of driving cessation" (Waldorf 2001, p. 23).

Implementation of "age-based testing" produces a group of travelers who could serve as a resource in understanding travel behavior changes and mode choice after driving cessation. A richer understanding of driving cessation and accommodation will enable informed planning and policy making to support the mobility of non-drivers in communities, as "the [transportation] needs of older citizens are predictable so accommodating them is possible" (Freund, 2004, p. 114). Nevertheless, the wider implications of this potential challenge need to be placed against the backdrop that "mobility is critical to well-being" (Coughlin \& Lacombe 1997, p. 91).

\footnotetext{
${ }^{1}$ For the current status of senior licensing laws in the U.S. refer to the AAA Public Affairs website (www.aaapublicaffairs.com).

2 Based on personal communication with M. Grosz of the Florida Department of Highway Safety and Motor Vehicles.
} 


\section{Study Objective}

With an aging national population and a particularly high concentration of older persons in Florida (17.57\% of Florida's population in 2000 was older than 64 , the highest of any U.S. state), it is very important to understand older adult travel needs and behaviors, particularly at a point in time when they are no longer able to drive. This project is intended to provide additional insight into travel behavior changes for persons who lose their driving privileges, particularly their interest in, ability to, and subsequent use of public transit.

The public transportation industry has shown a key interest in the challenges and opportunities that can be presented as the baby boomers age and perhaps cease driving. With the large influx of new retirees expected over the next few years, some of them will lose their ability to drive; an opportunity is created for the public transportation community to provide a valuable service for these individuals. Within the industry, there is a range of expectations with respect to the size and opportunity this market may present to public transportation. While some feel there is an impending tidal wave of opportunity and need, others are more sanguine, reflecting on the prospect that few of the baby boomers have ever used public transportation; more are attached to auto mobility; and fewer live in areas sufficiently dense to support quality public transit service.

While it is premature to determine the magnitude of the role that public transportation might play in meeting the travel needs of elder baby boomers, it is certainly reasonable to anticipate that public transportation will be an important provider for some segments of the population. There will be individuals who will lose their driving privileges and will not have alternative mobility options that might be afforded through privately-purchased services or strong family support. Public transportation will be called on to provide a safety net for this segment of the population. Thus, it is prudent for the public transportation research community to begin to explore the nature of the travel demand that may arise and how the industry might position itself to respond. Towards that end, this research effort can make a useful contribution.

\section{Background}

At a time when 85 percent of persons over the age of 15 years hold a drivers license (Office of Highway Policy Information (OHPI), 2003), and each person in 2001 traveled 40 miles per day, of which 35 miles were in a personal vehicle (U.S Department of Transportation 2003, p. 9), mobility has reached unprecedented levels. This is coupled with seniors experiencing "longer, happier, fuller lives than their counterparts today and certainly than the elderly of just a few decades ago" (Rosenbloom 2004, p. 3). The ability to drive is for many people highly correlated to their level of enjoyment of life. Using the 1995 Nationwide Personal Travel Survey (NPTS) data, Evans (2001, p. 152), found that there was a 
substantial difference in trip-making associated with driving and that this association increases with age. This difference is most pronounced and most critical among the $75+$ population. While 75 percent of $75+$ drivers went out at least once on their trip day, just 44 percent of non-drivers age 75 and older went out. [This finding suggests that having access to a car, allows greater participation in activities outside of the home, and thus elevates ones enjoyment of life and well-being.]

A similar result was found by Straight (1997) in her study of travel behavior and preferences of drivers and non-drivers 75 years and older where she concluded that the "level of mobility is strongly related to whether or not one drives." However, caution needs to be exercised here, as some of the considerations that influence driving also influence the desire for mobility. For example, persons with serious mobility limitations such as being bedridden have constraints to mobility beyond their ability to drive a vehicle.

Rosenbloom (2004, p. 3), while reflecting on the potential rosy outlook, goes on to state that

there is no evidence that older people's desire to travel will decline at the same rate as their ability to drive or to find other options. Many older people may ultimately find themselves cut off from the very aspects of life that made their early retirement years so much better than those of older people only a few decades ago.

Along with the inability to drive and its impact on mobility, "declining health may well result in reduced activity regardless of the ability to drive" (Marottoli et al. 2000, p. S335). Thus, it can be argued that there are at least two generalized mobility challenges faced by the elderly: the means of mobility, e.g., personal transportation; and the physical capacity to be mobile, influenced by the physical/health status of the individual.

Being able to operate a car has become synonymous (and, in many cases, a necessary requirement) to experience enhanced levels of livability and consumption. Foley et al. (2002, p. 1288) describe the operation of a car as a "pervasive task of independence." The intimate relationship between man and the automobile has resulted in a situation where, "for most Americans, driving is considered essential to the well-being and essential to maintain a good quality of life" (Adler et al. 1999, p. 28). This dependence on driving has created a situation where giving it up may be experienced "as the first step towards a downward spiral of dependency" (Horowitz et al. 2002, p. 262). This state of dependency becomes critical when no family or friend is available nearby to assist the individual, which may lead to isolation, eating disorders, institutionalization, and premature death (McSwain, as quoted in Stanfield [1996]). Because of dependency on a lifestyle that has revolved around the capacity to drive an automobile, any changes brought about by transitions in personal 
mobility will have far reaching consequences, impacting not only the individuals involved, but their immediate families and society as well.

The uniqueness of the U.S. mobility environment has given rise to the above situation as, "in many areas of the country there is no adequate public transportation, and many people must drive if they are to function in their community" (Freedman \& Freedman 1996, p. 876). Indeed, "recent and contemporary urban development practices and public transportation policies have catapulted the private car into its role as the preeminent means of individual transportation" (Yassuda et al. 1997). This has resulted in negative and yet unwarranted perceptions of public transportation to be held by many people. Studies have related how the elderly have viewed public transportation in the U.S. as inconvenient, unpleasant, and even dangerous if it requires waiting at secluded bus stops or crossing busy intersections (Messinger-Rapport \& Rader 2000). Noting these negative perceptions of public transportation, the elderly may feel that after driving for many years, "they deserve better" (Shope 2003, p. 58).

The myriad factors that can influence driving ability and the onset of driving cessation have given rise to the need for a greater understanding of travel behavior during and after this period of transition. Adler et al. (1999) surmised that, the longer an individual drives, the more accustomed they become towards driving and the less likely they are to cease from driving even after diagnosis [of a condition that affects driving ability] and the greater risk they become to other road users. Mobility providers and, of particular interest in this research, public transportation operators can benefit from a better understanding of the potential size and mobility needs of the market of individuals who may be ceasing to drive.

\section{Scope of Study}

The focus of this study is mobility issues pertinent to senior residents in Florida. Despite the focus on Florida, national perspectives are used to provide additional context as well as permit comparison. Literature resources referenced in this project are based on studies conducted in the U.S., as published from January 1990 to December 2005. A variety of electronic databases related to aging/gerontology and transportation were searched, e.g., Ageline, Psylnfo, and Transportation Research Information Services (TRIS). The key search strings were "driving cessation" and "cessation of driving." The reader is referred to a publication entitled "Age-Related Disabilities that may Impair Driving and their Assessment," which provides an exhaustive literature review by Janke (1994) or to search the above-named databases for further references.

This particular research effort, while exploratory in nature and modest in the context of all that should be learned about the mobility needs of an aging population, will strive to provide greater insight into the impacts of driving cessation and the travel behavior implications to individuals and mobility providers. This project, supported by the Florida Department of Transportation Public Transit Office is part of the overall research work program of the 
National Center for Transit Research at the Center for Urban Transportation Research at the University of South Florida. The original work program consisted of the tasks referenced below in abridged form.

\section{Task 1. Liaison with Other Agencies}

The initial task involved a series of meetings with various agencies to explore the availability of data, critical policy issues and early experience since the Florida vision testing program took affect.

\section{Task 2. Literature Review}

There were several bodies of literature that were consulted to develop a strong context in which knowledge both helped shape the data collection phase and enabled the researchers to better understand how the findings from this work could be generalized to a larger population or domain.

\section{Task 3. Research Design}

This task involved refining the actual data collection and analysis plan in light of the project goals, knowledge about legal and practical experience in collecting this type of information from this population, and possible data processing methods. The project team had to make tradeoffs between content and methods in light of cost and other constraints. The research team then had to explore various data collection strategies such as surveys, interviews and focus groups. The possibility of travel diaries, exploration of how one might collect information about pre-driving cessation travel, and the prospect of doing longitudinal data collections (resurveyed after a period of time to see how behavior had changed) was explored.

\section{Task 4. Identifying and Locating Older Drivers}

This task developed a sample or enrollment strategy given the available information. This task also designed a strategy for obtaining commitment for participating in the research.

\section{Task 5. Conducting Surveys and Organizing Data}

This task involved carrying out the resultant data collection strategy(ies). This task was influenced primarily by the nature of the selected strategy. A combination of analytical and narrative or descriptive data was collected and a variety of methods were employed.

Task 6. Data Analysis

This task involved analyzing the data. This included some statistical analysis as well as qualitative analysis of the data.

Technical Memorandum One (Polzin and Page 2005) outlined the research plan as it evolved after exploration of data availability. Three situations meaningfully influenced the scope of this report. First, the Florida Department of Motor Vehicles had under contract an 
arrangement with another researcher to study the consequences of the driving vision test. This research, scheduled to have been completed in fall 2005 but not yet available as this report was written, reduced the need to focus exclusively on driving vision test results as a source of post-driving cessation participants. Second, the quality of the data in the Mature Drivers License Database was sufficiently compromised as to render its value less than originally expected. This resulted in a greater focus on alternative data sources to understand post-driving cessation travel conditions. Finally, the cooperation of personnel from the Department of Aging Services, Hillsborough County and the opportunity to work with their clients for information about post-driving cessation attitudes and needs provided a rich opportunity to gather focus group data. The subsequent chapters ( 4 and 5 , in particular), report on the research findings and results.

\section{Report Structure}

The study results are presented in five chapters. This first chapter provides an introduction and context setting of the study. Chapter 2 represents a literature review on developments that have impacted senior travel behavior. Developments such as the changing demographics of seniors, senior socio-economic status and the process of driving retirement (i.e., driving reduction ultimately resulting in driving cessation) are reviewed. Chapter 3 presents a descriptive overview of senior travel behavior as derived from analyses of publicly available datasets. In addition to presenting a quantitative description of senior travel behavior, qualitative research methodologies (in the form of focus group discussions) were also employed. Results from these discussions on senior travel behavior are presented in Chapter 4. Finally, conclusions and recommendations emanating from this study are presented in Chapter 5.

Note: In this report the terms "seniors" and the "elderly" are used interchangeably referring to persons 55 years of age and older. In addition, persons between 55 - 64 years of age are also referred to as the "young-old," 65 - 74 years the "old-old," and those 75 years and older the "oldest-old." 


\section{CHAPTER 2 - RECENT DEVELOPMENTS IMPACTING SENIOR TRAVEL BEHAVIOR}

Knowledge of driving cessation will provide valuable insight into travel and transit use by the growing population of older Americans. Indeed, "the challenge to understand personal lifestyle and transportation decision-making as people age" (Transportation Research Board (TRB) 2005, p. 24) still represents an increasingly critical research need in 2005/2006. In the process of striving to develop a richer understanding of driving cessation, determining its impact on subsequent travel behavior, and understanding the viability of public transit use in maintaining senior mobility and well-being, a number of recent developments influence our thinking. These developments are presented in this chapter.

\section{Older Drivers and Driving Cessation}

Kostyniuk \& Shope (2003, p. 408) remark that "there is no precise age at which a driver becomes an older driver." This fact is further emphasized by Coughlin (2001, p. 2) when he states that the "chronological age is not a perfect indicator of who is an older driver." According to Marottoli et al. (2000, p. S339), "Caution should be exercised in crafting legislation until acceptable levels of risk are identified in order to avoid over-regulating and unnecessarily preventing large numbers of people from driving, with potential substantial negative effects on their lifestyles." Rosenbloom (2003, p. 10) has reported that "many countries and a few U.S. states are moving away from age-based testing to behavior-based testing." Such a strategy has been argued to have merit; as Rosenbloom, in the same article, states, "Age-based testing is rarely useful or cost-effective." Nonetheless, widely reported incidents of tragic consequence resulting from elder driver accidents keep these issues in front of the public and result in different localities or states trying various different strategies to address an acknowledged problem.

Driving cessation can be voluntary (i.e., without legal intervention) (Dellinger et al. 2001) or mandated (i.e., forced), stemming from the intervention by a third party such as a family member or court. Driving cessation differs from driving restriction; the latter is a process where individuals manage their impairment by driving at specific times of the day along familiar routes and/or avoiding left turns for example. In a study by Straight (1997) of drivers and non-drivers over 75 years, it was found that 63 percent of drivers who still drive said they avoid traveling at night, 34 percent avoided driving in the rain, and 50 percent avoided driving during rush hour. According to Burkhardt et al. (1998, p. 450) to minimize the negative connotations surrounding the word "cessation" or "quitting," phrases such as "graduating from driving" or "driving retirement" may be more amenable, especially to males.

During a period of driving restriction, trip-making can still be accommodated "without searching for alternative travel modes" (Waldorf 2001, p. 24). This period provides a "window of opportunity" (Wang \& Carr 2004, p. 144) for the elderly to consider their future 
travel needs and transportation modes that may be suitable to meet them. This period of opportunity, evidenced by restrictions in driving behavior, may have a downside if remedial actions are not taken in that "anticipated mobility consequences actively discourage some persons from reducing or ceasing driving" (Burkhardt 1999, p. 11). Thus, unsafe drivers continue to drive, posing a danger to themselves and others while ignoring alternative transportation possibilities that may be available. By considering alternative transportation possibilities during the period of driving restriction, the trauma of being forced to quickly consider alternative modes and trip-making behavior when driving has ceased altogether is reduced.

\section{The Driving Cessation Process}

It is helpful to understand the concept of driving cessation from an aging perspective.

Figure 1 presents the process of driving cessation and the ceasing of trips made as a driver and the possibility of future travel being made as a passenger using private or public transportation. It is accepted in the majority of cases that driving cessation is a process and has been appropriately described as a "cessation continuum" by Dellinger et al. (2001, p. 435). Here, the cessation process occurs in stages as a gradual progression of selfimposed restrictions on driving

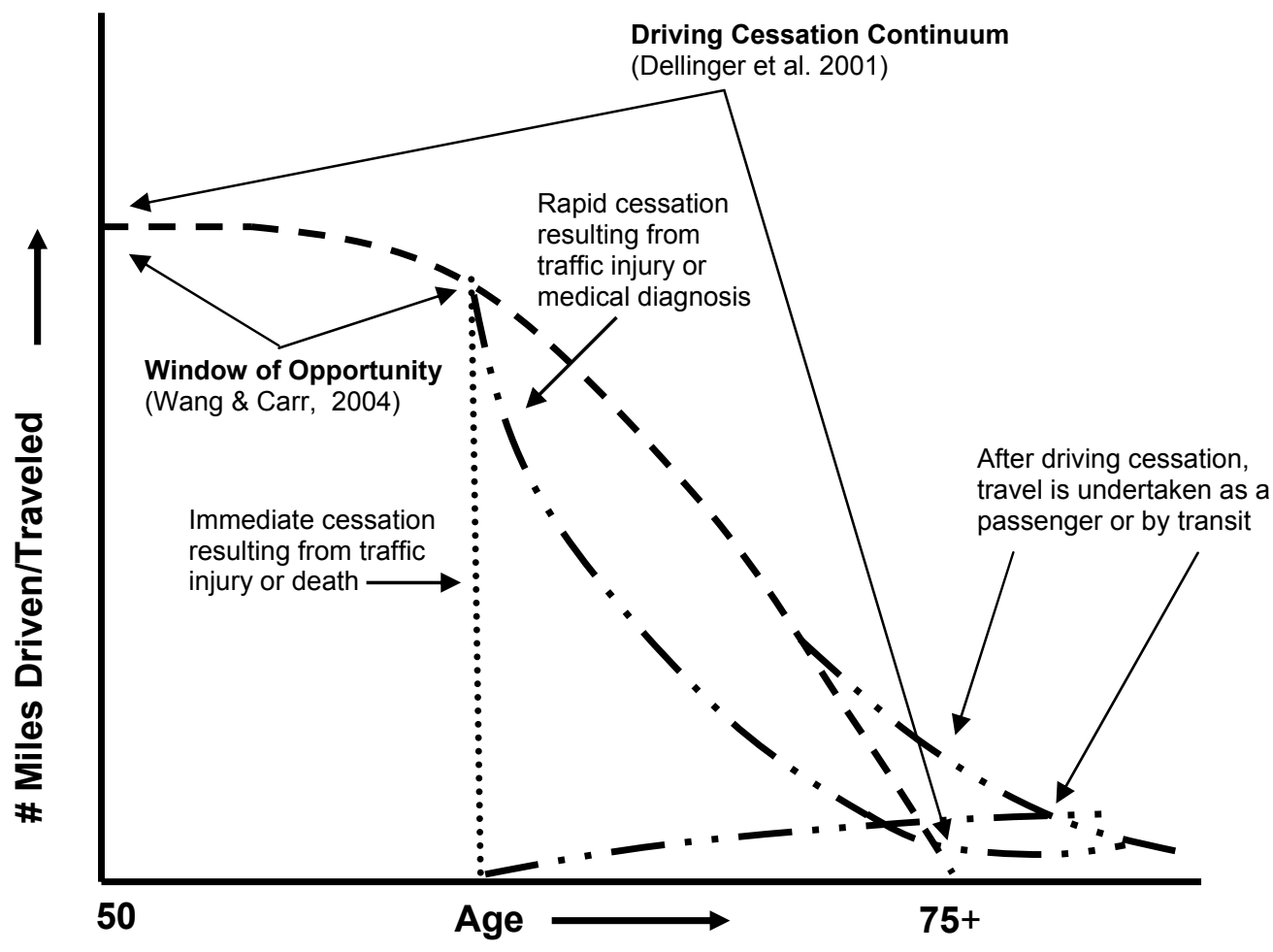

Figure 1 - The Process of Driving Cessation 
culminate in permanent cessation. Gilley et al. (1991, p. 944) noted, "Cessation of driving is not an all or nothing phenomenon but the eventual end point of a gradual reduction in driving activity." A similar definition was also expressed by Horowitz et al. (2002).

In Figure 1, assuming a starting point at age 50, there is relatively little change in the miles driven per year by the individual in the early years. This period of continued competent driving ability creates a "window of opportunity" (Wang \& Carr 2004, p. 144). According to Wang \& Carr, during this phase there is the possibility for medical interventions to be applied (e.g., appropriate pharmacotherapy for neurological disease, treatment of reversible ophthalmological diseases, physical therapy for fragility or muscle weakness and occupational therapy for functional deficits) that may help older adults maintain driving skills and confidence in their driving performance. According to Friedland (1997), other factors affecting the duration of this "window of opportunity" are the patient, the family, and the medical care team of the patient; difficulties of the individual adhering to advice regarding driving cessation; and failure of professionals to inform the individual of impairments impacting their driving ability.

\section{Seniors Who Retire from Driving}

Valid estimates of the numbers of senior drivers who give up driving are difficult to derive, as there is no way of determining if the holder of a driver's license is a regular/intermittent driver or permanent non-driver. As noted by Levy (1995, p. 461), "Not all drivers are legally licensed and not everyone who is licensed actually drives." This scenario is particularly pertinent to the senior population. An estimate of 1 million license holders who retired from driving annually was made in Spring 2005 (Staplin \& Freund 2005). However, in 2001, it was noted that "the literature has not yet provided estimates of the current or future incidence of driving cessation" (Waldorf 2001, p. 23). Nevertheless, research has shown that, after driving cessation, "the number one alternative to the car for older adults is not another mode: rather, it is riding with family members and friends" (Coughlin 2001, p. 3). Information on the data challenges encountered when determining driving cessation in Florida from available data are noted in subsequent discussion in this report.

\section{Driving Cessation - Other Factors}

Other factors, with the exception of anatomical or cognitive, can be grouped into two categories: gradual/planned and sudden/unplanned. Gradual/planned factors can be classified as being "involved," i.e., accepting that the impaired person is an adult who has the right to be included in decision affecting his or her life (Jett et al. 2002, p. 111). Such a strategy is time-consuming, and its success is dependent on the level of impairment in the individual concerned. In the case of sudden/unplanned factors, they can be incident- or accident-based or classified as being imposed, i.e., imposed on the individual by other parties, as the individual is unwilling to make the change by himself or herself (Jett et al. 2002, p. 111). 


\section{Gradual and Planned Cessation}

Sixty percent of participants in a study by Campbell et al. (1993) indicated that they voluntarily ceased from driving. Campbell and her colleagues went on to explain that such a response, though commendable, may indicate that these participants had a less severe disease/health condition than those participants in the study who identified a condition that precipitated driving cessation, or the participants may have had a condition but, since this diagnosis, have been in a state of denial about its impact. Another factor influencing driving cessation is for the impaired driver to acknowledge the potential danger that they may become to a loved one, neighbor or family pet, if they continue to drive (Jett et al. 2002).

Increasing age increases the chances of driving cessation (Campbell et al. 1993, Stewart et al. 1993). In a study by Dellinger et al. (2001) of those who ceased driving within the previous five years, two percent stopped in their 60s, 18 percent in their 70 s, 63 percent in their 80s, and 17 percent in their 90s. Forrest et al. (1997) reported that, as well as driving less with increasing age, women participants also were more likely to use avoidance strategies, such as not using freeways. Horowitz et al. (2002) estimated a five percent reduction in the number of study participants who drove with every year of increased age. Though aging is an accepted predictor in driving cessation, Owsley et al. (1998) pointed out the inappropriateness of guidelines that determine the suitability of driving for older adults based on age alone.

Driving cessation is predominately exercised by elderly women (Freund \& Szinovacz 2002). A study by Campbell et al. (1993) also found that women were twice as likely to report having stopped driving than were men. A similar finding also was reached in a study by Stewart et al. (1993). Approximately two-thirds of the participants in a study by Dellinger et al. (2001) who had stopped driving within the previous five years were female, though gender differences (with respect to driving cessation) did not reach statistical significance. In another study by Foley et al. (2002), women participants were three times more likely to cease from driving when compared to male participants.

One reason given by women participants who had ceased from driving, in a study conducted by Dellinger et al. (2001, p. 4), was that "someone else could drive them." Yassuda et al. (1997) also found that focus group participants preferred other people to make the decision to cease from driving for them. Nevertheless, Dellinger et al. (2001) noted that, for respondents who had ceased from driving, a subjective assessment of the driver's own driving ability was the primary factor in driving cessation, not advice from family or friends. A participant in Bauer \& Rottunda's study (2003) indicated elderly drivers did not want involvement of their children in deciding when they should stop driving. Indeed, the majority of participants in Bauer \& Rottunda's study decided for themselves. A similar finding was found in studies by Persson (1993) and Ralston et al. (2001). Campbell et al. (1993) found that participants did not include family as an influencing factor with respect to 
driving cessation; only the affected individual or legal requirement were involved. Despite the preceding, Hebert et al. (2002) noted that with family/caregivers there may be difficulty in objectively evaluating driving abilities of the affected loved one; this, in turn, may prolong the period before permanent driving cessation (i.e., lengthen the driving reduction phase), as they are unlikely to limit or stop their spouse/significant other from driving based solely on diagnosis.

The definition of a co-pilot is "somebody available in the car who can directly instruct and supervise" (Jett et al. 2002). In a study by Foley et al. (2000), 10 percent of 59 participants diagnosed with dementia had not ceased from driving at the time of the study. These persons always drove with someone else present in the vehicle as a co-pilot, in most cases, the spouse of the driver. Research by Freund \& Szinovacz (2002) suggests that the lack of an alternative driver in the home kept cognitively-impaired women on the road, especially where a spouse who may have been the primary driver had been outlived. Co-piloting as a strategy may work for a limited time, but, in situations where a decision is required quickly, driver response may be insufficient. Thus, it becomes a strategy that is not recommended in the process of driving cessation (Hartford Financial Services Group, 2000).

Some medications can affect driving skills, which, in turn, will influence driving cessation. Medications that may impair driving skills include antidepressants, hypnotics, antihistamines, glaucoma agents, and muscle relaxants (Carr, 2000). However, in a study by Stewart et al. (1993), it was found that specific drug ingredients or the total number of drugs used were not a significant risk factor for driving cessation, a surprising result to the study team. Yassuda et al. (1997) noted that the low frequency of the medication topic (i.e., a participant response from the survey instrument) may reflect the participant's lack of knowledge of the effects of drugs on driving ability, denial that drugs had any negative effect on driving, or even the belief that taking medicine was a part of normal aging.

\section{Sudden and Unplanned Cessation}

A life event may precipitate driving cessation (see Figure 1). Such an event may be in the form of a diagnosis of a disease or a personal loss such as the loss of a spouse/partner. In a study by Bauer \& Rottunda (2003), such life events experienced by participants ranged from a heart attack to a fall. A traffic crash often is a precipitator of driving cessation, especially when the individual had been advised against driving while managing some form of impairment. According to Dobbs et al. (2002), while life events may have a severe negative impact on driving ability (in the case of the diagnosis of dementia), this should not be the sole justification for the revocation of a driver's license, which, in turn, can bring about an immediate cessation of driving.

As already noted, gradual change in the process of driving cessation will allow managed interventions, where various parties may become involved in the decision for an individual to cease from driving. On the other hand, if such interventions by persons closest to the 
affected individual are not forthcoming, medical professionals and/or governmental agencies, i.e., state drivers license agencies, have a "moral and legal obligation to care for the demented individual and to protect the safety of the public" (Berger \& Rosner 2000, p. 306). Campbell et al. (1993) found that the potential of license revocation/cancellation if driving is not curtailed significantly increases the odds of driving cessation among elderly persons. The potential loss of insurance coverage (Carr 2000) also may bring about a sudden loss of driving privileges for the affected individual, leading to rapid or immediate cessation of driving. The revocation of the driver's license by a third party has the potential to have the opposite effect. Burkhardt et al. (1998) identified research that concluded older drivers might be more likely to resist driving cessation, while claiming that a third party (e.g., state driver licensing authority) had forced them to continue driving by taking away their license prematurely.

\section{Demographics}

Results from the U.S. Decennial Census in 2000 showed that persons 65 years and over represented 12.4 percent (35 million persons). Population forecasts for the year 2030 indicate that this same age cohort will be more than 20 percent of the entire U.S. population. Figure 2 indicates that the forecasted percentage of persons of the total U.S. population over 65 years of age will continue to grow for the foreseeable future. By the year 2030, the number of persons 65 years or older (estimated to be $71,453,471$ ) will have increased by more than 100 percent (based on Census 2000 figures of 34,991,753). In the case of Florida (depicted in Figure 3), the percentage of persons 65 years and older of the population in 2000 was 5.13 percentage points higher than the national percentage $(17.57 \%$ compared to $12.43 \%$ ) and, in future years, is forecast to continue to retain its lead over the national percentage. The proportion of persons 65 years and older in Florida is predicted to be the highest of any state in the year 2030 (27\%), representing a 180 percent growth in the year 2030 (compared to Census 2000 figures). 


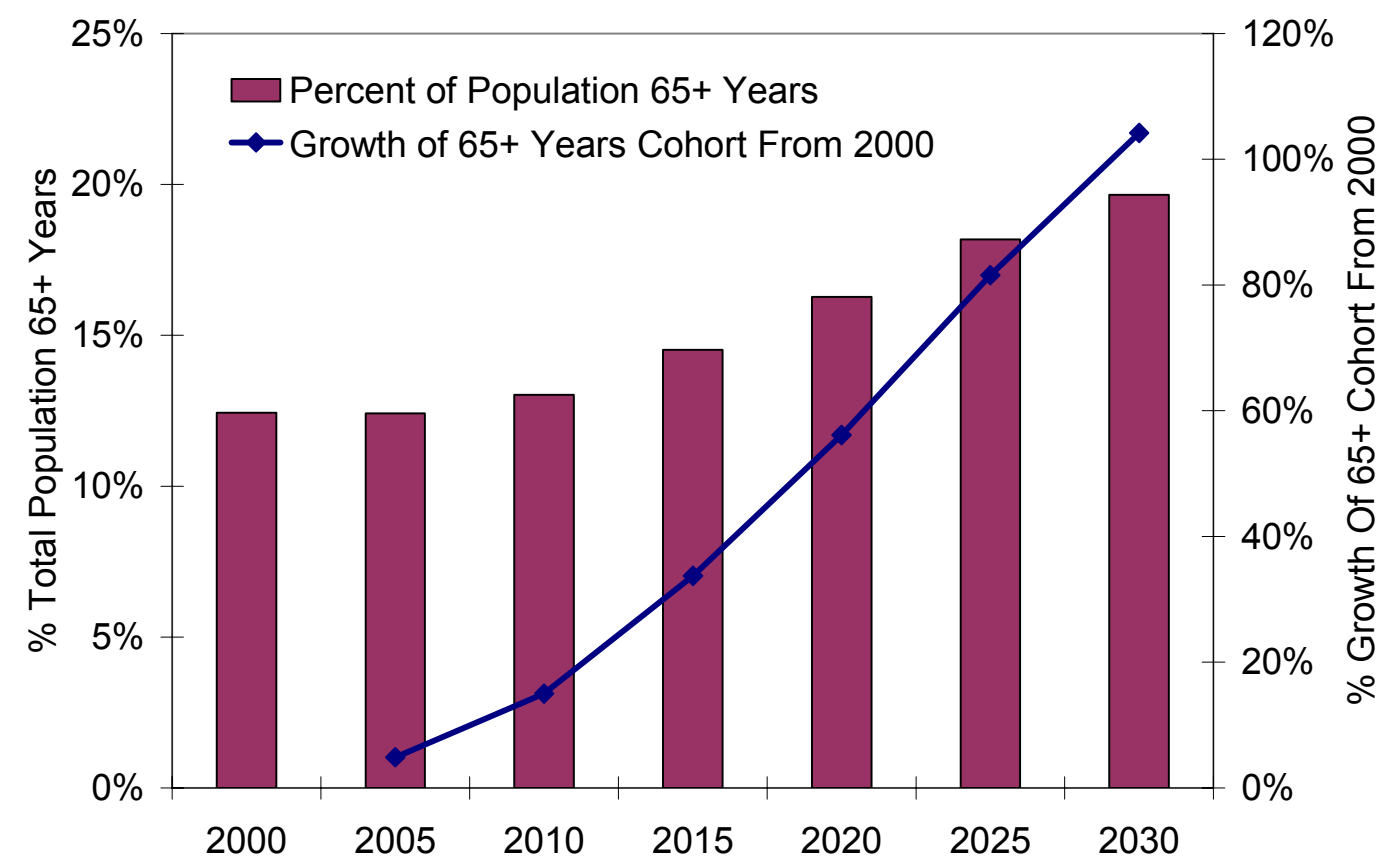

Figure 2 - Percentage of Persons 65 Years or More of Total Population $(2000-2030)$

Source: U.S. Census Bureau (2005)

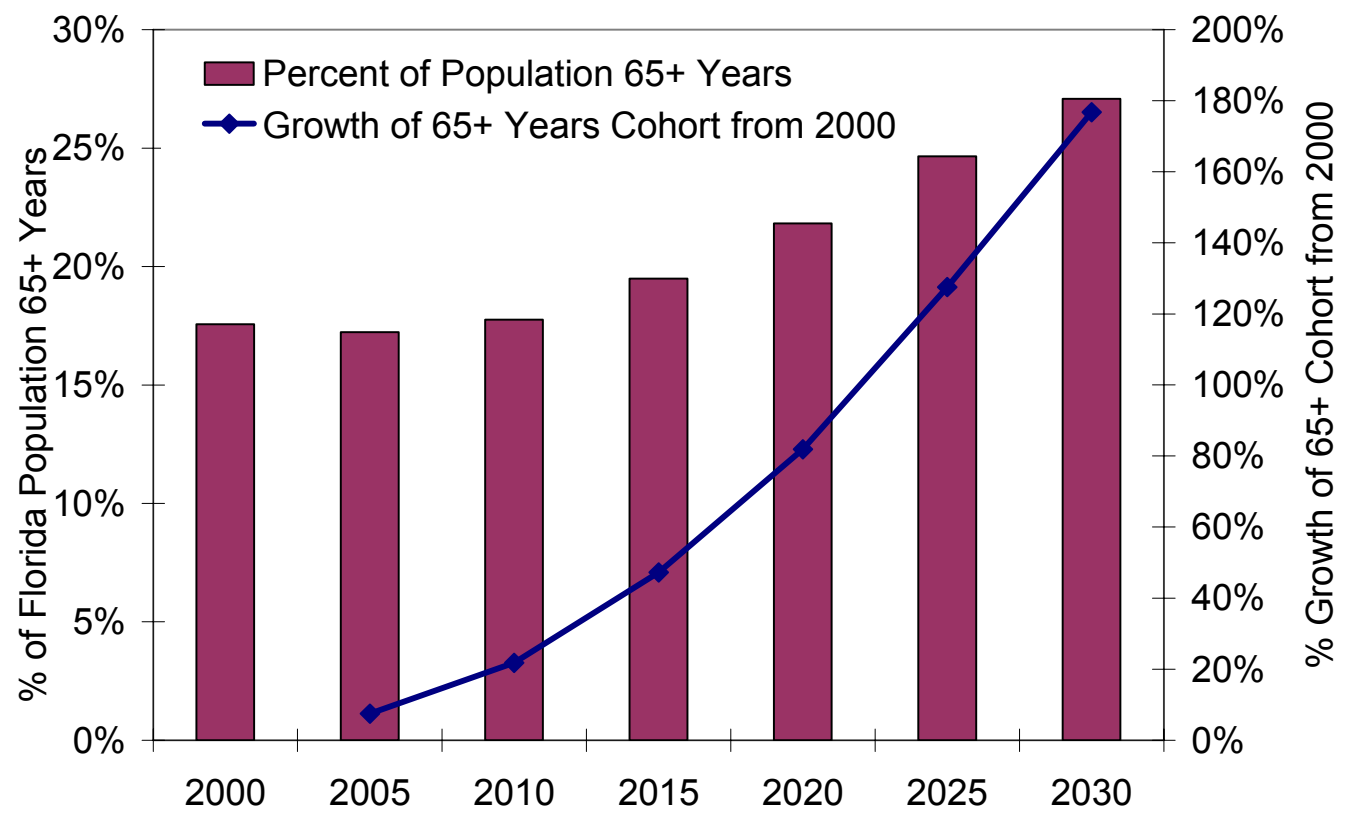

Figure 3 - Percentage of Persons 65 Years or More of Florida Population $(2000-2030)$

Source: U.S. Census Bureau (2005) 


\section{Closing Gap of Licensure Rates by Gender}

In the year 2000, 92 percent of males over the age of 65 in the U.S. were licensed, compared to 68 percent of females, a difference of 24 percentage points (Office of Highway Policy Information 2001; Decennial Census 2000). As illustrated in Figure 4, in the year 2000 , with each age cohort less than 65 years, the percentage of licensed persons increased while the difference between the proportion of persons licensed according to gender decreased. For example, for the age cohort $55-64$ years, 97 percent of males and 89 percent of females were licensed in 2000. A similar exercise was attempted to illustrate the proportion of licensed persons according to age cohort for Florida for the year 2000. Unfortunately (after discussions with the Federal Highway Administration (FHWA)), discrepancies between the number of licensed drivers and the cohort population figures (according to the Census) resulted in this effort being suspended. With each passing decade into the future, the differences between male and female licensure rates will close while at the same time, stabilizing above 90 percent.

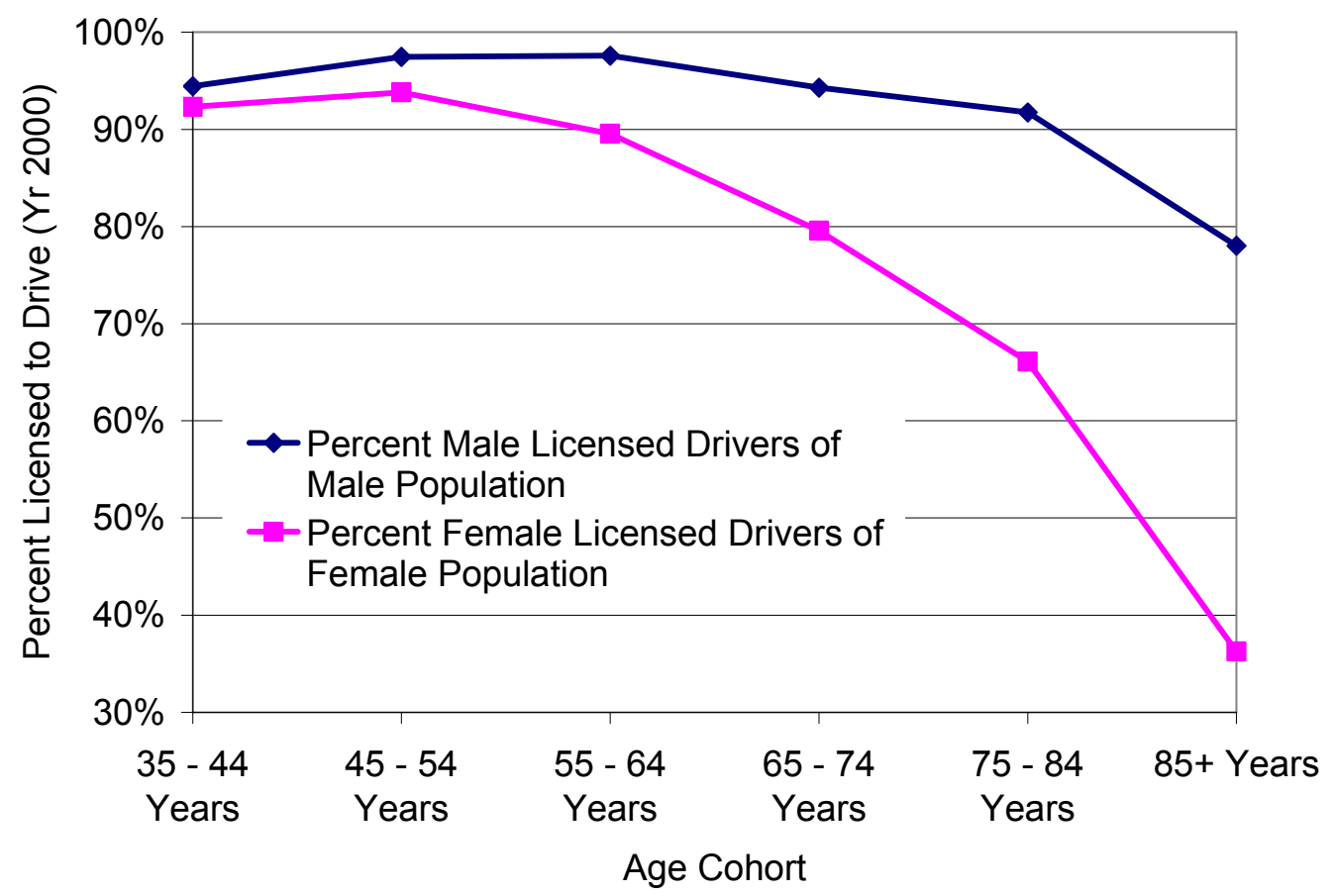

Figure 4 - Percentage of Population Licensed by Age Cohort and Gender in $\mathbf{2 0 0 0}$

Source: U.S. Census Bureau \& OHPI/FHWA

This potential future scenario of driving licensure rates for the age cohort 75 to 84 years (in a national context) is illustrated in Figure 5. Taking the population of persons between 75 and 84 years in 2000, 92 percent of males were licensed compared to 66 percent of females (see Figure 3). Ignoring the effects of immigration and driving cessation, in 2010, 94 percent of males and 79 percent of females in the 75-84 year cohort are predicted to be licensed. Thus, as we move further into the future, the percentage of licensed persons in 
the senior age cohorts will increase and then stabilize in tandem with the differences between licensure rates (according to gender) diminishing.

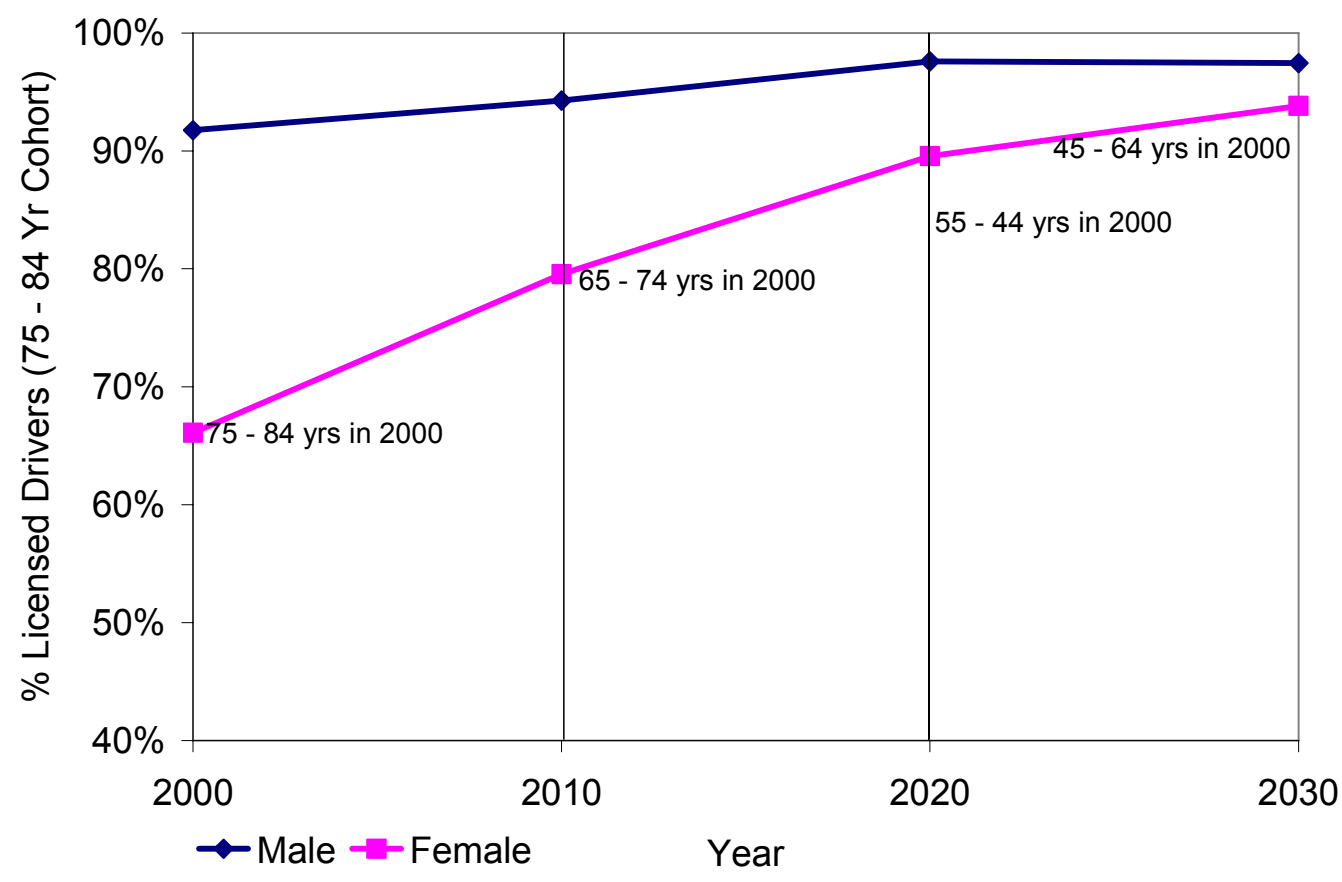

Figure 5 - Predicted Percentage of National Population Licensed in the 75 to 84 Year Cohort by Gender Source: U.S. Census Bureau \& OHPI/FHWA

\section{Moves Toward Age-Based Driver Testing by State Licensing Authorities}

In Chapter 1, it was noted that several American states in recent years have implemented "age-based" driver licensing regimes. In 2001, 33 states did not require any further licensing requirements as people aged (Coley 2001). In contrast, 18 states in 2001 did require seniors to fulfill age-based requirements when applying for or renewing their drivers' licenses. In the space of four years, as of July 2005, the number of states imposing agebased requirements on seniors when applying for or renewing their drivers' licenses increased to 24 , a 33 percent increase (AAA 2005). The threshold for accelerated renewal (i.e., a situation where the frequency of testing is increased once an age threshold is reached) also varies from state to state. According to Molnar \& Eby (2005), "the beginning age for accelerated renewal ranges from 61-years-old (Colorado) to 81-years-old (Illinois)." Indeed, under this regimen, the time validity of licenses also is impacted, ranging from " 1 year (Illinois for age 87 and older) to 5 years (Arizona, Colorado, and South Carolina)" (Molnar \& Eby 2005). 
Age-based testing is one of several strategies used to assess the driving ability of seniors as they age. According to research by Cobb \& Coughlin (1997), there are three principal tools used to identify unsafe senior drivers: assessment or judgment of the driving examiner - the single most important control in all jurisdictions; screening of the person's driving record; and medical reporting. The "in-person" assessment of a senior driver by a driving examiner under the "age-based" testing regimen has resulted in a variety of benefits or disadvantages arising as to the effectiveness of this strategy. Benefits of accelerated licensing periods according to Levy (1995) can be described as:

- $\quad$ increasing the visibility of a policy to the target population;

- $\quad$ reducing the length of period before a problem is detected;

- increasing the likelihood of recognizing problems of individual applicants; and

- becoming more informed of the changes occurring to individuals over the years (Coley 2001).

On the other hand, disadvantages or disbenefits of an accelerated licensing regime according to Lange \& McKnight (1996) can be described as:

- discouragement of driving by seniors;

- license revocation of drivers who fail the tests;

- self-regulatory termination of driving by those who fear that they cannot pass the test (these may be insecure but safe drivers); and

- $\quad$ withholding of pertinent health information with respect to personal driving ability drivers may be afraid to mention certain symptoms, if they fear that acknowledging a specific ailment will jeopardize their right to drive (Walser 1991).

The gradual implementation by states of age-based testing of senior license holders is based on the premise that senior drivers pose a greater risk to themselves and other road users the older they become. Despite the supposed benefits of such a scenario, there have been a number of concerns expressed against unwarranted moves in this direction. First, "laws imposing requirements only upon those above a certain age may be discriminatory if they do not produce clear safety benefits; and second; in the absence of specific medical problems, age alone has not been shown to be associated with poorer driving performance" (TRB, quoted in Rock, 1998, p. 69). In light of these two statements, the implementation of age-based testing may precipitate driving cessation by those applicants who fail (on their initial attempt) or current drivers (with accident free driving histories) who choose not to renew their licenses for fear of failing. These safe drivers who prematurely have to end their driving will suffer inordinately due to the frustration of adjusting their travel behavior to accommodate an unanticipated new mobility regime. This frustration is likely to be exacerbated if alternative transportation is limited or not available. Here arises a dichotomy, as; on the one hand, society may precipitate driving cessation of senior drivers, while on the other the provision of alternative transportation modes are inadequate or nonexistent. 
Stamatiadis et al. (2003) noted this concern where it was stated that "age-based license restrictions pose numerous society questions regarding the availability of travel alternatives for persons without drivers' licenses."

Several studies have found positive correlation between age-based licensure laws and safety with respect to senior drivers (Nelson et al. 1992; Levy 1995). Such a scenario may be achieved through reducing licensure rates of seniors, which possibly may contribute to an enhanced traffic safety environment. On the other hand, Rock (1998), using Illinois crash data, found a tenuous relationship between frequency of license renewal (for persons 81 years and above) and crash rate, thus producing negligible benefits of such a policy. Results from a study by Lange \& McKnight (1996) also called into question "the ability of age-based renewal testing to yield significant reduction in proportions of unsafe drivers among the elderly."

In Walser (1991, p. 4),

an experiment conducted in Pennsylvania suggests that states need to monitor older drivers even more aggressively. It also indicates the tremendous social ramifications that would result if even present-day tests were used across-the-board. Between 1978 and 1985, licensing officials used a computer to randomly select 365,000 drivers over age 45 (the majority were over 65) and notified them that their licenses would not be renewed unless they came in for general physical and eye examinations. Of those who were examined, more than 77,000 subsequently had new restrictions added to their licenses. Almost as many -- some 72,000 -- chose not to come in for the exams, and their licenses expired as a result.

It is accepted that there is a link between chronological age and driving performance; however, "the probability of deteriorating performance increasing with increasing age, the presence of individual variation means that no specific chronological age can be singled out as an appropriate age at which a driver's license should automatically be denied" (Waller 1991 , p. 502). Indeed, trying to weed out unsafe drivers according to age is a challenge in an environment where seniors are living longer, healthier, and more active lives. McKnight (2003) notes that few age-related declines in ability are susceptible to experimental variation. This is despite having the same "cause" (i.e., disease) the "effect" (i.e., the impact of the disease on driving ability) may not be explicitly controlled for in cases. This scenario is also confirmed by Messinger-Rapport \& Rader (2000), who indicate that there is no single predictor of adverse driving events (which may be a precursor to driving cessation) that can be applied in the office (i.e., under experimentation). 


\section{Increased Susceptibility to Injury Arising from Motor Vehicle Crashes}

Contrary to media reports about the involvement of seniors in traffic accidents, research conducted by the Insurance Institute of Highway Safety (IIHS) has shown that "seniors have very low crash rates per capita, especially compared with teenagers" (IIHS 2001, p. 1). In fact, in 2004, "the rate of fatalities per capita among older people ( $\geq 70$ years) has decreased 26 percent since 1975 and is now at its lowest level" (IIHS 2005, p. 1). Nevertheless, "as people age, their injury thresholds become lower" (IIHS 2001, p. 2), increasing their susceptibility to injury. Advances in vehicle technology and safety have impacted on the susceptibility of seniors to survive injury even when involved in a crash. Nevertheless, Waller (1991, p. 500) noted at the time that, "currently available [occupant restraint] systems, (i.e., pre 1991) are designed primarily to protect young drivers in frontal collisions. Thus, the shoulder belt that may safely restrain and protect the younger driver may, for the older driver, break ribs, which in turn may puncture lungs and result in immediate death."

Despite the fewer number of seniors involved in traffic accidents, when compared to other age cohorts, older people have higher rates of fatal crashes per mile driven. This situation results in the classic "U" shaped curve, plotting motor vehicle crash deaths per 100,000 people according to age as depicted in Figure 6 . It has been indicated that as seniors get older, they gradually reduce the number of miles driven, i.e., driving exposure. According to a chief scientist at the IIHS (IIHS 2001, p. 2), "Controlling for differences in exposure, it becomes clear that older drivers are at increased risk. The main reason older drivers are dying is their physical fragility, not overinvolvement in crashes."

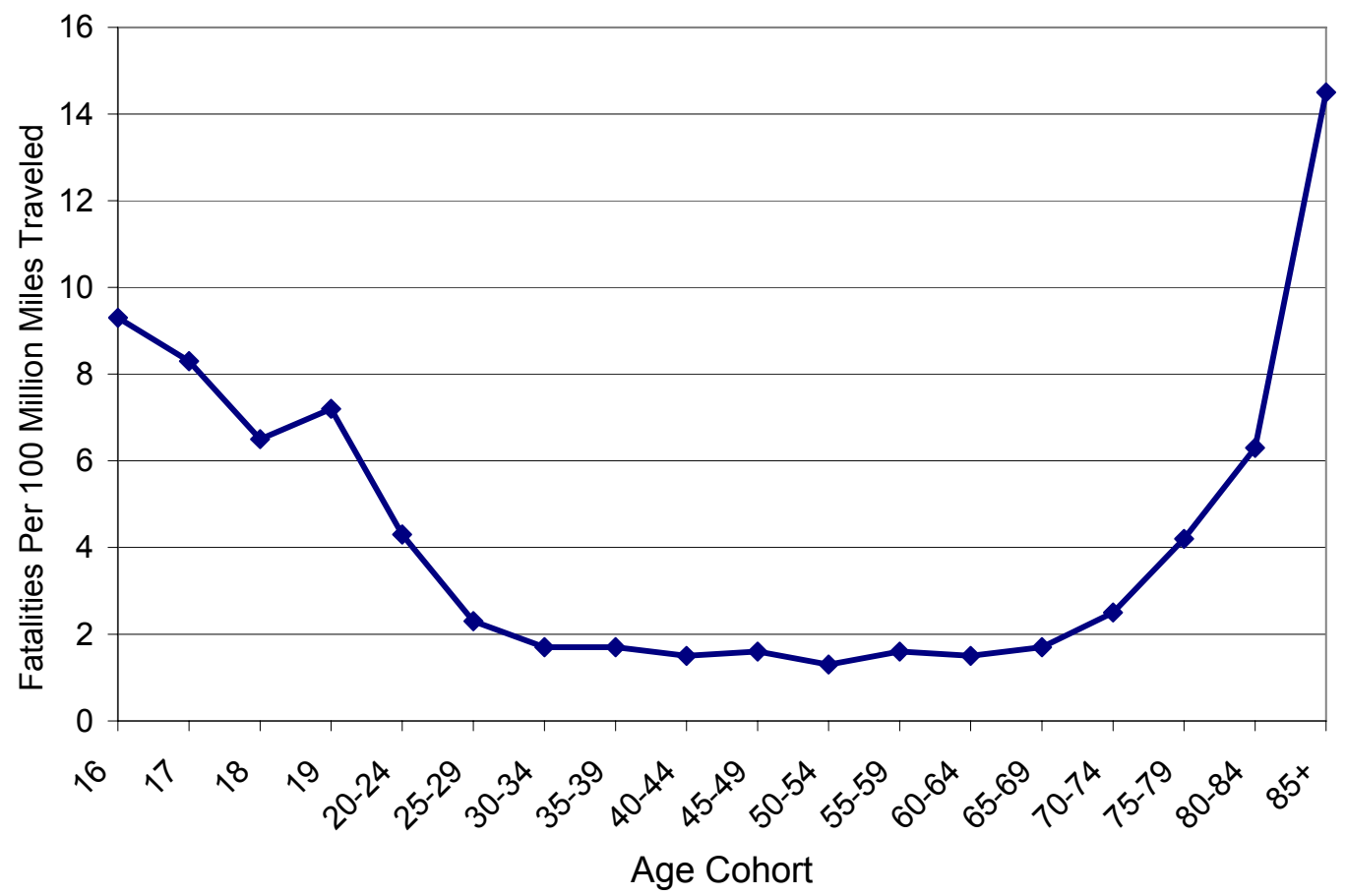

Figure 6 - Passenger Vehicle Fatal Crash Involvements Rate per 100 Million Miles Traveled (April 2001 - March 2002)

Source: Insurance Institute of Highway Safety 
"Crashes are rare events and may not accurately reflect declining driving ability" (Trobe et al. 1996, p. 415). Thus, attempting to identify unsafe drivers through age-based testing strategies may not provide the complete assurance that such testing strategies are effective, as "despite decades of research, no screening test for driving abilities have been developed that are sensitive enough to accurately identify the people who will crash without falsely identifying other drivers who won't" (John Eberhard, quoted in IIHS 2001, p. 7). Research by Morrisey \& Graboswki (2005) did find evidence linking age-based testing and crash fatality - that in-person renewal requirements reduced fatalities for older drivers (in particular drivers aged 85 and older). Despite this impasse, the implementation of age-based testing represents a positive move away from continuing with the status quo (i.e., renewing by mail for life) as "unlike younger drivers, the performance of older drivers is not likely to improve as a result of their accident experience" (Freedman \& Freedman 1996, p. 876).

\section{Seniors Potential to be More Dependent on Outside Resources for Mobility}

Contemporary socio-economic, demographic and cultural trends could lead one to anticipate that future seniors are more likely to live alone, less likely to have as many children in proximity, less likely to have siblings in proximity, and less likely to live in locations with quality transit and walkable destinations than prior generations. These conditions are the result of the number of trends that have been underway over the past several decades. This includes lower fertility rates, i.e., fewer siblings and children, high rates of divorce, and high immobility levels resulting in more frequent relocations away from family and friends. Figures 7 and 8 present indicators from the Decennial Census and Survey of Income and Program Participation (SIPP) that provide insight into the "personal environment" of seniors. Between the years 1990 and 2000 (in the age cohorts illustrated), there were increases in the percentage of seniors whose living arrangements were described as "living alone." The increase in "living alone" status for all persons 65 and older approximated 2 percent; there was a 3 percent increase for persons 75 years and older. One might expect this trend to increase dramatically as the numbers of baby boomers, a generation accustomed to high mobility and divorce and noticeably fewer offspring, increases. This may be particularly true for females who tend to outlive males. In very practical terms, this means there will be poor households where an individual who has ceased driving does not have other household members available to provide mobility.

Exploring the need for personal assistance as one ages, Figure 8 illustrates the percent of seniors who needed assistance with activities in 1986 and 1991. It is evident from Figure 8 that the need for personal assistance with everyday activities (e.g., personal care, preparing meals, etc.,) increases with age. Hobbs \& Damon (1996), reporting on data from the 1991 SIPP, noted that women 75 years and older were more likely to require more assistance than men, and elderly Hispanics or African Americans may require more personal 
assistance than Whites. This also includes assistance needed to get around outside of the home. This factor may be indicative that driving oneself is no longer an option for the senior

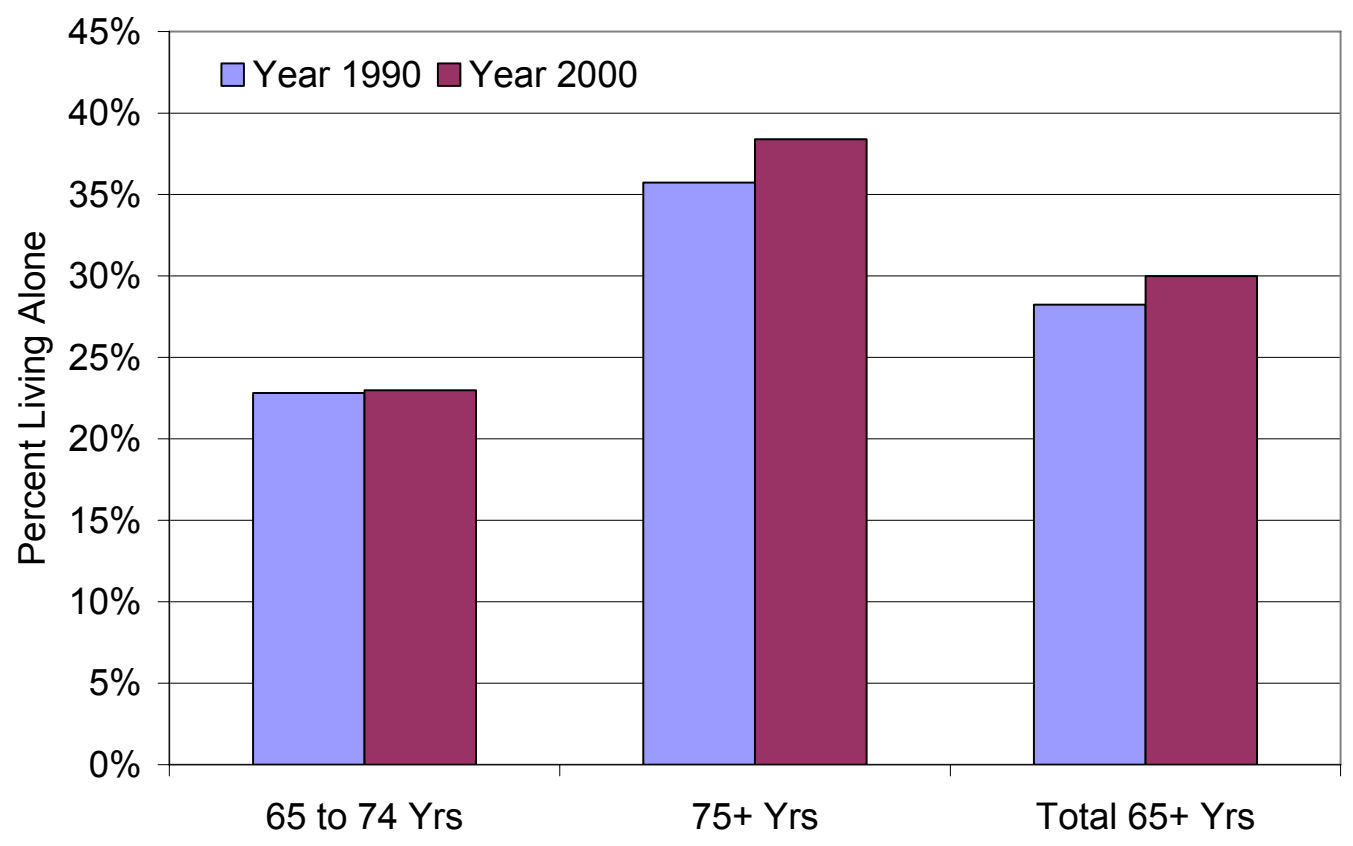

Figure 7 - Living Arrangements of Adults 65 Years and Older 1990 and 2000 Sources: Fields \& Casper (2001) and Goldstein \& Damon (1993)

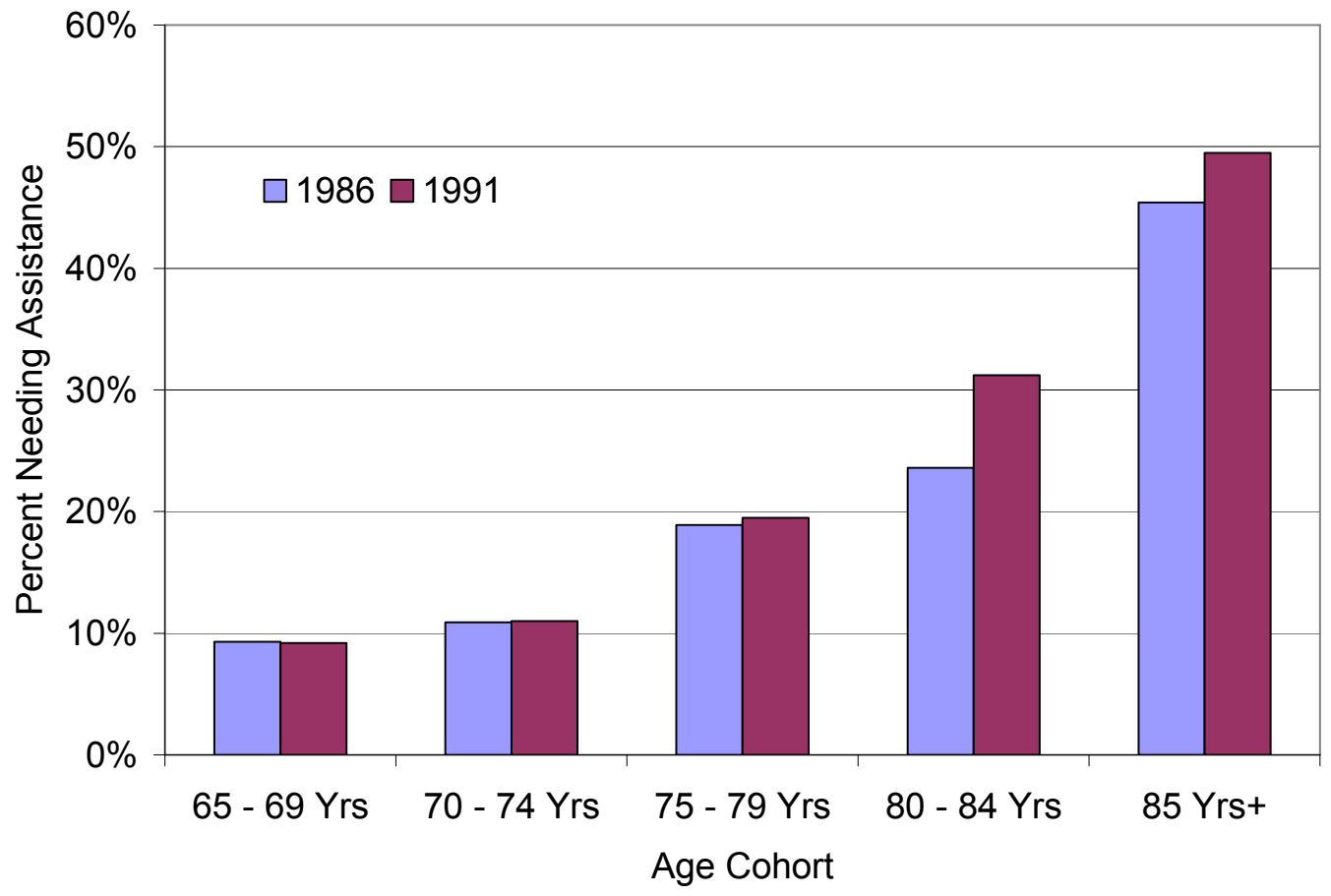

Figure 8 - Persons Who Needed Assistance with Activities by Age Source: Hobbs \& Damon (1996) p. 3-18 \& Harpine et al. (1990) p. 21 
and is thus dependent on others for transportation; the use of public transportation may be a challenge even if it is available.

The combination of socio-demographic changes, societal and family structure changes is resulting in a situation where the next generation of seniors is less likely to have their mobility needs met in the same ways as prior generations. Indeed, future seniors are less likely to have familiarity with transit use and may be less likely to consider it. This potential scenario is confirmed by Kostyniuk \& Shope (2003), where, in their study of 1,000 senior drivers (current and former) in Michigan, 60 percent of the respondents indicated that they had never used public transportation in their lives and, of those who had, the experience was acquired a long time ago.

Simultaneously, auto travel on the ever more congested roads is likely to be higher risk for senior drivers. The collective impact of these changes is likely to complicate the already difficult challenges of meeting mobility needs for post-driving cessation seniors.

\section{Desire to Drive Despite Impaired Health}

Results of an American Automobile Association (AAA) survey in 2005 of 1,000 healthcare professionals (Auto Spectator 2005) indicated that older patients did not talk about driving ability during medical visits. Elderly patients may fear that if the topic is broached, it may lead to further inquiry by the healthcare professional, ultimately leading to a mandate that driving must be curtailed or ceased altogether. There are myriad impairments that may impact driving ability and cessation. Senior drivers may engage in selective driving restrictions to overcome the impacts of a particular impairment, but, in the case of seniors suffering from dementia, research has shown that "the driver with dementia often lacks this insight" (Hunt 2003, p. 35).

Continuing to drive despite diagnosis of any form of impairment that directly impacts driving capability (i.e., extending further along the curve in Figure 1) can be the result of several factors where the affected individual (Adler et al. 1999):

- experiences no problems while driving and therefore does not limit driving;

- experiences some problems while driving but does not understanding the gravity of how such problems can impact driving ability and therefore continues to drive;

- $\quad$ suffers from the lack of transportation alternatives;

- resides in a rural versus urban location;

- wants to maintaining self worth/dignity;

- wants to minimize inconvenience to themselves and immediate family, i.e., the individual is the sole driver in household; 
- adopts a coping strategy where individuals with dementia may not have the cognitive skills required to adapt to the changes in lifestyle brought about by driving cessation (Hunt, 2003), and,

- is a male - men tend to cease from driving at a later stage of their lives; older males have been socialized to be the primary driver and generally have more years of driving experience (Bauer \& Rottunda 2003).

A number of studies mentioned throughout the literature have shown that the decision to cease driving should be a decision that involves the individual concerned, those closest to that individual, and professionals. The professional may be the family physician, occupational therapist, or social worker. The involvement of the professional is vitally important, as the patient and the immediate family may not be able to objectively evaluate the driving ability of the impaired patient (Adler et al. 1999). In future decades, there will be numerically more seniors, most of whom will have been licensed drivers the majority of their lives. The potential of seniors to drive until late in life (despite certain impairments) has given rise to increased concern about the potential safety impacts on themselves and society and the availability of alternative transportation modes. It also has contributed to renewed calls for age-based testing and other strategies to ensure senior driving competence.

\section{Retirement Migration and Driving Cessation}

There are two types of retiree migrants: "dependency migrants," i.e., those persons relocating due to deterioration of their health or financial resources, and "amenity migrants," i.e., persons relocating to attain a better lifestyle. The majority of retiree migrants to Sunbelt states such as Florida are those in the latter category. Earlier work by Longino et al. (1991) identified a three-stage retiree migratory process, as shown in Figure 9. The first is amenity migration, where affluent and healthy retirees migrate to enhance their lifestyles. The second is where seniors migrate to be closer to persons who can provide help as and when required. 


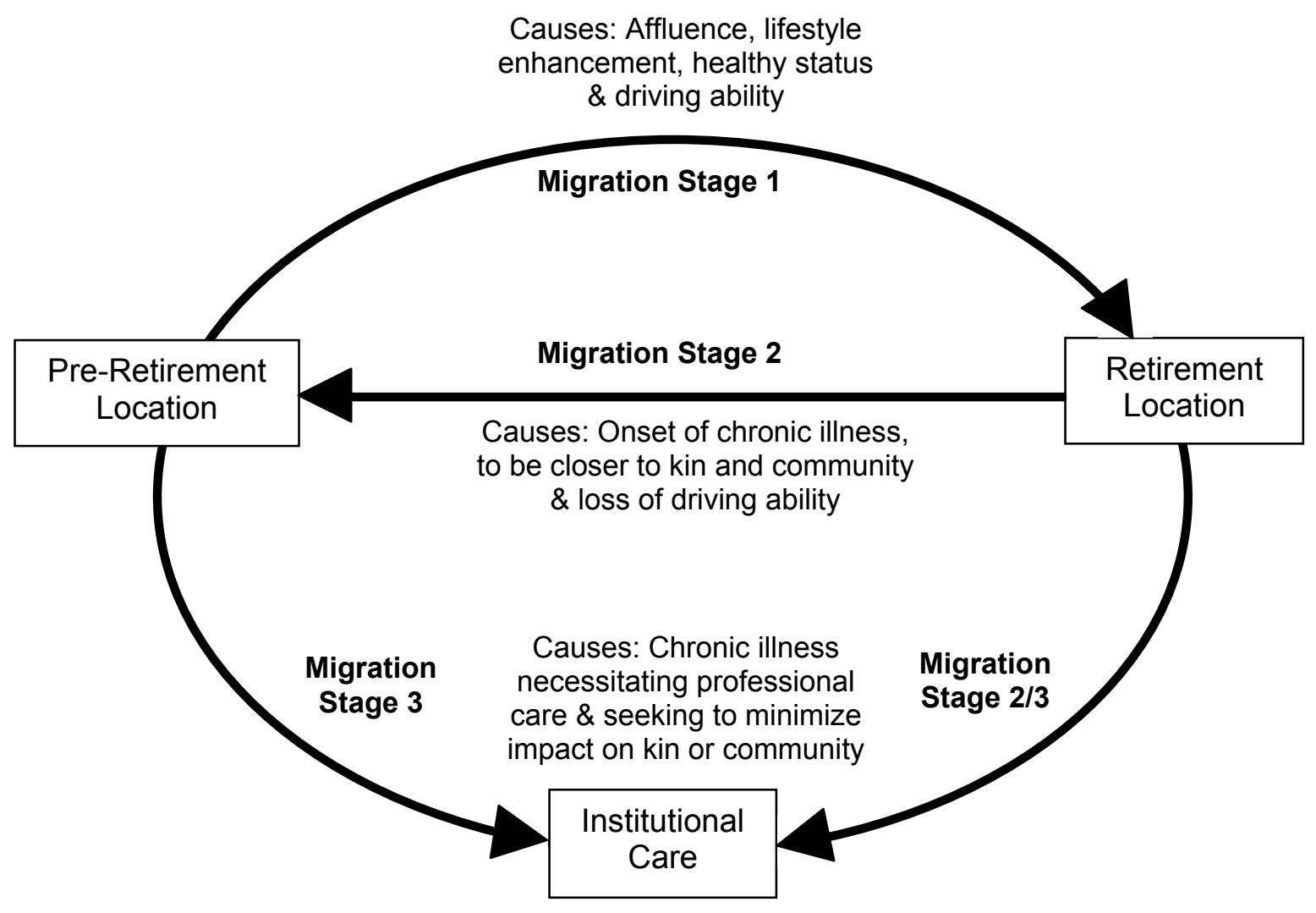

Figure 9 - The Retirement Migratory Cycle

Such retirees who make this type of move often have suffered from the loss of their spouse or are chronically ill. The third stage is the move from exclusive care by kin to institutional care. This last stage can be undertaken by retirees who chose to "age in place," migrants who returned to their pre-retirement locations, or those who went directly from their "amenity" retirement locations to institutional care. Longino (1995), in his exhaustive analysis of American retiree migration trends, notes 10 critical factors (based on a Where to Retire magazine subscriber survey) that retirees consider when migrating:

1) Low crime rate

2) Good hospital nearby

3) Low overall cost of living

4) Mild climate

5) Low overall taxes
6) Low housing costs

7) Friendly neighbors

8) Major city nearby

9) No state income tax

10) Active social/cultural environment

It is apparent that transportation was not explicitly considered as a factor (possibly taken for granted by the retiree). On the other hand, the lack of an explicit mention of a transportation-related factor was not the case in a study conducted by Haas \& Serow (1993), where it was found that problems associated with urbanization such as congestion were a "push" factor precipitating senior interstate migration. Nevertheless, it is evident that, 
for the majority of factors mentioned by seniors precipitating migration, accessibility to personal transportation enables the benefits sought from such migration to be realized.

As discussed earlier, the relatively increased affluence of seniors today, as evidenced by increased levels of mobility, has resulted in this group becoming immobile in another sense, "where they have shown an increasing disinclination to move after retirement" (Rosenbloom 1993, p. 297). In such cases, seniors age in place in their pre-retirement locales. Of those who do change locations to take advantage of transportation opportunities, Kostyniuk et al. (2000) found that, of the 60 seniors who had ceased from driving, only 1.2 percent indicated that they had moved to a place with better transportation, and another 1.6 percent moved to a senior community that provided transportation services. It becomes evident that, in the migratory model put forward by Longino et al. (1991), availability or lack of personal transportation plays an integral role in the first and second retiree migratory moves.

\section{Mobility and Retirement Location}

Earlier in this report, it was noted that family involvement can play a role in determining the driving cessation process. When driving does cease, "moving to a location or setting where driving is less essential for meeting the basic necessities of life is one way to address mobility problems" (Kostyniuk \& Shope 2003). In such a situation, proximity to family or friends may facilitate personal transportation needs. In a study by Longino et al. (2002), a major factor for seniors who chose to age in place was proximity to family and friends. In a similar study by Schiamberg \& McKinney (2003), proximity to family was rated as the most important factor by 80 percent of participants who intended to age in place. Longino et al. (2002) also found that, when asked about their most important factors in selecting Florida as a retiree destination, a significant percentage of survey respondents indicated proximity to friends (39\%), proximity to religious or ethnic group (34\%), and other relatives $(27 \%)$ as most important.

Coughlin (2001, p. 3) notes that baby boomers have pushed beyond their parents' communities in pursuit of the American Dream, where their aging in place may present an even greater service challenge to our current idea of public transportation. Straight (1997) explored the potential of seniors moving to a more mobility-friendly neighborhood. Respondents were asked whether they would consider moving if their community had houses or apartments available near shopping; most non-drivers said they would not. According to analysis of the 2000 Census data, Frey (2003, p. 8) concluded that, with respect to persons above 55 years, "suburban residences are more likely than city residences and the suburban aging in place phenomenon should be evident." In the analysis it was determined that 70 percent of persons between 55 - 64 years lived in the suburbs of large metro areas, compared to 69 percent of persons 65 years and up. The suburbs often have been seen as a challenge to public transportation service providers, and, unless truly viable and attractive transportation services are greatly expanded or 
reinvented, they may not meet the mobility needs of older adults who do not or who no longer drive but are situated in these suburban environments.

The lack of public transportation alternatives in potential retirement communities may stifle migration and the accompanying economic impacts for seniors who do not drive. Stanfield (1996), in an article on aging in America, notes that an individual who wanted to retire back to his native Culpepper (Virginia) later found out about the lack of public transportation in his home town and subsequently decided against moving and continued his retirement in an assisted living facility in Takoma Park (Maryland). The difference between access and mobility can be summarized as follows: "Access refers to people's ability to access goods, services and activities; whereas mobility refers to physical travel that provides access" (Victoria Transport Policy Institute 2006). The importance of accessibility to transportation (especially for the transportation disadvantaged population similar to the senior population mentioned earlier in this paragraph) cannot be underestimated. Longino \& Bradley (2003, p. 906) remind state strategic planners that "unplanned and uncontrolled housing development for retirees may attract new immigrants in the short term but render it impossible to deliver the quality of life that older migrants may be looking for." The type of developments alluded to by Longino \& Bradley (2003) and Stanfield (1996) and evident in the typical suburban environment, in many cases, have developed without an adequate public transportation infrastructure, which, in turn, may limit the quality of life attractiveness as permanent and stable retirement locations for the oldest-old as their personal transportation needs may be not met.

One should note here that the modest attention to mobility options as one ages (as revealed in research to date) may be significantly explained by the fact that many individuals do not necessarily plan for a post-driving cessation period in their lives. This is not to suggest some negligence in anticipating such a situation, but rather an acknowledgement that many individuals do not have such periods of existence, i.e., periods of limited mobility options. They either have support from their households or, in many cases, continue to drive up until close proximity to their death (Foley et al. 2002). Unfortunately, one of the greatest disappointments of this research effort has been the inability to explicitly discern the size of the population that goes through the driving cessation process and the mobility alternatives available to this group. Also, recognize that many of the conditions that would lead to driving cessation also are conditions that significantly impact the overall desire and ability to participate in activities that would require transportation. Thus, one needs to be careful in speculating on the magnitude of travel demand for post driver cessation individuals.

\section{Household Composition and Driving Cessation}

Persons living with a senior driver do have a role to play in the driving cessation process, despite the fact that some drivers who cease to drive have indicated that they made the decision themselves without outside influence. Household composition is, therefore, a factor in the driving cessation process. Kington et al. (1994, p. 1329), in a study of 2,429 
respondents, found that "individuals who lived in households with more adults were less likely to drive." The research team went on further to note that this situation may have arisen because, where there are other adults in the household who are able to drive, those who can no longer drive choose to live or remain in such households. In a study of Public Use Microdata Sample (PUMS) from the 1980 Census of Population, Cutler \& Coward (1992) were able to determine that the majority of elderly persons $(77 \%)$ live in households where personal transportation was available. Nevertheless, Cutler \& Raymond were not able to determine how many of these persons actually were drivers or passengers (as the census data collected did not permit this).

In a study by Taylor \& Tripodes (2001, p. 521) it was found that "the composition of the household in which an elder lives also determines the transportation resources available ... as the presence of a licensed driver in the home was the most important predictor of perceived mobility following driving loss." Waldorf's study (2001) came to a similar conclusion where it was found that the "presence of an additional driver in the household is the single most important factor influencing whether older people intend to use alternative transportation modes."

\section{Transit Service Provision Planning}

Understanding the travel behavior of seniors post-cessation of driving may contribute to informed planning and policy making to support the mobility of non-drivers in their communities. Transit providers should note that "the [transportation] needs of older citizens are predictable so accommodating them is possible" (Freund 2004, p. 114). In the coming decades, more and more seniors will have had the experience of driving and the longer an individual drives, the more accustomed they become towards driving, and the less likely they are to cease from driving even after diagnosis [of a condition that affects driving ability] and the greater risk they become to other road users (Adler et al. 1999). Thus, maintaining the interest of seniors in transit cannot be taken for granted by transit providers.

Public transit must assess the markets where its current strengths lie, consider what new markets exist or are evolving, evaluate how these new markets can best be served, and evaluate the areas where it is possible to strengthen the role of public transit. ... [Transit] operators who do nothing to deal with the major changes in the travel patterns of most Americans ... will see their ridership erode - and their public political support with it (Rosenbloom \& Fielding 1998, p. 1).

Policy change often takes many years, and transit agency reaction to it may follow. Informed planning decisions may enable transit providers to become increasingly adept (i.e., proactive) in meeting the mobility needs of seniors in the years ahead. 


\section{CHAPTER 3 - AN OVERVIEW OF SENIOR DRIVER AND TRAVEL BEHAVIOR IN FLORIDA}

Chapter 1 described the unique mobility environment that many seniors face in the U.S., that is, one dominated by the use of the personally-operated motor vehicle (POV). The extent of this dominance of the POV has resulted in a perception held by many seniors that travel can be facilitated only by this particular mode without due consideration of other alternatives (if available). Nevertheless, to what extent does the POV facilitate senior travel, and do seniors use alternative transportation modes in meeting their travel needs? This chapter aims to answer these questions and others by presenting an overview of senior travel and driving behavior in Florida. This will be achieved through the analysis of two datasets, the National Household Travel Survey (NHTS) and the Mature Drivers License Dataset (MDLD).

\section{National Household Travel Survey 2001}

To better understand the short and long distance travel behavior of Americans, the Bureau of Transportation Statistics (BTS) of the U.S. Department of Transportation (USDOT), FHWA and the National Highway Traffic Safety Administration (NHTSA) have intermittently, since 1969, collected detailed data on personal travel. The National Personal Travel Survey (NPTS), as it was referred to in 1969, has since been collected in 1977, 1983, 1990, 1995 and 2001. The 2001 survey was conducted over the period of March 2001 to May 2002 and covered all 50 states. The goal of the NHTS is to create a national inventory of daily and long distance travel. Such information is useful for policy makers and strategic planners in the course of defining the safety, quality, and efficiency of the U.S. transportation system.

The primary method of collecting data was via the Computer Aided Telephone Interview (CATI) from a sample of the non-institutionalized population. CATIs were facilitated using the Random Digit Dialing Method (RDD). The survey process included: household interviews, in-person interviews and odometer readings from personal motor vehicles. Interviewees and their respective trip-making behavior came from households/persons representing all socio-economic backgrounds, ethnic groups, and ages (including, for the first time, children ages 0 to 4 years old). Each respondent was asked to give details of all trips made (both local and long distance but not international) on a particular travel day.

Over 106,000 household interviews were conducted, and approximately 163,000 person interviews were completed. Of the 106,000 households interviewed, approximately 70,000 households provided usable information. In the case of person interviews, 161,000 were usable. The unweighted person response rate (in households where at least half of the adults completed the person interview) was approximately 60 percent for both the full sample and the national sample. The overall unweighted survey response rate was 29 percent and 37 percent of the full sample and national sample, respectively. Refer to the 
2001 NHTS manual (2001 National Household Travel Survey User's Guide, 2004) for more information on the survey and weight estimation methodology and response rates.

The 2001 NHTS dataset contains four separate files: household, person, vehicle and travel day trips. The household file contains information relating to each household, e.g., number of vehicles; the person file contains information relating to each person, e.g., age, race, etc.; the vehicle file contains information relating to the household vehicle(s), e.g., vehicle type; and the travel day trip file contains information detailing each trip made on the household's randomly-assigned travel day. Details (i.e., number of records) of each file and weighted sums are presented in Table 1.

Table 1 - NHTS Data File Statistics

\begin{tabular}{|l|r|r|}
\hline \multicolumn{1}{|c|}{ Data File } & \multicolumn{1}{c|}{ Sample Size } & \multicolumn{1}{c|}{ Weighted Sum } \\
\hline Household (unit = households) & 69,817 & $107,365,346$ \\
\hline Person (unit = persons) & 160,758 & $277,203,235$ \\
\hline Vehicle (unit = vehicles) & 139,382 & $202,586,200$ \\
\hline Travel day person trips (unit = trips) & 642,292 & $407,262,485,207$ \\
\hline
\end{tabular}

\section{Dataset Caveats}

The following caveats are given in interpretation of the 2001 NHTS dataset.

- The disability status is not explicitly defined (as in other omnibus surveys, e.g., Transportation Availability and Use Survey or SIPP) but may be inferred from the respondent's response to the question, "Do you have a medical condition that makes travel outside the home difficult?" The actual type of disability/impairment is not identified in the NHTS dataset.

- Despite data being collected over a number of years, the NHTS is not a longitudinal survey as the travel behavior of the same persons have not been followed in each of the survey years.

- There were tiny samples for age cohorts in Florida. Use of the NHTS in understanding travel behavior is primarily in a national context. Due to limited resources it was not possible for BTS to conduct state-by-state sampling surveys to derive statistically accurate travel behavior estimates for each U.S. state. The exceptions to this are states that funded add-ons.

\section{Demographics}

The population of Florida approximated 16,350,565 persons, according to Census estimates for the year 2001, of which of 2,837,295 (17\%) were age 65 years or older. Population estimates for the same year computed from the NHTS survey approximated 14,529,899 persons, of which 2,617,939 (18\%) were 65 years and older. Breaking down the Florida population by age cohort reveals differences between NHTS and Census estimates, shown 
graphically in Figure 10. Figure 10 illustrates Census and NHTS estimates of the Florida population by age cohort in 2001 and the difference between the two estimates (with Census estimate as base). It is evident that, at the oldest-old age cohorts, the differences are significant, with NHTS estimates being approximately 40 percent less than the estimates derived from the Census for persons 85 years and older. This is no doubt partially attributable to the fact that NHTS does not include institutionalized persons in the database.

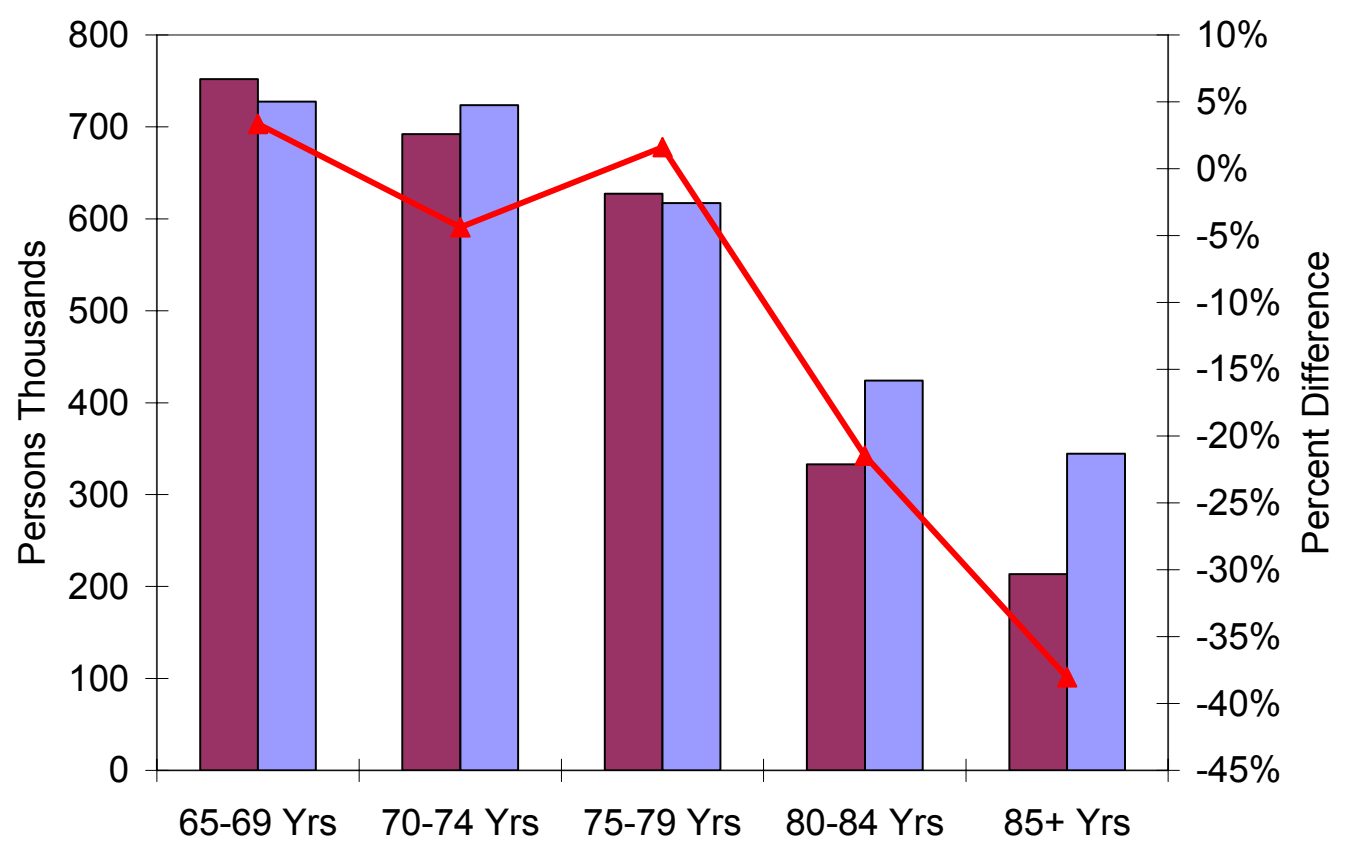

$\square$ NHTS $2001 \square$ CensusEstimate $2001 \rightarrow$ Difference

Figure 10 - Florida Population Estimates by Age Cohort (Year 2001)

Source: NHTS 2001 and U.S. Census Bureau (2005)

\section{Households}

The 107,000 households estimated by the NHTS are further categorized according to stage in the life cycle. Life cycle refers to the stages that households go through, i.e., from one adult to two adults with one child, etc. Households are broken down according to 10 different life cycles, of which life cycles 9 (one adult retired and no children) and 10 (two adults retired and no children) specifically refer to retired persons. Figure 11 presents NHTS data on annual household income according to life cycles for Florida and are compared nationally. Generally, there is a good correlation between Florida and national data for life cycles 9 and 10 . Nevertheless, it is evident that households of two retired persons generally had higher incomes than households comprising 1 retired person. Approximately 60 percent of households in life cycle 9 had annual incomes up to $\$ 25,000$ when compared to life cycle 10; approximately 60 percent of households had incomes up to $\$ 45,000$. 

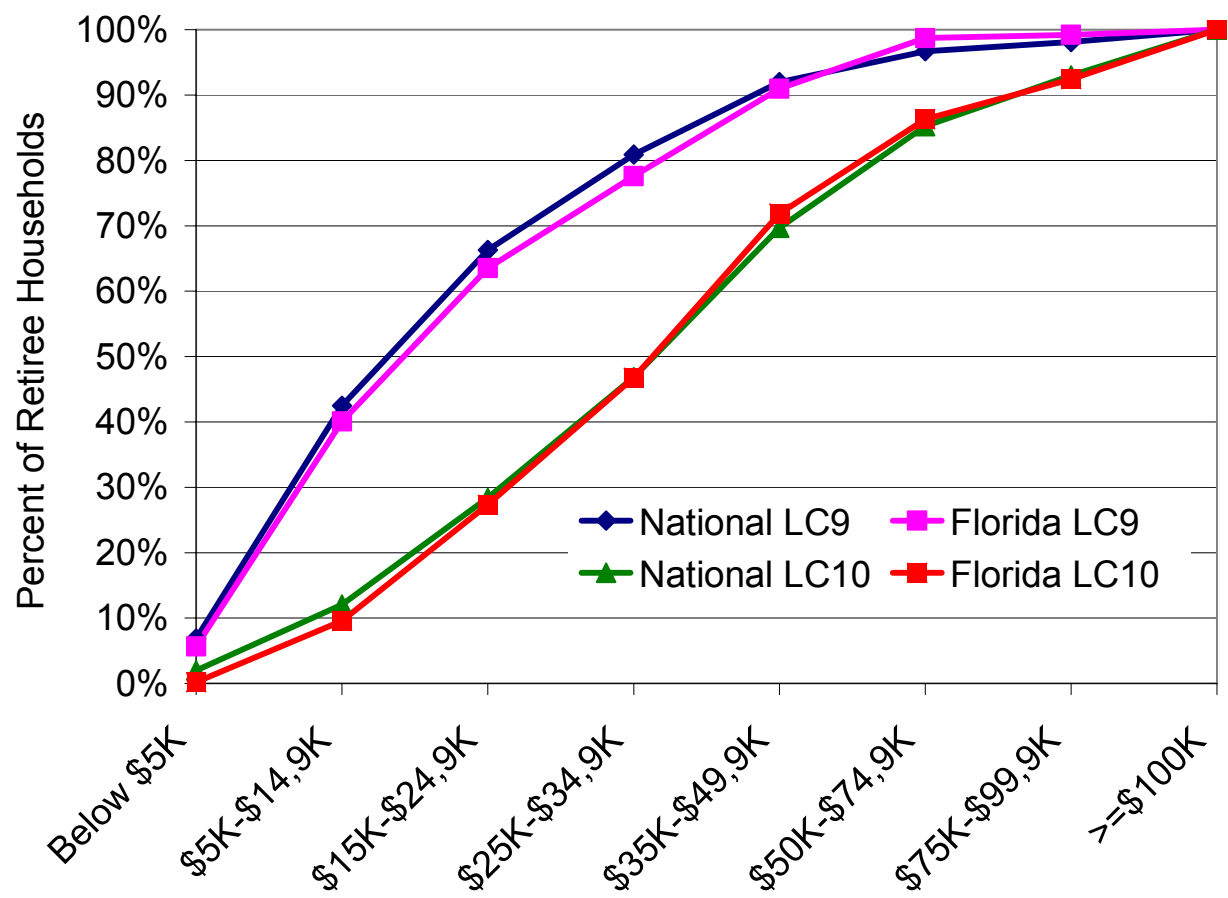

Figure 11 - Percent of "Life Cycle" Households by Income (Year 2001)

Source: NHTS 2001

\section{Household Vehicle Ownership}

Figure 12 presents statistics that show average household vehicle ownership by life cycle. Typically, as family size increases, more vehicles are owned. Life cycle 8 (2 or more adults and 1 child between 16 and 21) represents the stage of highest household vehicle ownership. In this case, at least two adults will own one car each, and the newly licensed teenager, in many cases, will have access to a household vehicle, if not own one personally. Focusing on life cycles 9 and 10, the sharp drop in average vehicle ownership for households in life cycle 9 is due to many seniors living alone and not having direct access to a vehicle. According to NHTS national data, of the 8.7 million zero-vehicle households, 2.7 million (32\%) were households in life cycle 9, representing the largest percentage of zerovehicle households). Data representing life cycle 10 alludes to the fact that where there are two or more retiree persons in a household, there is more likely to be a household vehicle available. 


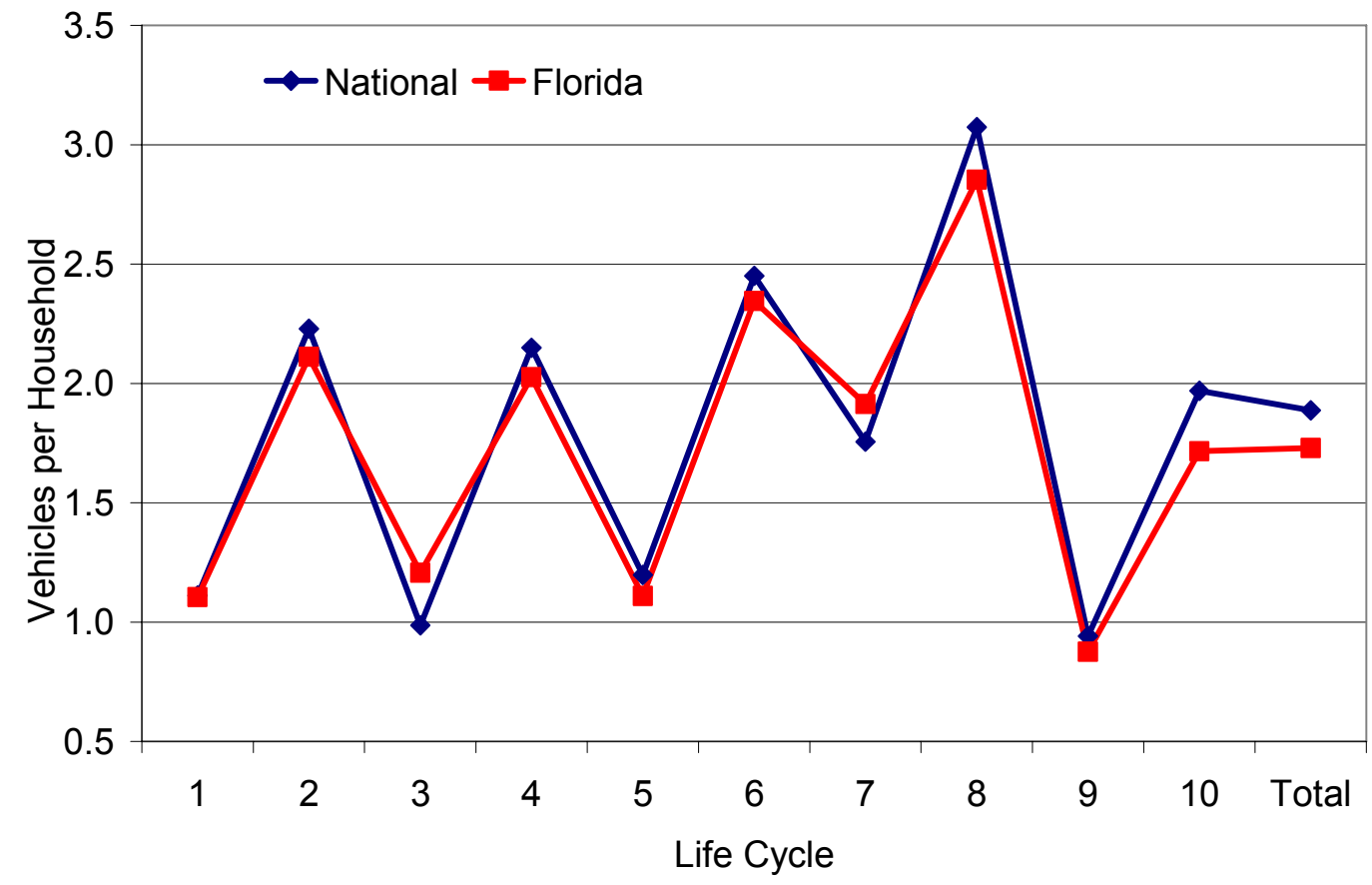

Figure 12 - Vehicles per "Life Cycle” Household (Year 2001) Source: NHTS 2001

\section{Driver Status and Travel}

Figure 13 presents statistics with respect to driver licensure status by age. Comparison is made between licensure estimates using NHTS data and statistics obtained from the FHWA. Differences between the two data sources increase significantly in the oldest old age cohorts (i.e., 75 years and older). It is in these same age cohorts that the estimation of the numbers of licensed seniors who are going through the process of driving reduction or have ceased driving altogether presents a formidable challenge.

Figures 14 and 15 present data representing the driver/passenger status of personally operated vehicle (POV) travel. Figure 14 clearly indicates the dominance of POV travel by seniors. Nationally, in 2001, approximately 90 percent of trips were undertaken by POV (as driver or passenger) for persons aged 65 years and older. Ease of accessing POV directly from home and, similarly, the flexibility of POV operations (i.e., to fit in with individual schedules) have made this the preferred choice of travel for many seniors. (Chapter 4 will discuss results from focus group sessions that explored senior travel behaviors and perceptions). Figure 15 illustrates the driver status of seniors for all trips made. It is evident that the majority of old-old seniors, i.e., $65-74$ years, when they travel, drive themselves. 


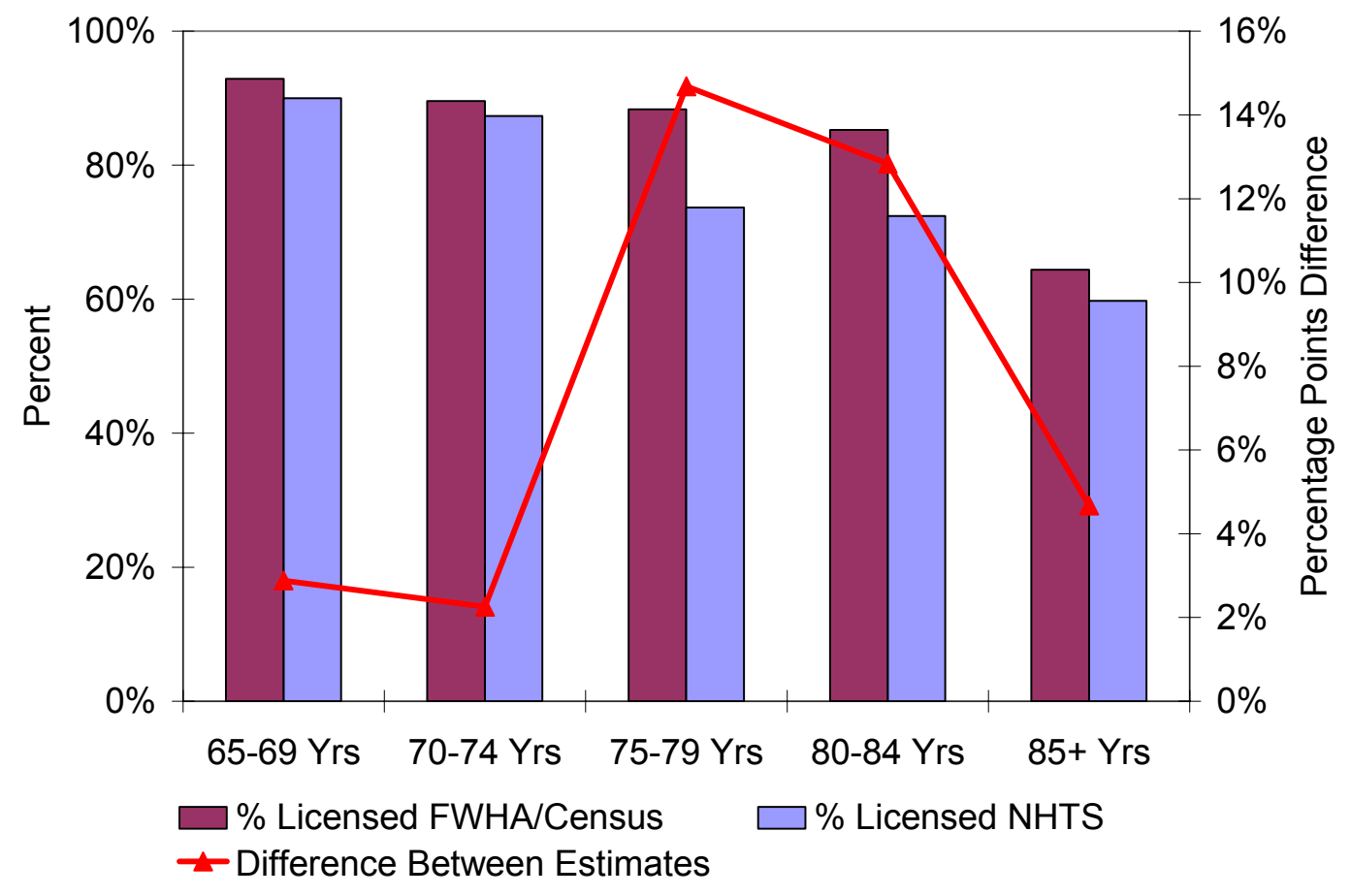

Figure 13 - Licensure Rate by Age Cohort (Year 2001)

Source: U.S. Bureau of Census, OHPI/FHWA \& NHTS 2001

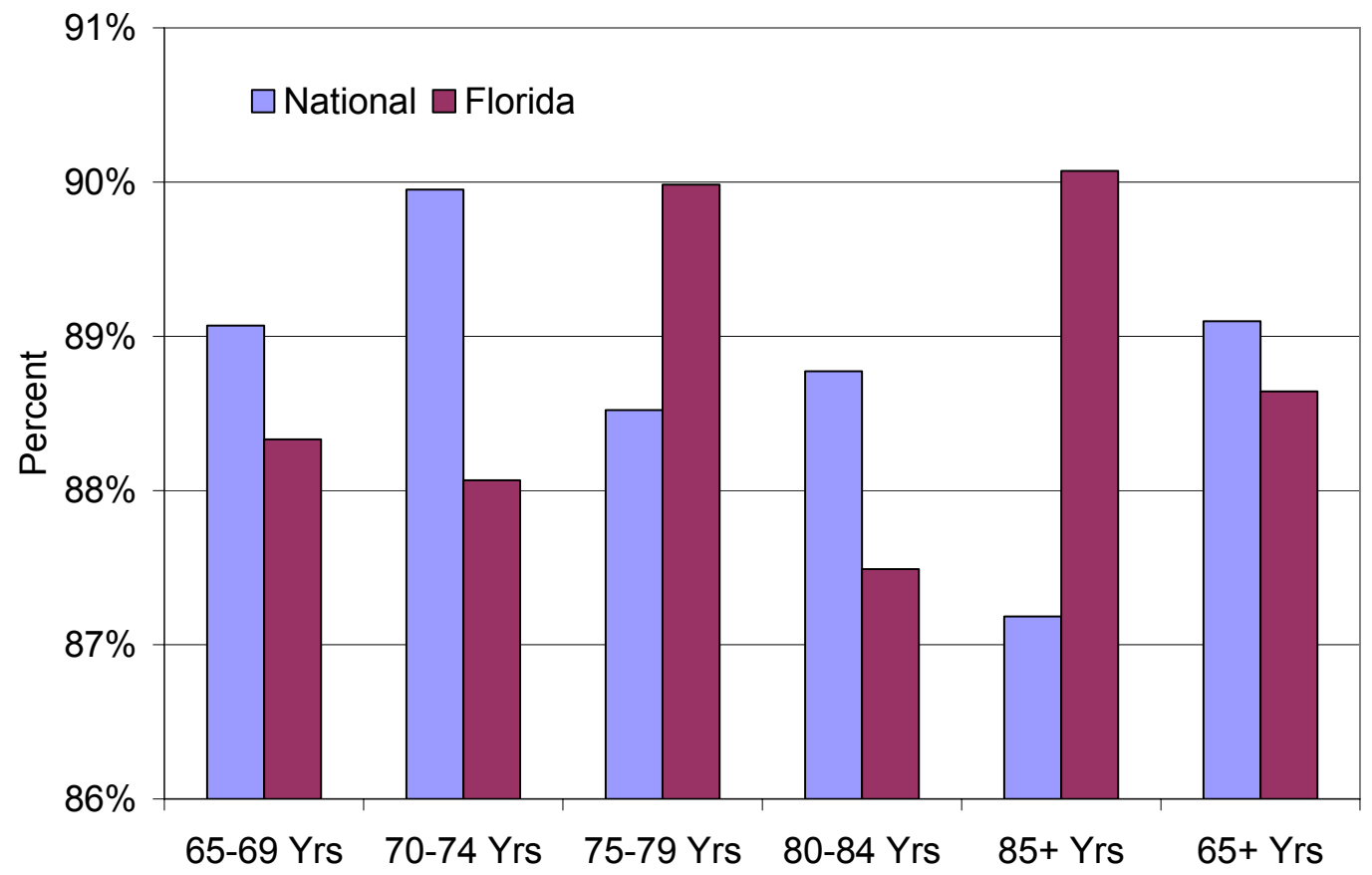

Figure 14 - POV Travel (Driver/Passenger) Proportion by Age Cohort (Year 2001)

Source: NHTS 2001 


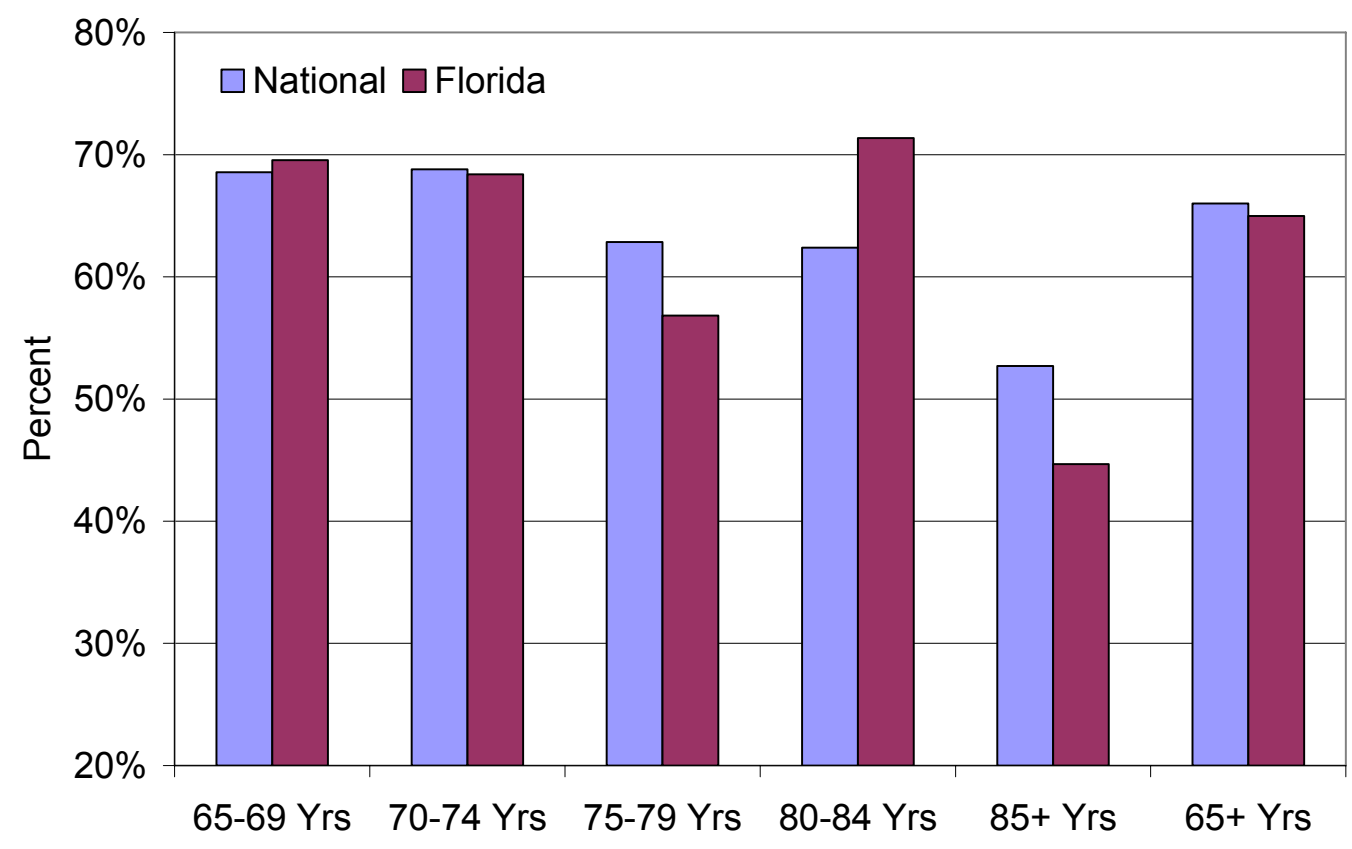

Figure 15 - POV Driver Status of All Trips Made by Age Cohort (Year 2001)

Source: NHTS 2001

Nevertheless, as one gets older, the proportion of seniors who drive themselves declines (of all trips made), to the point that, for the oldest-old seniors (i.e., 85 years and older), 52 percent (45\% in Florida) were drivers on their trips in 2001.

\section{Transit Use}

Public transportation (i.e., transit) may represent a transportation alternative for seniors. National and Florida transportation mode statistics are presented in Table 2. It is evident that the use of transit in 2001 represented only 1 - 2 percent of trips, POV travel was the overwhelming choice of transportation. Figure 16 presents percentage of trips made by transit by age cohort. Even though, in all senior age cohorts, transit trip use is minimal, there seems to be an upward trend post-75 years of age. This upward trend may be due to widowhood (with its concomitant financial implications) and the increasing desire of seniors in the oldest-old age cohorts to remain mobile despite limitations brought on by age. The desire to remain mobile may lead seniors to experiment in using public transportation.

Positive experiences resulting from using transit may encourage many seniors to continue to use public transportation. 
Table 2 - Modal Split for Daily Travel in 2001 Florida and the U.S.A.

\begin{tabular}{|l|r|r|r|r|}
\hline \multicolumn{1}{|c|}{ Mode } & \multicolumn{1}{c|}{ National } & \multicolumn{1}{c|}{ Percent } & \multicolumn{1}{c|}{ Florida } & \multicolumn{1}{c|}{ Percent } \\
\hline POV $^{*}$ & $351,755,038,143$ & $86.4 \%$ & $18,428,149,196$ & $88.4 \%$ \\
\hline TRANSIT $^{* *}$ & $6,652,380,701$ & $1.6 \%$ & $219,534,970$ & $1.0 \%$ \\
\hline WALK & $35,366,367,241$ & $8.6 \%$ & $1,445,556,470$ & $6.9 \%$ \\
\hline BIKE & $3,314,343,629$ & $0.8 \%$ & $259,707,218$ & $1.2 \%$ \\
\hline OTHER & $10,174,355,502$ & $2.4 \%$ & $496,735,787$ & $2.3 \%$ \\
\hline TOTAL & $406,940,657,644$ & $100.00 \%$ & $20,842,276,738$ & $100.00 \%$ \\
\hline
\end{tabular}

${ }^{*}$ POV Includes car, van, sport utility vehicle (SUV), pickup or other truck, recreational vehicle (RV), or motorcycle

${ }^{* *}$ Transit includes local public transit bus, commuter bus, city to city bus, commuter train, subway/elevated rail and street car/trolley (Source: NHTS 2001)

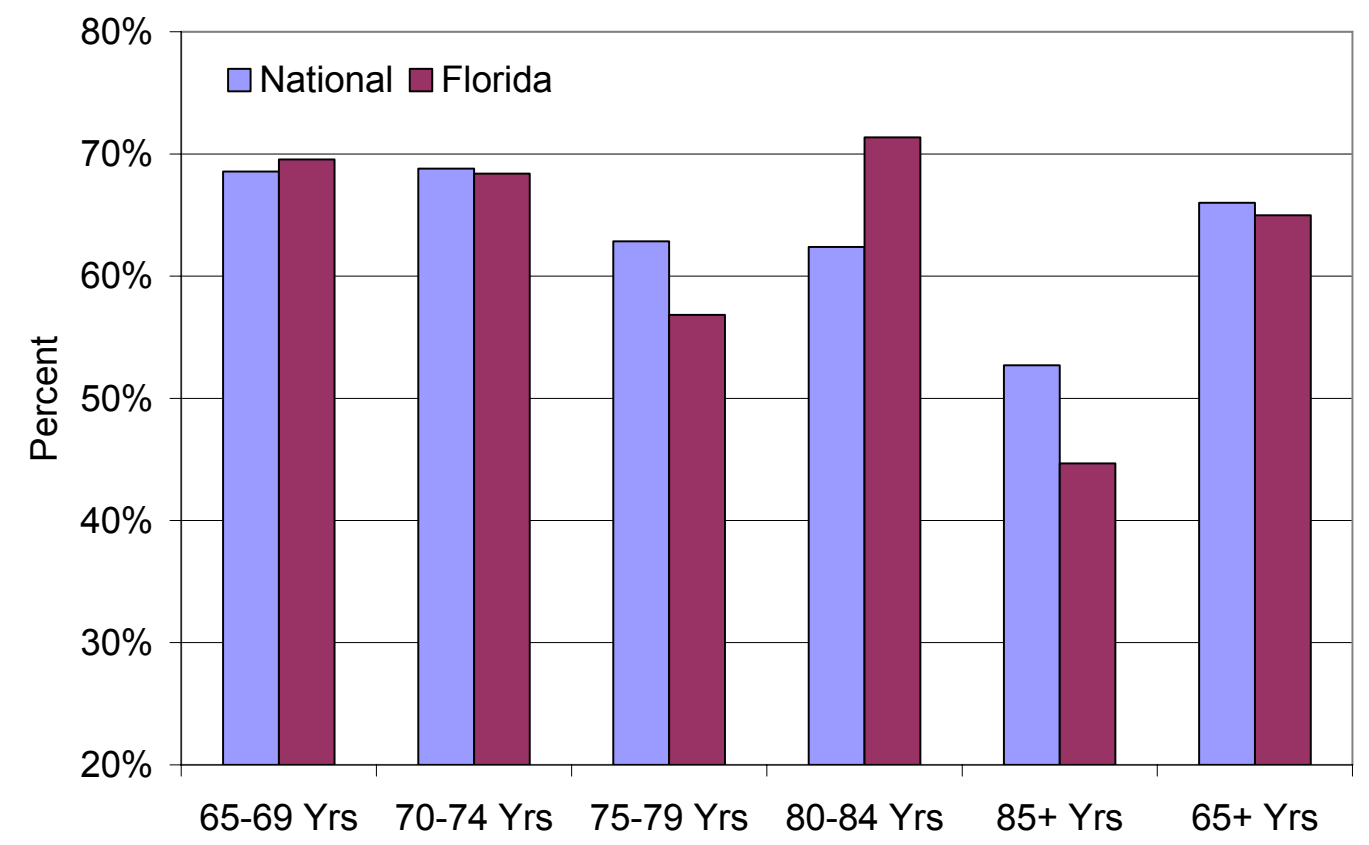

Figure 16 - Percent Transit Trips by Age Cohort (Year 2001) Source: NHTS 2001

\section{Transportation Availability and Use Survey Dataset (TAUS)}

During a three-month period in 2002, the Bureau of Transportation Statistics (BTS) of USDOT collected data on how people use transportation. Effort was made to include a representative sample of disabled persons in order to understand what barriers they face in using transportation and their overall satisfaction with the transportation system. This dataset, as well as containing information regarding the disability status of the trip maker, also provides information on the mode of transportation used, duration of trip, and the distance and purpose of the trip made by these individuals. 
The complete dataset contains 5,019 records, which, when using the full sample weights represents $273,643,273$ persons (the estimated U.S. population in 2002). Persons with disabilities represented 2,321 records, with the balance being non-disabled. When the dataset is weighted nationally, 49,460,359 (18.1\%) were disabled persons and $224,182,913$ $(81.9 \%)$ were non-disabled. These percentages match closely those of the Census 2000 for disabled and non-disabled persons. Of particular interest in this study, Transportation Availability and Use Survey (TAUS) contains variables directly related to the process of driving cessation, i.e., under what circumstances would the respondent stop driving. The results presented in this section revolve around driving cessation and mobility postcessation.

\section{- Driving Ability/Status}

Figure 17 presents driving ability versus age. (Only those respondents aged 15 years and above are considered to legally have driving ability.) As can be seen in all ages (i.e., < 15years) there is a high percentage of persons who consider themselves drivers (i.e., currently driving). For example, of the estimated 141 million persons in 2002 between the ages of $25-64$ years, 88 percent were classified as currently driving (i.e., holding a drivers license). With respect to the "other" category, this includes respondents who refused to give their age during the CATI, or their age was not indicated on the mail/internet survey.

Despite age not being given, it was inferred, given the likely probability, that respondent was older than 15 years.

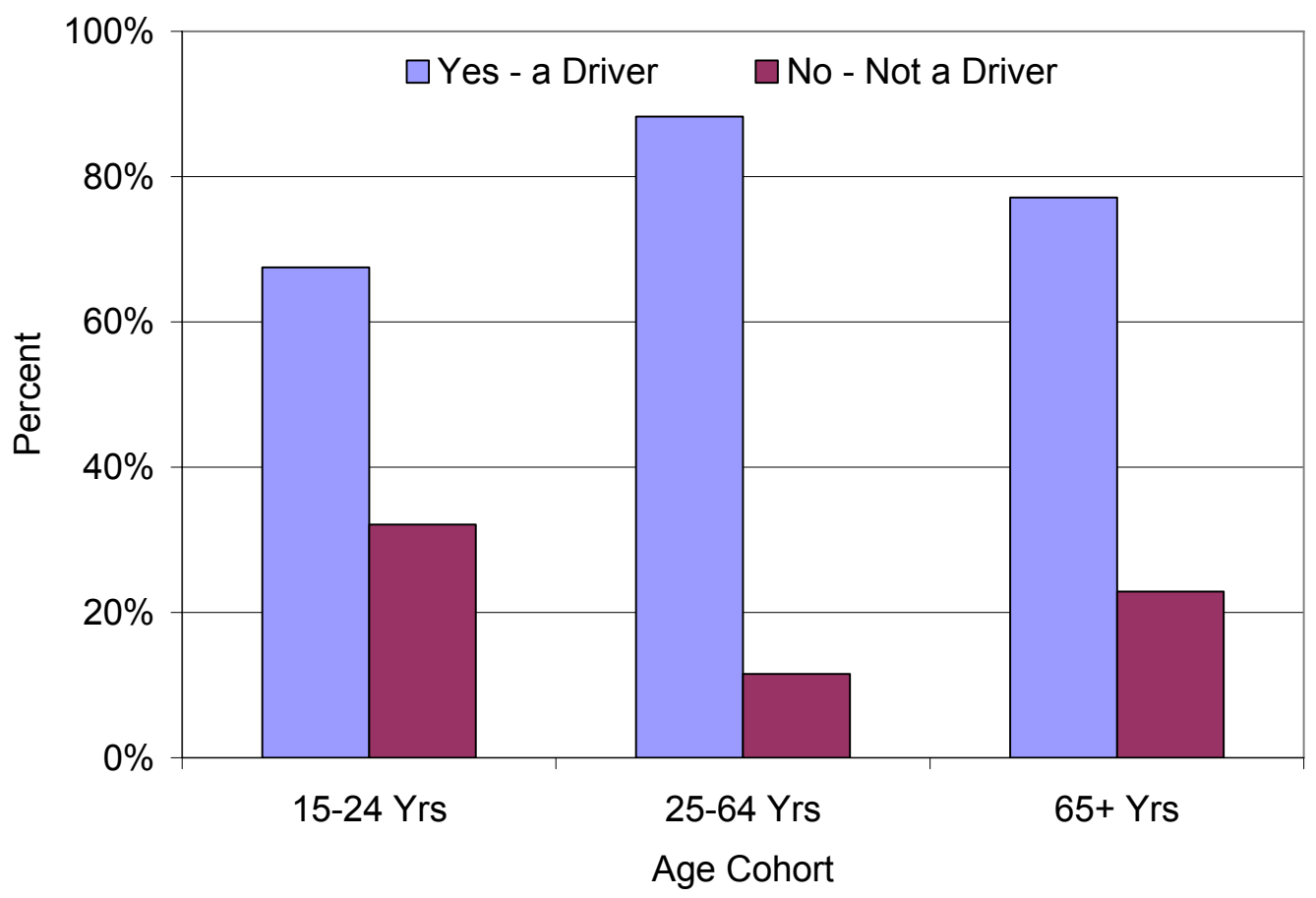

Figure 17 - Age versus Current Driver Status Source: TAUS 
Figure 18 presents statistics according to disability and driving status. As can be seen, disability status does impact current driving ability. The highest percentage of persons describing themselves as "currently driving" for both disabled and non-disabled is found in the 25-64 years cohort. The 65+ age cohort also reveals the large differences between current driver status. In both cases (i.e., non-disabled versus disabled currently driving and non-disabled versus disabled not currently driving), the difference is approximately 30 percentage points. This may imply a greater impact of disability status and the ability to drive during the later years of life and the subsequent need to cease from driving altogether by those classified as disabled.

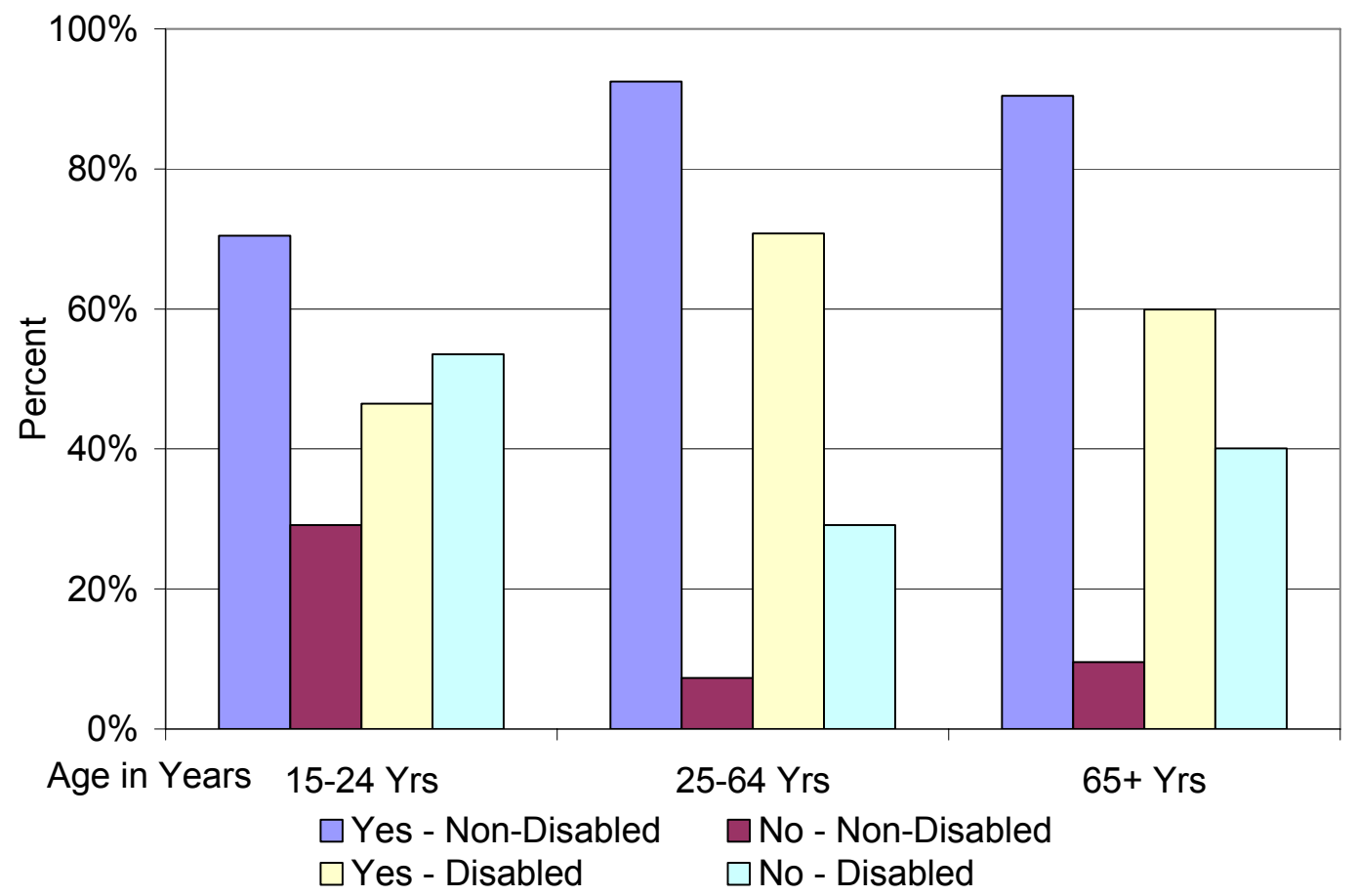

Figure 18 - Age versus Current Driver and Disability Status Source: TAUS

Despite having to cease from driving, was this planned? The literature review contained in Technical Memorandum One (Polzin \& Page 2005) identified a number of studies that concluded the average adult has not and does not plan to cease from driving. This does vary according to gender (i.e., women are more prone to give up driving earlier than males) and the length of time as a regular driver. The results presented in Figure 19 indicate that disability status does have an impact on planning (or thinking for that matter) to cease from driving. Based on a sample of 1,323 valid responses (representing 39 million persons over 55 years), 90.32 percent of disabled persons indicated that they were not planning to cease from driving, compared to 89.01 percent of non-disabled. Though the difference is marginal, it is possibly indicative of the disabled persons greater dependency on being able to drive to fulfill life's needs and therefore holding on for as long as possible to this means of mobility. 


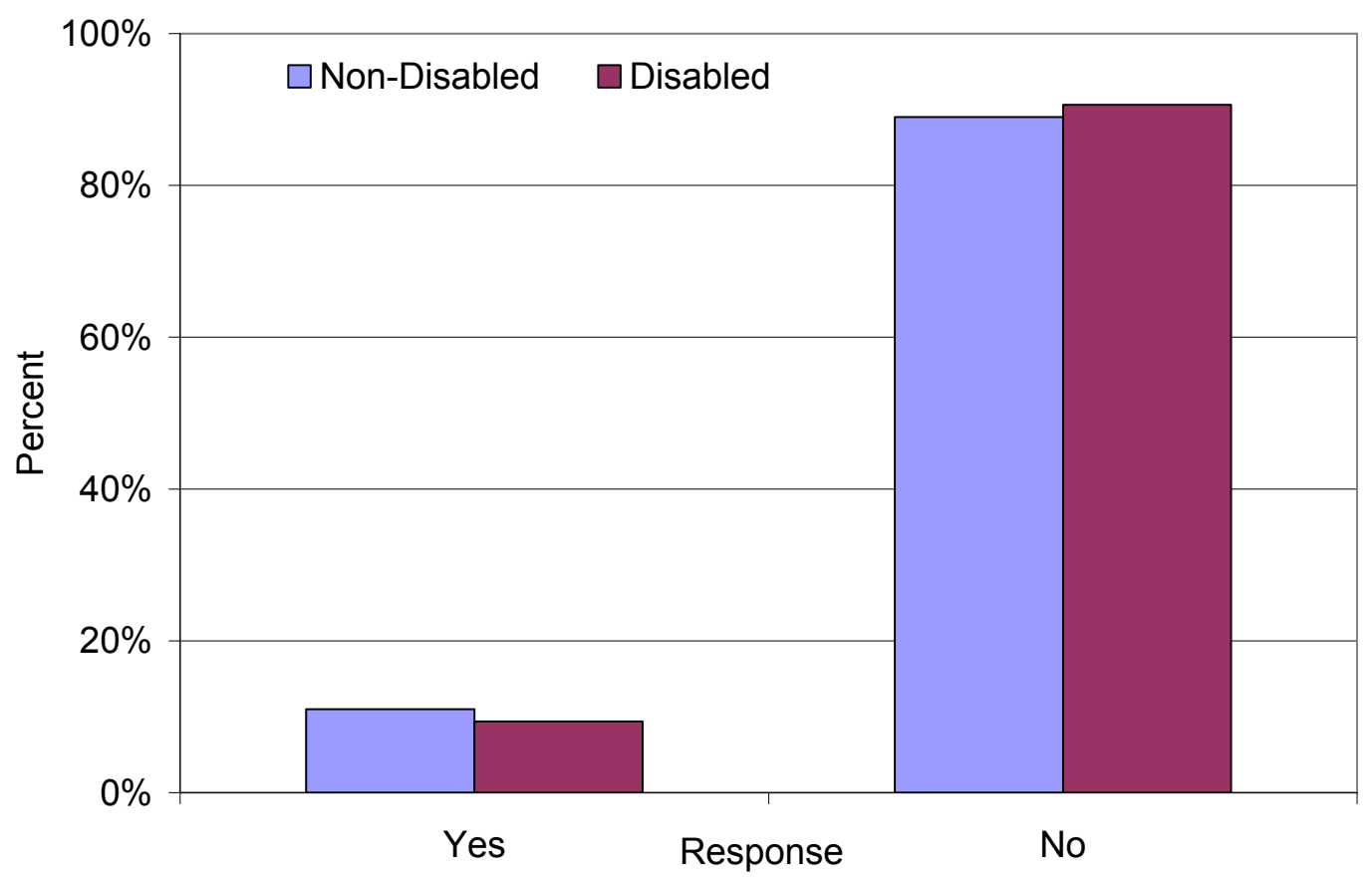
Figure 19 - Responses of Seniors (55+ Yrs) to the Question: "Do you ever Plan to Give up Driving?" Source: TAUS

Table 3 presents statistics with respect to the type of transportation most frequently used by persons over 55 years ranked in order of percentage use (results reflect only those records where age was indicated). Confirming auto dependence, it is clear for both groups that personally driving a motor vehicle and traveling in a motor vehicle as a passenger are the

Table 3 - Type of Transportation Used Most Frequently

\begin{tabular}{|l|l|r|l|l|r|}
\hline \multicolumn{3}{|c|}{ Non-Disabled (55+ years) } & \multicolumn{3}{c|}{ Disabled (55+ years) } \\
\hline Rank & Transportation Mode & Percentage & Rank & Transportation Mode & Percentage \\
\hline 1 & $\begin{array}{l}\text { Personal Motor Vehicle as } \\
\text { a Driver }\end{array}$ & $83.94 \%$ & 1 & $\begin{array}{l}\text { Personal Motor } \\
\text { Vehicle as a Driver }\end{array}$ & $58.81 \%$ \\
\hline 2 & $\begin{array}{l}\text { Personal Motor Vehicle as } \\
\text { a Passenger }\end{array}$ & $9.94 \%$ & 2 & $\begin{array}{l}\text { Personal Motor } \\
\text { Vehicle as a } \\
\text { Passenger }\end{array}$ & $32.93 \%$ \\
\hline 3 & Public Bus & $1.71 \%$ & 3 & Public Bus & $2.32 \%$ \\
\hline 4 & $\begin{array}{l}\text { Walking/Non-Motorized } \\
\text { Wheelchair... }\end{array}$ & $1.08 \%$ & 4 & $\begin{array}{l}\text { Paratransit Van/Bus } \\
\text { By Public Trans Auth }\end{array}$ & $1.93 \%$ \\
\hline 5 & $\begin{array}{l}\text { Subway/Light Rail/Or } \\
\text { Commuter Train }\end{array}$ & $0.93 \%$ & 5 & Taxicab & $1.41 \%$ \\
\hline
\end{tabular}


top-ranked modes. As expected, a larger percentage of non-disabled persons (84\%) personally drive a motor vehicle when compared to the 59 percent of disabled. In third place for both groups is the use of public transit. It is evident that, for disabled, using this mode of transportation takes a slightly greater percentage of trips when compared to nondisabled persons use of transit.

The transportation used most frequently and ranked in fourth place differs for both groups. For the non-disabled person, walking and the use of a non-motorized wheelchair accounts for 1 percent of trips. In the case of disabled persons, the challenges of walking have given rise to their greater use of specialized transportation in the form of paratransit. In this case, 2 percent of trips are made by this mode by disabled persons. In fifth place (at 1 percent), the use of subway/light rail/commuter train is an option for the non-disabled. The challenges of using rail (i.e., access to and availability of) with respect to disabled persons have impacted on their preference for the use of the taxi-cab by this group. Approximately 1 percent of trips are by this mode.

\section{Mature Drivers License Dataset (MDLD)}

The nature and reasoning behind the creation of the MDLD were presented in Chapter 2. Chapter 2 also presented insight into the data cleaning process that was undertaken, nevertheless, the caveat that the MDLD was not created for research analysis has guided the types of analyses undertaken that are presented below.

The MDLD was created in the 2000-2001 Federal fiscal year through the submission of a 163 Grant proposal to the Florida Department of Transportation (FDOT). The MDLD is a database of public record information on each driver holding a Florida Drivers License (DL). The objectives of creating the MDLD were twofold; first, to create a dataset of all drivers 55 years and above holding a Florida Drivers License (DL), and second, to allow the analysis of the MDLD without interfering with the operations of the full DL dataset. Prior to 1999, the operating platform of the MDLD was the Wisconsin File Handler Program. In 1999, the system migrated to an Oracle (Version 9) platform. The development of the MDLD is one initiative of the Florida Department of Highway Safety and Motor Vehicles (HSMV) that seeks to assess the driving behavior of persons 55 years and older holding Florida issued drivers licenses.

The MDLD that was analyzed as part of this study, contained driving records of persons who were 55 years or older at the date of transfer with a valid Florida DL; such persons may not necessarily be residents of Florida. (Files from the HSMV were transferred to CUTR via File Transfer Protocol [FTP] on September 9, 2005). Thus, the latest year of birth indicated in the birth year variable is 1949 . The MDLD transferred was made up of 12 files/datasets that contained information such as demographics, DL type, conviction records, etc. The MDLD transferred did not contain personal details, e.g., name, street address, social security numbers, etc. These were removed to ensure data protection. Nevertheless, ZIP Codes 
were included in the dataset. Details of the file types and number of records are shown in Table 4.

Table 4 - Florida Mature Drivers License Dataset File Types and Contents

\begin{tabular}{|l|l|r|}
\hline \multicolumn{1}{|c|}{ File Suffix } & \multicolumn{1}{|c|}{ File Type } & Number of Records \\
\hline AA & Basic Person Information & $6,248,893$ \\
\hline BB & License Record & $6,248,892$ \\
\hline CC & Exam Records & 378,585 \\
\hline DD & Identification History & $1,180,616$ \\
\hline EE & Driver School & 378,585 \\
\hline FF & Correspondence & 104,823 \\
\hline GG & Cancellations & 94,334 \\
\hline HH & Convictions & $5,188,387$ \\
\hline II & Crash Records & 337,374 \\
\hline JJ & HTO (Habitual Traffic Offender) Revocations & 19,484 \\
\hline KK & Revocations & 511,913 \\
\hline LL & Points Suspensions & 13,493 \\
\hline MM & Disqualifications & 769 \\
\hline NN & Suspensions & 232,588 \\
\hline
\end{tabular}

Source: MDLD

As the MDLD is a dynamic dataset, when a new variable is required, it is simply added to the dataset. Thus, the MDLD transferred had more than 6 million rows and at least 100 variables/columns. The basic person information file represents the total number of records in the MDLD, approximately, 6.2 million records. The full dataset of Florida DL holders at the time of transfer was 19.8 million records. Thus, the MDLD represented 30 percent of the full Florida DL database when transferred. The DL number represents the primary/key field in all the files.

\section{Mature Drivers License Dataset Caveats}

The following caveats are given in interpretation of the data.

\section{- Year of Birth of Driver License Holder}

Each DL number contains a two-digit year of birth indicator. For example in the DL number Z123-456-58-229-0, 58 is the year field (1958). The year of birth also is one of the variables in the person record file. There are cases where the year indicated in the year of birth variable does not match the two-digit year of birth number contained in the DL number. In this case, it is assumed that the two-digit year of birth number in the DL number overrides the value given in year of birth variable. 


\section{- Dynamic Database}

The MDLD is a dynamic dataset; the size of the MDLD changes continuously as records are added or removed. The dataset size (12 ASCII files) on the day of transfer approximated 15 million records (or 1.5GB) and represented a "snapshot" of the dataset at that point in time. Analysis performed on the MDLD (at HSMV) in December 2005 will give different answers when compared to the MDLD transferred to CUTR in September 2005.

\section{- Deceased Status}

In the MDLD, deceased status of a person is identified either as a flag or as a date of death. There are many cases where one of these variables is completed, and in others the record will show completion of both of these variables. Persons who have died in Florida are made known to HSMV on an ad-hoc basis, and records of such persons are purged from the MDLD. Unfortunately, the lack of continuity in this exchange of information has resulted in the MDLD appearing to have many persons who are deceased who have "live" records. Without personal details, it is impossible to accurately identify the status of such persons (i.e., through the National Death Index) and thus remove them from the dataset.

\section{- Research Potential of Database}

According to an internal report detailing the creation and use of the MDLD of the HSMV in 2001, the MDLD is not designed for research (Sauls et al. 2001). This is partly due to the dynamic nature of the dataset (explained above) and also to legal requirements that regulate the length of time records can be kept in the dataset. Purging of the dataset is undertaken to keep within legal requirements, but consistency of this effort cannot be guaranteed as some records are kept for longer than others, (e.g., conviction records), while some records of persons who have died also remain in the dataset.

\section{Cancellations}

In Technical Memorandum One (Polzin \& Page 2005), it was noted that driving cessation can be voluntary (i.e., without legal intervention) or mandated (i.e., forced), stemming from the intervention by a third party such as a family member or court. With respect to the MDLD, voluntary driving cessation can be inferred from those seniors who have given up their licenses for cancellation. In the MDLD, File GG (see Table 4) represents those licenses cancelled. It must be noted that many others may stop driving but retain their licenses, so the MDLD gives only a partial picture of seniors who have ceased to drive. According to this file (i.e., GG), there were 75 cancellation codes, of which, code 4 represented those who voluntarily gave up their licenses. Numbers of persons who voluntarily gave up their licenses since 2000 are indicated in Table 5. 
Table 5 - License Cancellation Statistics Voluntary Surrender of License

\begin{tabular}{|l|l|l|l|l|l|}
\hline Year & $\mathbf{2 0 0 0}$ & $\mathbf{2 0 0 1}$ & $\mathbf{2 0 0 2}$ & $\mathbf{2 0 0 3}$ & $\mathbf{2 0 0 4}$ \\
\hline Voluntary Surrender & 3,500 & 3,599 & 4,313 & 5,657 & 7,658 \\
\hline Percent of Total Cancellations in 2004 & $75.4 \%$ & $77.1 \%$ & $77.5 \%$ & $72.9 \%$ & $78.7 \%$ \\
\hline
\end{tabular}

Source: MDLD

Table 5 clearly indicates that the voluntary surrender of licenses was the predominant reason for license cancellation in the years indicated. To further this analysis, it would be useful to understand the voluntary surrender of licenses by age. Table 6 provides us with this information for the year 2004. Though it is possible to determine the proportion of license holders who voluntarily surrendered their licenses according to age cohort, the fact that the MDLD transferred contains records of persons who have died would result in answers not reflecting the true picture.

Table 6 - 2004 License Cancellation Statistics Voluntary Surrender of License by Age

\begin{tabular}{|l|l|l|l|l|l|l|}
\hline \multicolumn{1}{|c|}{ Age Cohort } & $\mathbf{5 5 - 5 9}$ & $\mathbf{6 0 - 6 4}$ & $\mathbf{6 5 - 7 4}$ & $\mathbf{7 5 - \mathbf { 8 4 }}$ & $\mathbf{8 5 +}$ & Total $^{\mathbf{*}}$ \\
\hline Number & 169 & 224 & 851 & 3,424 & 2,922 & 7,590 \\
\hline Percent of Total Cancellations in 2004 & $2.2 \%$ & $3.0 \%$ & $11.2 \%$ & $45.1 \%$ & $38.5 \%$ & $100 \%$ \\
\hline
\end{tabular}

${ }^{*}$ Full Total from this Dataset Source: MDLD

From Table 6 it is evident that, of all persons recorded in the MDLD who voluntarily surrendered their licenses in 2004, persons aged 75 - 84 years formed the largest share (45\%). This age cohort is of particular importance as "fragility begins to increase at ages 6064. At age 75 , older drivers begin to be markedly over involved in crashes. ... The rate of motor vehicle crash deaths per capita among males in 2004 began to increase at ages 6569 and increased markedly at ages 75-79 and ages 80-84" (Insurance Institute of Highway Safety, 2005). Indeed, research has shown that the impacts of driving impairments become significant for persons 75 years and older.

\section{Revocations and Suspensions}

As indicated earlier, driving cessation can be forced, i.e., mandated by the courts or driver licensing center. The Revocation and Suspension Datasets of the MDLD are of particular interest here. This file contains records of all licenses revoked or suspended for a variety of reasons. (Note: Suspensions are temporary in nature and the length is determined by the type of violation. A revocation can be from 1 day to permanent depending on the seriousness of the offense.) Figure 20 presents summary statistics of licenses revoked or suspended for the period 2002 to 2004 . Additional analysis by age on licenses revoked (as an example) may yield further information. Table 7 presents data according to age cohort for the top five revocation categories in 2004. 


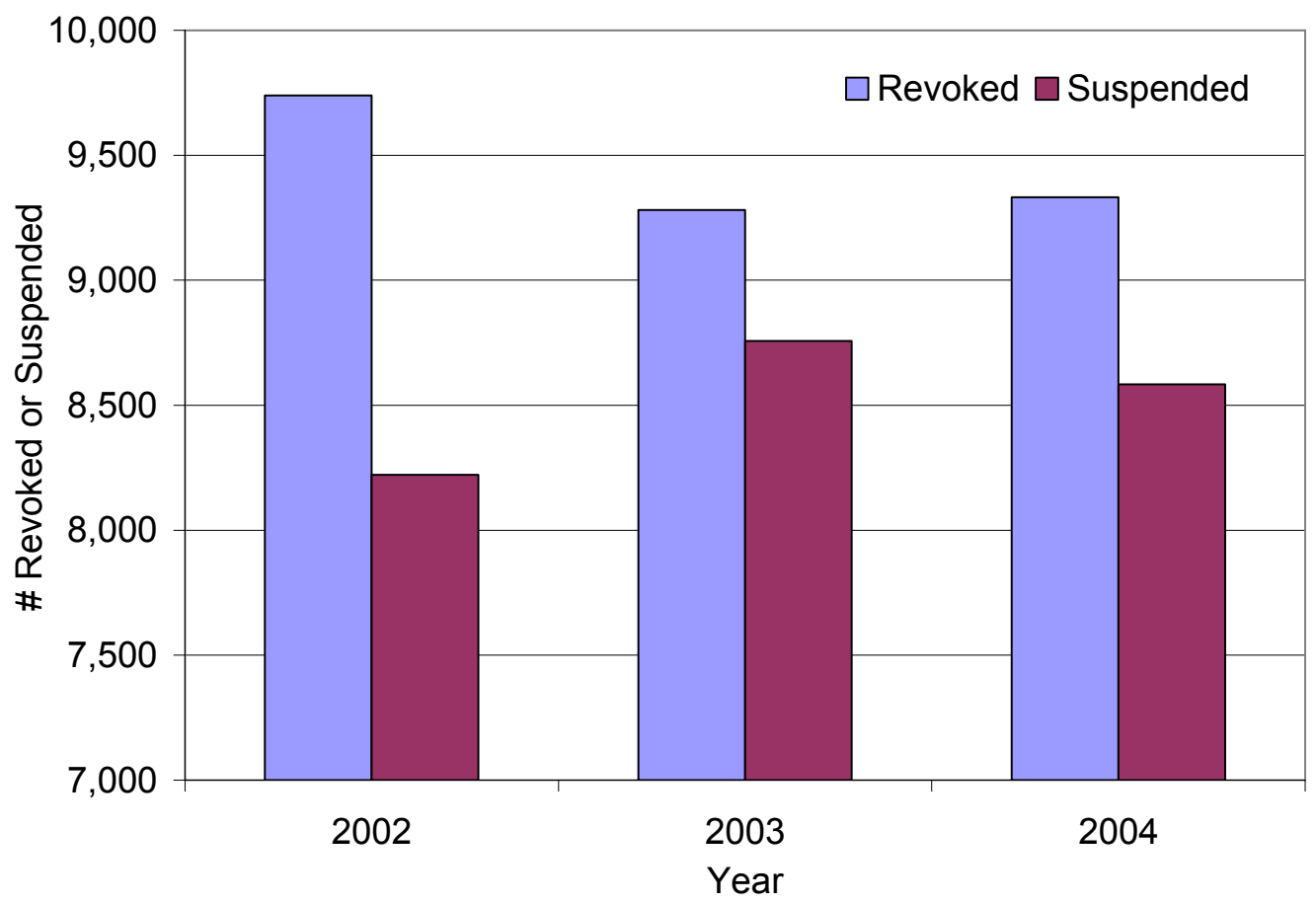

Figure 20 - Licenses Revoked or Suspended $2002-2004$ Source: MDLD

Table 7 also reconfirms the significance of the $75-84$ year cohort. In this case, approximately 30 percent of license revocations in 2004 were persons in this cohort. Furthermore, the top five reasons for license revocation represented 96 percent of all licenses revoked in this age cohort and 99 percent for persons 85 years and older. It is apparent that physical impairments that can impact driving capability in senior years become a more prevalent reason for license revocation as age increases. For persons 85 years and older, all of the top five reasons for license revocation have some link to physical health status, e.g., vision or musculoskeletal decline.

\section{Estimates of Former Drivers Needing Alternative Transportation Options}

Chapter 1 noted the challenge of deriving valid estimates of drivers who have retired from driving. A hypothetical figure of 7,000 drivers who failed their driver license renewal exam was given for Florida. Nevertheless, it was indicated that in 2004, approximately 407,000 persons 65 years and older successfully renewed their Florida Drivers License and further 7,211 persons voluntarily surrendered theirs. ${ }^{3}$ Suppose one percent of all applicants over the age of 65 years (approximately 411,100), who applied for license renewal failed $(4,110$ persons) leaving a balance of 407,000 persons who were successful. Thus, in 2004 ,

\footnotetext{
${ }^{3}$ As reported by M. Grosz of the Florida Department of Highway Safety and Motor Vehicles.
} 
approximately $11,320(4,110$ plus 7,211$)$ former drivers 65 years of age per year would need to look for alternative modes of transportation to remain active in their communities. To this estimate one would have to add senior former drivers who had to give up their licenses by court mandate, i.e., through revocation or suspension. This estimation is anticipated to grow in future years in tandem with increasing licensure rates and the senior population.

Table 7 - License Revocation Statistics by Age Cohort in 2004

\begin{tabular}{|c|c|c|c|c|c|}
\hline Age Cohort & $55-59$ & $60-64$ & $65-74$ & $75-84$ & $85+$ \\
\hline Rank 1 & $\begin{array}{l}\text { Driving Under } \\
\text { the Influence } \\
\text { (DUI) }\end{array}$ & DUI & DUI & $\begin{array}{l}\text { Failure to } \\
\text { submit } \\
\text { medical } \\
\text { report }\end{array}$ & $\begin{array}{l}\text { Failure to } \\
\text { submit } \\
\text { medical } \\
\text { report }\end{array}$ \\
\hline Rank 2 & $\begin{array}{l}\text { DUI - Property } \\
\text { Damage/ } \\
\text { Personal Injury }\end{array}$ & $\begin{array}{l}\text { Failure to } \\
\text { submit vision } \\
\text { report }\end{array}$ & $\begin{array}{l}\text { Failure to } \\
\text { submit vision } \\
\text { report }\end{array}$ & $\begin{array}{l}\text { Failure to } \\
\text { submit vision } \\
\text { report }\end{array}$ & $\begin{array}{l}\text { Failure to } \\
\text { submit vision } \\
\text { report }\end{array}$ \\
\hline Rank 3 & $\begin{array}{l}\text { Violation } \\
\text { Controlled } \\
\text { Substance }\end{array}$ & $\begin{array}{l}\text { DUI - Property } \\
\text { Damage/ } \\
\text { Personal Injury }\end{array}$ & $\begin{array}{l}\text { Failure to } \\
\text { submit medical } \\
\text { report }\end{array}$ & $\begin{array}{l}\text { Incapable of } \\
\text { operating } \\
\text { vehicle - } \\
\text { medical } \\
\text { reason }\end{array}$ & $\begin{array}{l}\text { Incapable of } \\
\text { operating } \\
\text { vehicle - } \\
\text { medical } \\
\text { reason }\end{array}$ \\
\hline Rank 4 & $\begin{array}{l}\text { Failure to } \\
\text { submit medical } \\
\text { report }\end{array}$ & $\begin{array}{l}\text { Failure to } \\
\text { submit medical } \\
\text { report }\end{array}$ & $\begin{array}{l}\text { Incapable of } \\
\text { operating } \\
\text { vehicle - } \\
\text { medical reason }\end{array}$ & $\begin{array}{l}\text { Inadequate } \\
\text { vision }\end{array}$ & $\begin{array}{l}\text { Inadequate } \\
\text { vision }\end{array}$ \\
\hline Rank 5 & $\begin{array}{l}\text { Failure to } \\
\text { submit vision } \\
\text { report }\end{array}$ & $\begin{array}{l}\text { Incapable of } \\
\text { operating } \\
\text { vehicle - } \\
\text { medical reason }\end{array}$ & $\begin{array}{l}\text { DUI - Property } \\
\text { Damage/ } \\
\text { Personal Injury }\end{array}$ & DUI & $\begin{array}{l}\text { Inadequate } \\
\text { field of vision }\end{array}$ \\
\hline $\begin{array}{l}\text { All } \\
\text { Revocations }\end{array}$ & 1,484 & 854 & 1,283 & 2,117 & 1,578 \\
\hline $\begin{array}{l}\% \text { of top } 5 \\
\text { of All } \\
\text { Revocations }\end{array}$ & $93.7 \%$ & $91.3 \%$ & $90.3 \%$ & $95.7 \%$ & $98.8 \%$ \\
\hline $\begin{array}{l}\text { Age Cohort } \\
\% \text { of All } \\
\text { Revocations }\end{array}$ & 20.2 & 11.7 & 17.5 & 28.9 & 21.5 \\
\hline
\end{tabular}


[This page left blank intentionally] 


\section{CHAPTER 4 - FOCUS GROUPS}

Analysis of datasets provides only quantitative perspectives of senior travel and mobility. As noted earlier, this project is intended to provide additional insight into travel behavior changes for persons who lose their driving privileges, particularly their interest in, ability to, and subsequent use of public transit. To achieve this qualitative research in the form of group discussions with seniors, focus groups were held to identify issues and concerns surrounding current and former drivers with respect to their views on and their potential use of public transportation as one of several transportation alternatives.

\section{Focus Group Methodology}

A total of five focus group discussions, including one pilot session, were conducted with seniors 55 years and older in Hillsborough County at senior centers located in urban, semiurban and semi-rural areas of the county. This strategy increased the potential that a diversity of participants would participate, reflecting the senior population makeup of the county. The focus groups were conducted in late January and early February 2006. Participants were recruited with the help of the County Aging Services Department through advertising the focus group discussions at senior centers under their jurisdiction (see Appendix A). Participation of seniors was entirely voluntary and, if they were interested, they were prescreened at the time of their initial telephone inquiry. Prescreening was undertaken to ensure that only former and current drivers over the age of 55 became participants in the focus group discussion sessions and to clarify any issues that may have been raised by the interested senior at the time of initial contact. Closer to the date of the focus group discussion, successful applicants were contacted to confirm their availability and given details of the date, time and place of the focus group.

Each focus group discussion lasted no more than 90 minutes. Two CUTR researchers were present at each session, a moderator and an observer. The format at each focus group session included a welcome and introduction with an explanation of focus group participant rights, discussion, and questionnaire completion, followed by closure and thanks (for detailed breakdown, see Appendix B). A questionnaire was designed to provide sociodemographic information as well as further probe issues raised in the discussions in order to undertake quantitative analysis. Two types of questionnaires were given, one for former drivers (i.e., those who had permanently stopped driving) and another for current drivers (i.e., those who had reduced their driving exposure). Each of these questionnaires is presented in Appendices $C$ and $D$. Each focus group discussion was digitally recorded and transcribed afterward. The discussion transcripts as well as results from participant surveys were combined to create a holistic perspective of senior issues and concerns about and their potential use of public transportation as one of several transportation alternatives during and after the process of driving retirement. 


\section{Socio-Economic and Demographic Profile of Focus Group Participants}

A total of 44 seniors participated in the focus groups; the average size of each focus group was 9 participants. Nineteen participants (43\%) were male and 25 were female $(57 \%)$. The actual age of each participant was not collected but categorized according to age cohort; thus, the ages of participants ranged from 55 years to a maximum of over 85 years of age. Figure 21 presents the age breakdown of focus group participants.

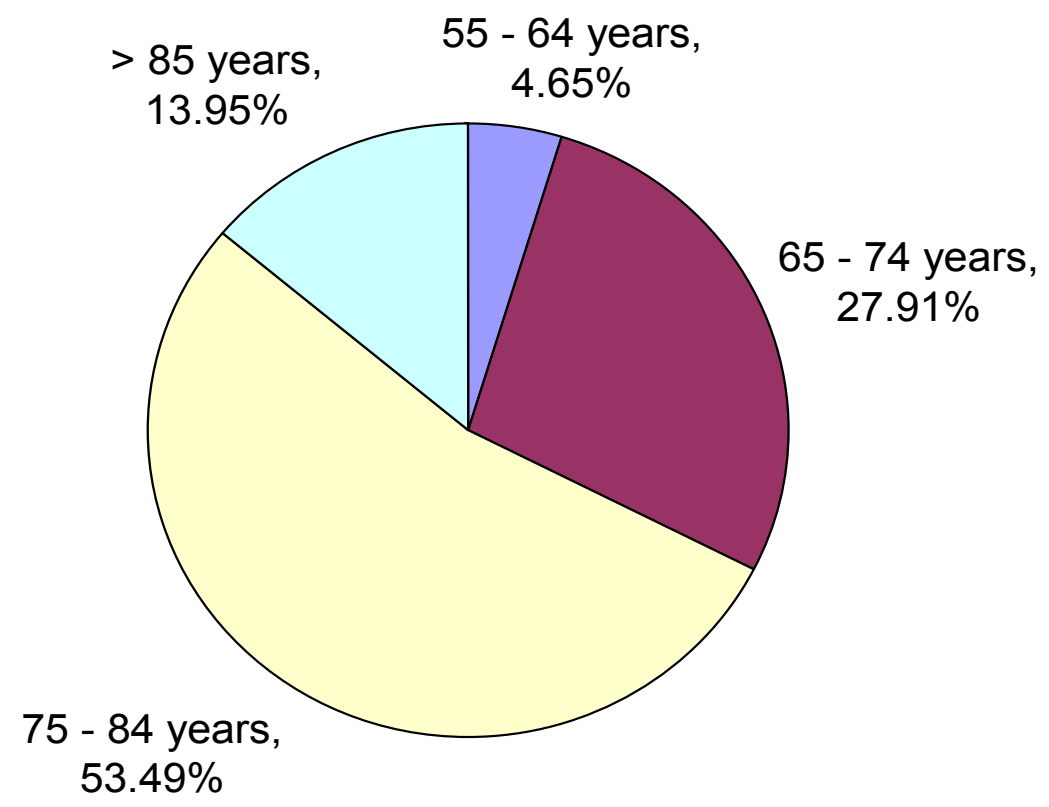

Figure 21 - Age Breakdown of Focus Group Participants

The racial makeup of participants was as follows: White (non-Hispanic), 64 percent; African American/Black, 25 percent; Hispanic (of any race), 9 percent; and Other, 2 percent. Income characteristics also were categorized by cohort, below an annual income of $\$ 30,000$ per year or above $\$ 30,000$. A total of 26 participants indicated an annual income below $\$ 30,000$ per year, 9 participants indicated above $\$ 30,000$, and 9 participants preferred not to give any indication of their household income status.

A direct question about each participant's marital status was not asked. Nevertheless, marital status could be inferred from answers to the question, "Who would be your first choice in assisting you with transportation if you needed it?" Twelve (29 percent) of the 42 focus group participants (who answered this question) indicated spouse or significant other. As to household size, 18 focus group participants lived in one-person households; 14 in twoperson households; 6 in three-person households; and the balance (of the 42 focus group participants who answered this question) were in households of four or more persons. 


\section{Current Driving Status of Focus Group Participants}

Forty percent of the participants (18 participants) had permanently stopped driving, and the remaining 60 percent (26 participants) were currently still driving but had reduced their driving exposure. All focus group participants who were currently driving had driven in excess of 21 years; of the 26 current drivers, 92 percent had driven more than 40 years and 2 had driven between 21 to 40 years. The length of time (in years) at the point of driving cessation for 17 former drivers is presented in Figure 22.

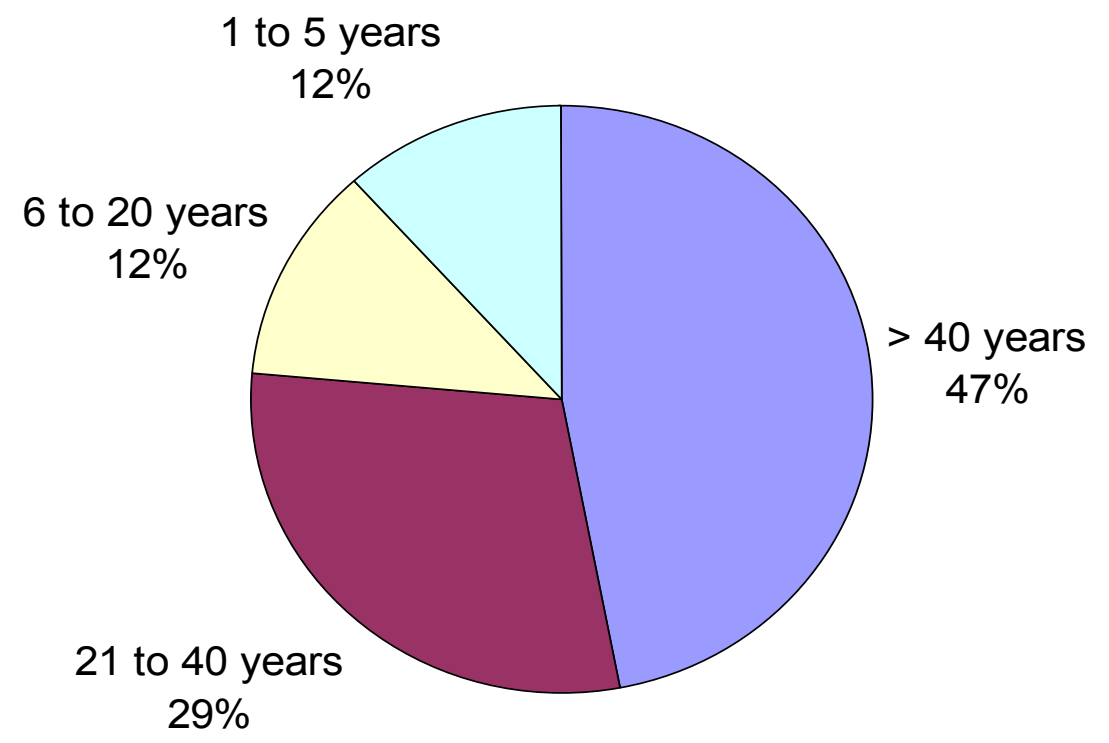

Figure 22 - Years of Driving Experience at Point of Driving Cessation

At the start of each focus group, discussion participants were asked to publicly indicate by voice affirmation or a raised hand whether they classified themselves as a current (with reduced exposure) or former driver. At the end of each session, each participant had the choice of taking the questionnaire reflecting their current driving status; (18 took questionnaires relating to permanently stopping driving and 26 currently driving though with reduced mileage). There may have been some reluctance by focus group participants to publicly admit their driving status (among their peers) but, through the acceptance and completion of the questionnaire in privacy, participants felt more comfortable with indicating their current driving status. 


\section{Current Licensure Status of Focus Group Participants}

As to focus group participant licensure status, 30 participants $(68 \%)$ indicated that they held a valid driver's license issued by a state in the U.S. Noting that these 30 participants were holding valid drivers licenses, $4(13 \%)$ had additionally indicated that they had permanently stopped driving. Of the 18 participants who indicated permanently stopping driving, 13 $(72 \%)$ did not hold a valid license, $4(22 \%)$ held valid licenses, and 1 failed to indicate.

Questions about the year of license issue and the U.S. state of issue were not asked. Instead, a question was asked as to when the current license held would expire. A typical driver's license issued by the State of Florida has a maximum validity of 6 years. Results indicated that 4 focus group participants held licenses that were to expire in 2006; 15 between 2007 to 2008; 8 between 2009 to 2010; and 3 beyond 2011.

\section{Reasons for Driving Reduction or Cessation}

Focus group participants were asked why they had stopped or reduced their driving in recent years. A variety of reasons were given, which can be grouped into two broad categories: internal (i.e. personal) and external. Internal factors included personal health/well-being, wealth and lifestyle change, etc.; external factors were traffic volume, traffic congestion, and driver attitude. From the qualitative questionnaire, the primary factor that influenced the permanent cessation of driving of 15 seniors (three participants failed to indicate) is presented in Figure 23.

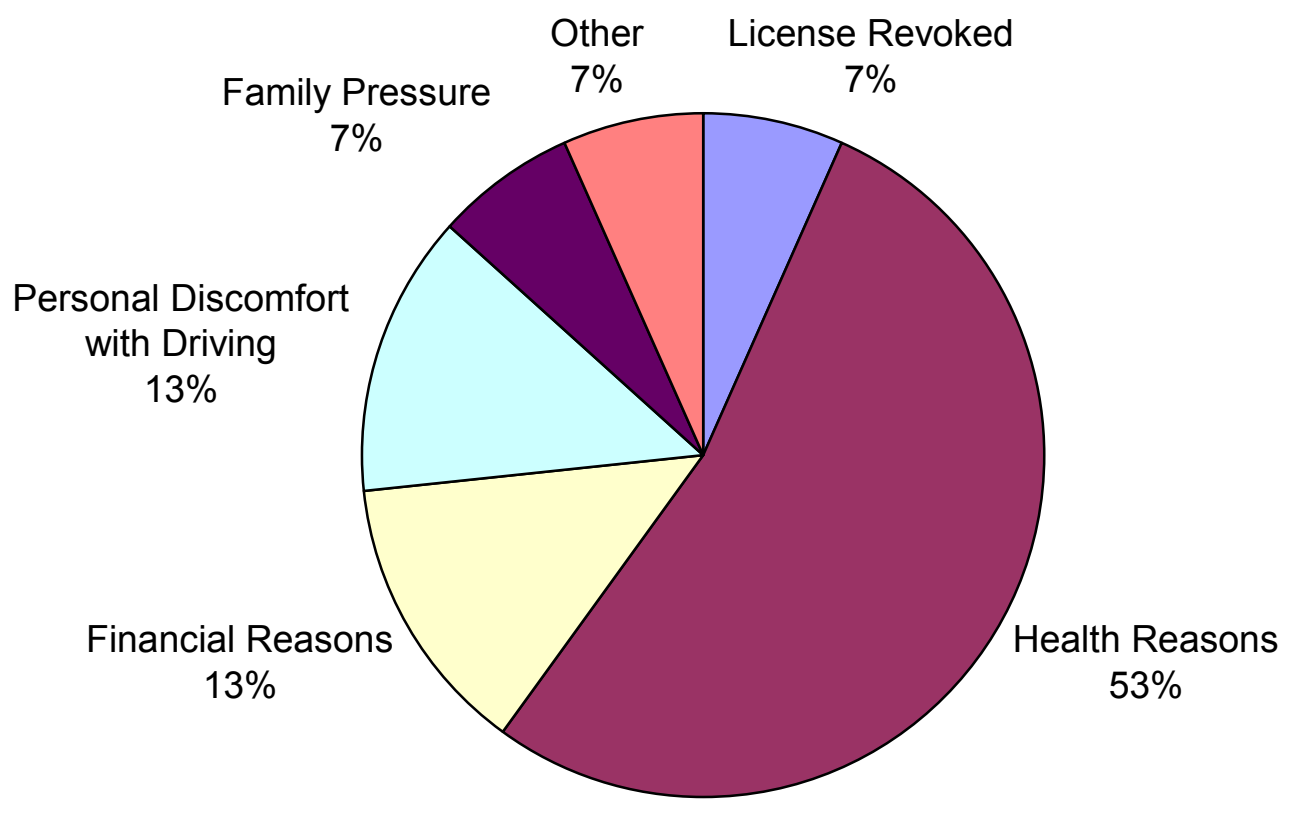

Figure 23 - Factors Influencing Permanent Driving Cessation 


\section{- Health/Well-being}

Debilitating health conditions were a major contributor to either reducing driving or ceasing from driving. Of the 17 respondents who had indicated that they had stopped driving, health factors were indicated as the primary reason in 8 cases. Health conditions such as heart attacks, congestive heart failure, strokes, visual degenerative diseases (e.g., macular degeneration), muscle spasms, and nervous conditions were cited by focus group participants as contributory factors to their current driving status. These factors also may contribute to an increased accident potential of the senior driver, as one focus group participant suffering from visual impairment indicated; she stopped driving after her involvement in a traffic accident.

Visual acuity also impacted the desire and ability to drive at night. Many seniors indicated that they avoided driving at night. The avoidance of night driving curtailed participation in an evening activity where the senior also would be responsible for driving themselves. The pivotal importance of vision in driving for many focus group participants also led them to realize that their own limitations may not only affect themselves and their driving capability but the well-being of other road users. Realization of this responsibility also was noted as a factor influencing driving reduction/cessation. As one focus group participant noted, "Don't want to kill nobody and nobody to kill me!"

Changes in personal characteristics due to the aging process may have precipitated changes in driving behavior. One focus group participant noted that, despite driving on the freeway, many times they had become "timid" in their old age and thus avoided freeway driving which, in turn, reduced their driving exposure. In another case, a focus group participant used the word "frightened" to describe her fear of driving along a freeway that she drove frequently and without any concerns in years gone by.

\section{- Wealth/Economic}

A change in income levels (i.e., transitioning from a regular salary to fixed income), possibly due to retirement or the loss of a spouse, for several focus group participants induced a change in driving. Changes in lifestyle necessitated greater scrutiny of personal finances, resulting in prioritizing the financing of needs rather than wants. Many participants complained of the price of gas and how, in managing their finances, limits on how much was spent on gas played a role in reducing their driving exposure. It is interesting to note here that this group of seniors can remember when gasoline was priced well under $\$ 1$ per gallon. Recollection of these memories may have influenced personal expenditures on gasoline at the current prices to be perceived in a more negative context by seniors.

In another case, the loss of a motor vehicle through theft or the high cost of repair precipitated immediate driving cessation. This was due to the costs in time and money, especially insurance costs, of replacing or repairing the motor vehicle. The lack of a personal motor vehicle does not necessarily result in the cessation in driving, as one focus 
group participant indicated that, despite not having a car, she had access to one belonging to a family member and was able to drive the car as and when needed.

\section{- Lifestyle Change}

The transition to retirement was, for some focus group participants, a marker signaling a transition in reducing their levels of driving exposure. As one focus group participant noted, "I reduced driving as I'm not working anymore." The onset of retirement also saw the transition in the frequency of life maintenance trips, e.g., grocery shopping. As one focus group participant stated, "I drive to the store once in a while." It became clear that driving reduction or cessation was the result of a change in many contributing factors. For many seniors, driving less was associated with a reduced need to drive and not exclusively a decision to forego activities due solely to a reluctance to continue driving.

\section{- Traffic Volume}

The on-road activities of other road users were cited by many focus group participants as a contributing factor precipitating their reduction in driving or ceasing from driving altogether. Such activities of other road users would include talking on a cell phone, shaving while driving, cutting in, etc. Seniors were concerned about other road users (in particular, drivers) as the behaviors of other drivers while multi-tasking made seniors concerned about any potential negative impact on them as they drove along. Descriptive terms used by focus group participants to depict these other drivers were "crazy" or "nuts."

For some of the seniors interviewed, increasing traffic congestion, traffic composition, and the attitudes of other drivers (in particular road rage) may have changed their perspective on driving, precipitating driving reduction. In some ways, driving for these seniors in current traffic conditions had become a stressful and frightening chore instead of a necessary but pleasurable means to facilitate them in meeting their needs. No doubt, some of the tendency to reference intolerable driver behavior is a natural attempt to minimize the significance of their own declining capabilities in tolerating the admittedly more challenging driving environment.

\section{- Family/Social Circle}

Relocating to be closer to adult children for some seniors had resulted in a transition from them being drivers to becoming passengers in cars driven by their adult children (or grandchildren). Relocating to be closer to family members also had resulted in a repositioning of the individual's "center of activity." For example, during pre-retirement, physical location did not limit possibilities in connecting with friends or family due to being able to drive. Now in retirement with each passing year, a spouse or friend from a peer group may die, focusing affections of an individual on their living children or grandchildren and activities in their immediate vicinity. As the individual social circle gets smaller, in particular, when no immediate family is at hand, as one focus group participant said, "I just don't want to drive, got nowhere to go." 
The social circles of all the seniors interviewed were connected by the ability to drive, either by the individual themselves or some other person who would transport the individual. These circles operated in two ways: the senior being able to connect with his peers, and his peers being able to connect with him. As coworkers, senior family members, and friends/neighbors passed away, family/social circles became smaller, and opportunities for new relationships developing became fewer. The need to physically connect with such "shrinking" groups can be partially fulfilled by telephone as a substitute for travel. One focus group participant indicated that diminishing physical health impacted on his potential to connect with others if he had to drive himself safely. This led to his wife and daughter to encouraging him to retire from driving.

\section{- Active Lifestyle}

Though reduced driving, there were some seniors who were very active at this stage in their lives. Volunteer work, either with churches, charities or other non-profit institutions, played an important role in the volunteers' lives, and most were premised on the ability to drive and continue driving. Indeed, some of these volunteer activities were to assist other seniors with meeting their transportation needs by driving them to where they needed to go. The level of participation in voluntary activities was somewhat influenced by the availability of personal finances; as one focus group participant noted, "Volunteering is costing me money to volunteer." Limited incomes for some seniors result in expenditure on gasoline starting to threaten a shift from driving as a life-enriching experience to being rationed to essential trips are made driving oneself. A graphic indicating factors that influence reduction in driving exposure is presented in Figure 24.

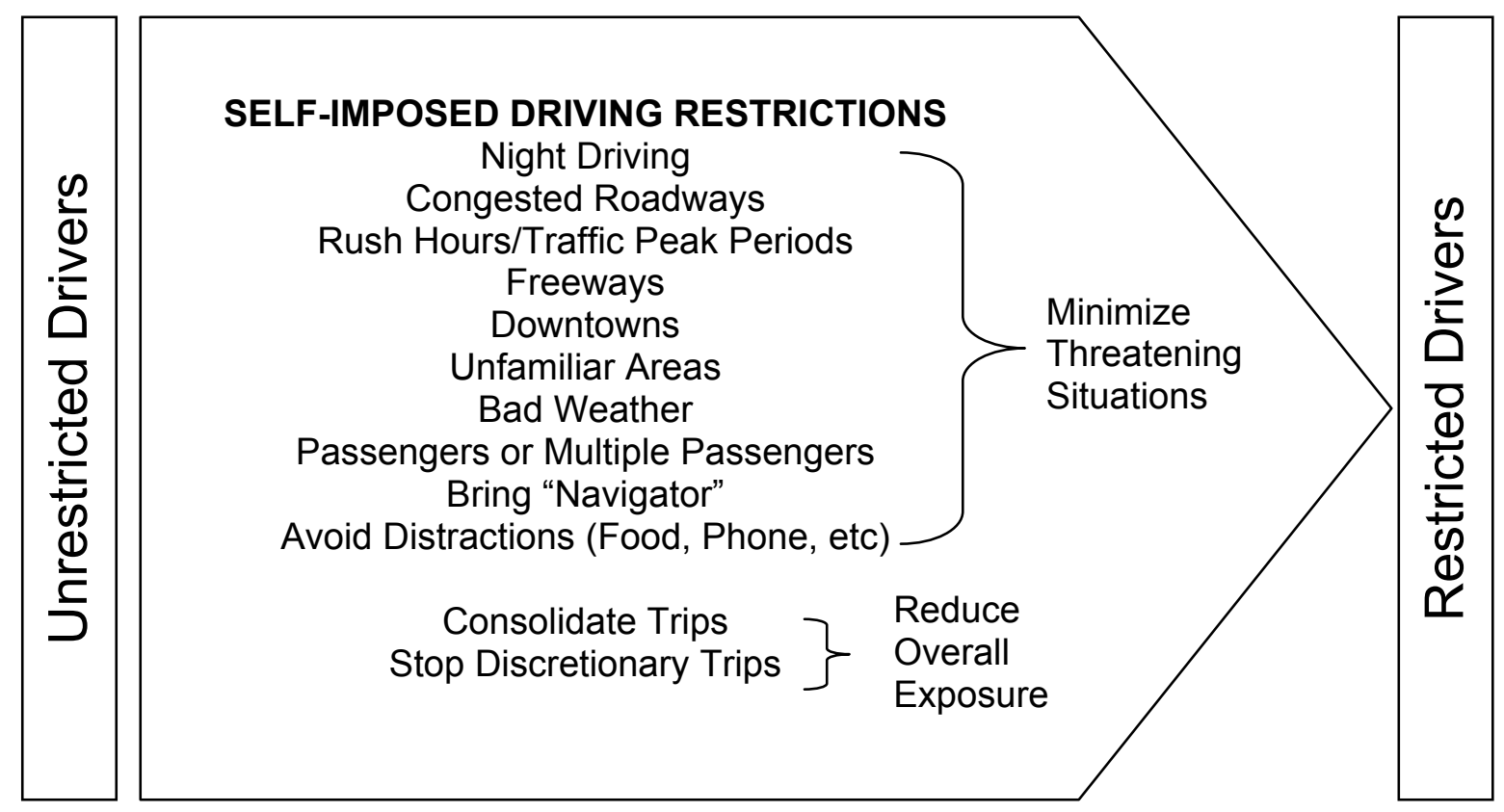

Figure 24 - Self-Imposed Driving Restrictions on Seniors 


\section{Timing of Driving Reduction or Cessation}

Questions were fielded to focus group participants to explore the events that triggered a change in personal driving behavior. Some of these trigger events have been noted. Trigger events were either sudden, i.e., a traffic accident, or gradual, i.e., developing a fear of driving in heavy traffic. As one focus group participant stated, "You are scared when you get on the road. You have to watch everybody." Trying to minimize accident exposure, some seniors also indicated that they tried to minimize their insurance premiums, which had been increasing due to their age. To maintain an affordable premium, which may also be influenced by mileage, seniors may be cutting down on their driving. This speculation was inferred through the strategies being implemented by seniors to maintain the affordability of their premiums, particularly as the majority of focus group participants were on limited incomes. Another trigger event, which may go unnoticed and then suddenly impact on driving behavior, is failing the vision screening part of the driver license renewal process.

Other focus group participants noted that traffic volumes on the routes that they regularly traveled were constantly increasing over time, leading to traffic congestion. Despite the cost of gas, many focus group participants felt that this would not have any impact on the number of road users. This observation was coupled with the view that there were greater numbers of younger drivers on the roads. The interaction of senior drivers with other road users has impacted on the safety risk of all road users. Such a scenario has been exacerbated by the relatively rapid growth in roadway travel with reference to vehicle miles traveled (VMT). This is particularly true in Florida, a state that has one of the fastest rates of VMT growth in the nation. As one ages, senior drivers are losing their ability to cope with multiple stimuli while at the same time, the probabilities of these conditions (i.e., traffic congestion) on the roadway are increasing significantly.

\section{Consequences of Driving Cessation or Reduction}

Earlier it was noted that lifestyle change was one of several factors that precipitated changes in driving behavior. Driving cessation or the process of driving reduction also precipitates further change. For this cyclical process not to degenerate into complete immobility and/or non-activity for an individual, positive attitudes and experiences, towards these changes can arrest the process. To understand some of these attitudes and experiences focus group participants were asked how their lives had changed as a result of changes in their driving behavior.

\section{- Positive Experiences}

One benefit of driving cessation or driving less was that one had more time on their hands for doing other things. One focus group participant noted that, although he had reduced driving exposure, he was able to do "a lot of reading." In another case, time was spent getting more exercise. Driving cessation also brought physical and mental relief to one focus group participant who suffered from panic attacks when she sat behind a steering 
wheel. In another case, the relief gained from not having to drive was described as being more "content" with oneself, as there was no pressure to go places. Driving only when it was absolutely necessary saved on gas expenditure and perhaps insurance premiums if mileage was taken into account, providing positive benefits resulting from a reduction in driving.

Another benefit of not driving expressed by one focus group participant was no longer facing the responsibility of being liable for causing harm to oneself or another road user due to their diminished driving ability. Family support was seen as a vital ingredient that can add significantly to positive experiences during the period of driving transition. Being able to rely on family members to assist with transportation 24/7 may result in minimal negative experiences. As one focus group participant put it when responding to life changes after driving cessation, "Well, mine has not changed that much because I have five children and all of them have grown and all have cars and trucks and when I want to go somewhere I just simply call one of them. They will take me anywhere I want to go." The extent of positive experiences during the period of driving transition is somewhat dependent on the strength of familial relationships.

\section{- Negative Experiences}

Negative experiences far outweighed the positive experiences shared by the focus group participants. Lives had become "dull," "terrible" or "boring" after driving cessation. At times, focus group participants expressed some form of remorse at not being able to drive as evidenced by statements such as "I miss driving." Dependence on others for travel arrangements is one result of driving retirement that has had the most profound impact on seniors. The dependence on others for meeting personal travel needs may entail constantly seeking out others to provide transportation. An experience related by a focus group participant explains this scenario where the first provider of transportation, say a family member, may have had a last-minute change of plans and can no longer assist the senior in need. The senior is then forced to ask another person, and so on. With each round of this process, there is a loss of self-esteem coupled with increased frustration, which, in an extreme case, may result in the senior not meeting his travel needs at all despite the possibility of investigating public transportation alternatives for the sake of retaining their self-dignity. Such a scenario was ably put by a focus group participant who stated, "To ask one of my relatives to come and do something for me, it is like I am cutting my throat, and I never ask unless it is extremely necessary, and that hurts."

Concerning the issue of being dependent on someone else, it is important to many people as they lose their own mobility, or there is strong evidence that reliance on others leads to a far less reliable travel option. People forget, change their mind, make superficial invitations that they do not follow through with, get sick, or otherwise are unable to provide a ride. Clearly, breakdowns in communication and the revelation that others may not have been 
sincere or sufficiently disciplined to follow through on a commitment is disconcerting to relationships, especially familial ones.

Lifestyle changes resulting from driving retirement not only make an individual less mobile but can result in them becoming the receiver of travel assistance, relegated from being the provider of travel assistance to others. This change in roles from being the provider to the receiver is similar to the change from being a boss to becoming the employee. Such a scenario was ably expressed by a focus group participant who stated that, "My life changed plenty because I have never been in a way that asking people to take me places. I have always been a way to go myself and be my own boss. But now I know I can't because, if my wife don't drive and I want to go somewhere and she feels bad or something like that. I don't go because I wait until she gets ready to go, because, she has got to go. The only place that I can go that she will always go, is the church or the store and the warehouse." Being able to personally drive releases the individual to explore their world; nevertheless, when a senior can no longer drive, initially they may feel tied down to their immediate environment as they can no longer go where and when they want to go.

Negative experiences of changes in driving behavior can also impact on the psyche of an individual, as evidenced by experiences shared by focus group participants. One focus group participant indicated that he did not go to the cemetery as much as he would like. In another case, seeing a daughter across town, now only occurred 2 - 3 times a year. Another focus group participant indicated that she was not able to physically connect with family members out of town, unless taken. Personal activities out of the home having to revolve around daylight hours to avoid night driving was another negative experience resulting from driving reduction. In an extreme case, the desperation of the drastic lifestyle change that may be brought about by driving cessation was expressed by one focus group participant who stated, "I feel very bad since I stopped driving. Yes. I feel crazy. I don't do nothing. I don't go anyplace. I don't go to church. I don't go anyplace!"

\section{Medical Treatments and Driving Reduction}

Some focus group participants who had reduced their driving did not like having to drive long distances to keep an appointment arranged by a third party; this was particularly true for medical/doctors appointments. A local doctor in the immediate vicinity may send a senior patient across town to see a medical specialist. Such a scenario manifested itself in several ways.

\section{- Time of Appointment}

Some focus group participants had questioned from their doctor as to why they had to attend appointments during the early hours of morning. Honoring such an appointment would entail driving in the AM peak period of traffic, which many of them were reluctant to do. In some cases, focus group participants indicated that they had changed the time of the 
appointment to avoid traveling in peak hours or asked a family member or friend to take them if the appointment could not be changed.

\section{- Downtown Locations}

Several focus group participants who had reduced their driving indicated that they rarely traveled to/from and avoided travel through downtowns. Nevertheless, travel to/from or through downtown was necessitated either as driver or passenger in order to see a medical specialist. Remembering how downtowns were in years gone by and their current state (i.e., parking, one-way streets, and traffic congestion) increased the aversion of some focus group participants of going near downtowns.

The issue of dispersed medical treatment and its impact on senior travel behavior is of particular concern during the period of driving transition. As health care has become more specialized, health treatment often involves seeing numerous doctors or diagnostic care providers and accordingly requires multiple trips. The antidotal evidence suggests healthcare travel needs pose a significant challenge because the individual cannot choose the locations or times of travel as they can for many other services or social and recreational travel purposes.

\section{Feelings/Emotions when Driving Less or Not Driving}

Focus group participants were asked to share their feelings and emotions about driving less or not driving. Focus group participants indicated that they "hated" having to rely on others or felt "left out" of activities that were dependent on them being able to drive in order to participate in those activities. In another case, a focus group participant expressed a feeling of being "cheated." Probing this feeling further, the focus group participants went on to explain that "things that you used to do are now curtailed. Don't go out to dinner, see friends, visit the park, neighbors that you use to know, other places, all are difficult when you have reduced driving." "Let down" was another phrase used, with similar connotations to the term "cheated." The frustration of not being able to go where and when one wanted to go was described as a feeling of being "handicapped, " "helpless" or "useless," made all the more painful when one looked back on their active and independent lifestyles. The inability to drive would lead some focus group participants to describe their feelings as "bad" or "depressed." A focus group participant indicated that these feelings of depression had led them to cry as they remembered the things that they could do when they were able to drive. For many of the focus group participants, the enjoyment of life had become "unfair" after driving reduction or cessation.

Depending on others to meet transportation needs made some focus group participants feel guilty, even when a family member or friend would meet their need without hesitation. Being a member of a generation that was raised to be independent, this feeling of dependence was something that was difficult for some seniors to accept. In a few cases, focus group 
participants felt they were imposing and inconveniencing their adult children. Imposinghaving to ask their son or daughter for travel assistance, which may cause a scheduling change; inconveniencing -in order to meet the travel need the son or daughter would have to ask their boss, have to take time off work and finally may have to forfeit income. Focus group participants were concerned that their request for travel assistance not only impacted immediate family or friends but others not related to these groups, i.e., a boss of a family member/friend.

Being raised in a generation that espoused personal independence, this generation also endorsed the value of keeping one's word. For some focus group participants, the reneging on promises of travel assistance made them feel "mad" and deeply hurt. Feelings of resentment would increase when the transportation provider (i.e., family member or friend) gave excuses as to why they could not honor their promise. This had a double negative impact on the focus group participant as they would look back at how they were raised and provided for others and how such behavior would not be acceptable, especially from family members.

In a few cases, focus group participants who had accepted driving cessation felt "good" within themselves about not driving and did not miss it. In another case, a focus group participant described her situation of not driving as "having a marvelous time, all the time." In both cases, they had accepted their situation and had made good of it and had family members who supported them in meeting their travel needs. Nevertheless, as to how focus group participants felt about being satisfied with their lives after driving reduction/cessation, some indicated that they were forcefully satisfied, whereas others had accepted that the aging process brings with it limitations that they had accepted. It may be argued that, based on the anecdotal evidence from the focus group discussions, seniors fall into two distinct camps as it relates to their attitude toward their mobility status. One group seems resolved and positive, taking pleasure in the opportunities they still have. The other group seems bitter about their loss of mobility. This carries over to attitudes towards their families and the extent to which they have been able to help them attain mobility. There are obviously some jealousies (of friends whose families are more supportive), frustrations, disappointments, and joys. The focus group experience did not provide enough insight into the overall temperament of the participants to determine if their reactions and attitudes with respect to driving cessation were reflective of their overall attitude toward life and ageing or if the experience of driving cessation has meaningfully changed the respondents overall temperament. The significance of this change may well have impacts on overall attitudes and perceptions of well being.

\section{Transportation Mode Currently Used}

Focus group participants were asked to discuss their use of transportation during driving reduction or after driving cessation. For the majority of participants (former as well as current drivers), the automobile was the predominant mode for local trip-making. Answers 
to the survey indicated that 19 participants (46\%) drove themselves, $18(44 \%)$ were car passengers, $3(7 \%)$ public transportation users and $1(3 \%)$ walked. (Three participants did not indicate their primary transportation mode for local trip-making.)

\section{Preferred Choice of Assisting with Transportation}

Reliance on family (i.e., spouse, adult child, etc.,) to meeting transportation needs was stated as the first and ultimate choice by many seniors. If family members were nearby, and reliable, they were the preferred choice. If a family member was not in close proximity (or to minimize dependence on family out of personal choice), friends or other transportation providers (i.e., senior center bus) would be relied upon. Nevertheless, a proactive attitude in remaining mobile is required (despite limitations in available transportation providers) to avoid becoming housebound, as a response from a focus group participant illustrates: "Because I do not have family it limits me getting around. As there is no one close to see, I stay at home so they come to visit when they can." Reliance upon friends from one's peer group also presents an interesting dynamic, in that, as members of this peer group died, there would be fewer and fewer persons to assist with transportation and the senior would be "kinda forced to rely on family as you get older." Figure 25 presents responses ( $n=42)$ to the question, "Who would be your first choice in assisting you with transportation if you needed it?"

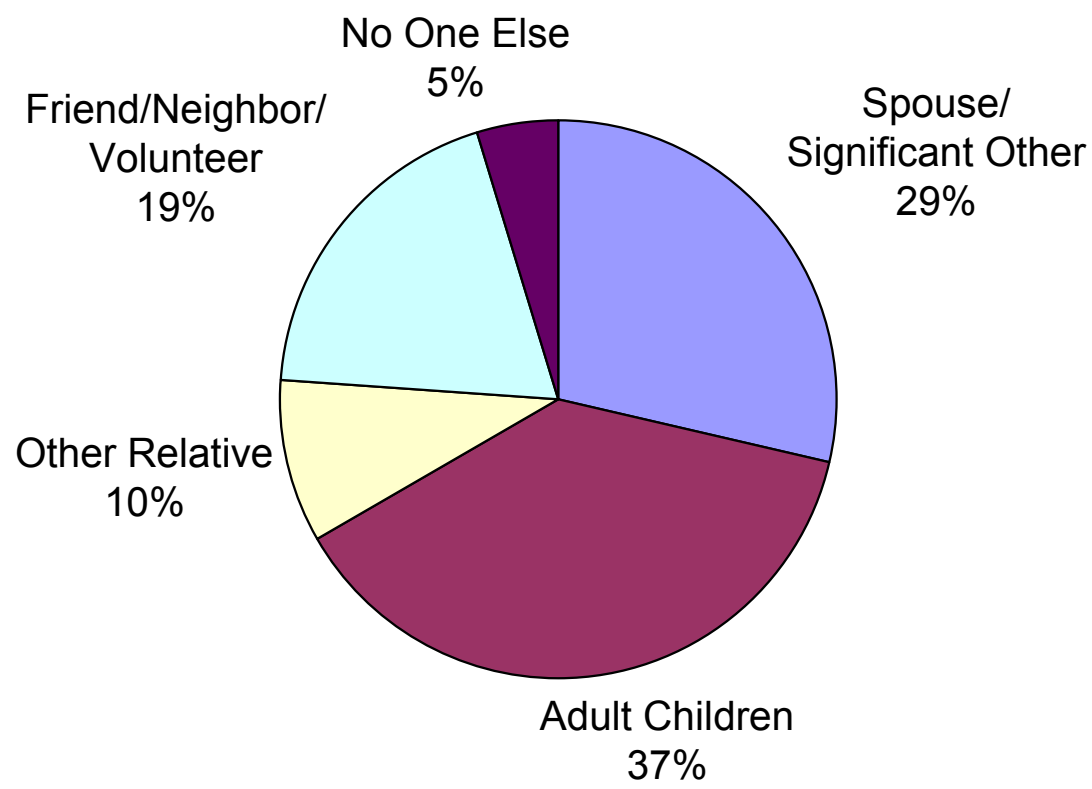

Figure 25 - Preferred Choice in Assisting with Transportation

Figure 25 clearly indicates that reliance on immediate family members for transportation provision was indicated by 66 percent of focus group participants. Responses to this question did not ask for a ranking of responses (only one response could be given); thus, it 
is not possible to give any indication as to the order of preferences. The ranking of more than one response may provide quantitative evidence to the progression of asking different parties for travel assistance and the resulting disappointment when each choice is denied. Focus group participants who indicated no one else, either drove themselves or had to rely on other transportation alternatives, such as public transportation.

A focus group participant was able to indicate that, at times, he would rely on family members or friends (as a first choice) who agreed to assist in meeting his transportation need. They either would not turn up, turn up late, ignore voicemail messages, or initially indicate that no charge for the trip was going to be requested but then turned up needing money for gas. This upset the focus group participant greatly, who for subsequent trips, opted to use public transportation or a taxi-cab rather than rely on a family member or friend. By using these modes, there was the certainty of knowing that the rides would not be free, and with planning he would get to and from where he needed to go at a time that fitted in with his schedule.

An advantage of relying on a family member indicated by a focus group participant is that payment for the trip is usually not required. Some form of payment was expected when friends provided transportation; as to how much one would pay depended on the relationship level between the senior and the provider of transportation, trip distance and length of time of the total trip. In the case of seniors with more than one living adult child, the sharing of responsibility in meeting a parent's transportation needs among the children also was cited as another advantage. If one child was not able to assist, arrangements would be made for another child to meet the need. Several focus group participants in this category indicated that such an arrangement was working well for them and that they were able to go to most places that they wanted to go.

Successful reliance upon family members for meeting transportation needs (the preferred choice for many seniors) cannot be taken for granted. Earlier, it was noted that seniors may feel that they are imposing or inconveniencing family members by requesting assistance with transportation. On the other hand, having more than one adult child may make it possible for one of them to assist with transportation while minimizing scheduling conflicts among all the siblings, as everybody is busy. These scenarios present an interesting issue associated with the temporal travel demand of elders being predominantly day oriented, which coincides with the time where the adult children are likely to be involved in employment or other activities. Elders who do drive frequently limit their driving to the daytime. Other health and stamina issues that seniors face may also result in many of them participating in activities that are typically scheduled during daytime hours, times not convenient for working adult children to provide transportation for their senior parents. Interestingly, this does coincide with transit service availability; however, most senior activities are in the midday period when service frequencies are lower with correspondingly higher wait times. 


\section{Role of Public Transportation During Driving Reduction or After Driving Cessation}

Focus group participants were asked what role public transportation (both fixed route and paratransit) had played during their period of driving transition in the county where they currently reside. Responses ranged from "none at all" to "yes." Quantitatively speaking, with respect to the 18 former drivers, 8 (54\%) had used public transportation since retiring from driving, 7 (46\%) had not, and 3 did not indicate their status. Responses also varied according to the residential location of each senior. Seniors interviewed at the senior center located in a semi-urban area indicated that public transportation was not provided where they lived. One focus group participant at this center went on to state that, in the 10 years of living in the area, he had never used public transportation.

The role of public transportation in meeting a senior's transportation needs was limited to the level of accessibility of a particular mode by the senior. Seniors confined to wheelchairs or experiencing difficulty with walking had found that accessing public transportation that does not come directly to their homes almost impossible. The challenges of accessing public transportation by some seniors were succinctly stated by a focus group participant who stated that, "I could not walk a block to public transportation. I am lucky to be able to walk to my car." Another focus group participant stated that, "I couldn't get on the bus, if I had to ride a bus." The level of accessibility to public transportation also impacts on the level of accessibility of the destination. Many focus group participants noted that public transportation may not take the rider exactly to where he wants to go; it takes him to a designated stop. This may be 4 or 5 blocks from where he exactly wants to go, resulting in the senior having to walk, which may be a challenge in itself. This segment of the trip getting to or from the public transportation access point plays a significant part in determining the attractiveness and preference of public transportation in meeting seniors' transportation needs.

One interesting point noted by some focus group participants is that, in order for them to access public transportation, they would have to drive to a certain place (i.e., park and ride) to access it. If they had to drive, then why not drive for the entire trip? Transit service viability was also another factor influencing whether public transportation had played a role in the senior's life. Focus group participants interviewed at the senior center in the semiurban area indicated that in times gone by, there was a paratransit bus service available that took them from their homes, to the senior center. A critical number of patrons were required for this paratransit service to be viable. Over time, as users of the service died, fewer and fewer patrons used the service, which in time was discontinued. For some focus group participants, using the service from their homes to the senior center each week was the only experience they had of public transportation in their adult years. 


\section{Factors Initiating Use of Public Transportation}

Discussion of factors that would influence focus group participants to include public transportation as a transportation option elicited a variety of responses. Responses are summarized as follows.

\section{- Cost}

Many focus group participants indicated that if there were a cost for use of public transportation it would have to be free or affordable. There was some debate about any cost charged being determined by one's income, but it had to be a fair price and have minimal impact on one's pocket book. Another cost that may influence the use of public transportation is the cost of a parking ticket. One focus group participant stated that he used the bus to go downtown on personal business to avoid getting a ticket.

\section{- Accessibility}

Being able to access services closer to one's home and delivery and pickup closer to the destination were cited as factors that could induce use of public transportation. Door-todoor service was the preferred option. If one had to drive to access public transportation, this would detract from using public transportation altogether for the trip in question.

\section{- Destinations Served}

Public transportation services serving the destination of interest was another reason given that may induce use of the service by the focus group participants. The non-availability of public transportation near one's home is another factor that discourages considering this mode as a viable transportation alternative. Having access to public events, theme parks (e.g., Busch Gardens), or areas of natural beauty was another issue raised by some focus group participants. They wanted to visit these places but were limited by physical ability, cost of transportation (having to take a taxi), and lack of information about public transportation access to these places.

\section{- Level of Family Involvement}

The strength of familial relationships has an impact on the use of public transportation. The transportation needs of several focus group participants were met entirely by family members or friends.

\section{- Past Experiences with Public Transportation}

Focus group participants who had lived part of their lives in a transit rich environment, e.g., New York City, had allowed these past experiences to determine their perception of public transportation in their current location. In all cases, comparing transportation services in a city such as New York to those provided in their current location would not be comparing apples with apples. These past experiences relegated fixed route services provided in their current location to be described by such negative terms as "really, really bad," "no good" or 
"terrible." The extent of the dislike of local public transportation services could be seen in the faces of several focus group participants as they discussed their use or non-use of public transportation.

\section{- Travel Time and Service Frequency}

Several focus group participants noted the long travel times (the actual line haul trip may not be long but the waiting times at either end of the journey) and low frequency of buses as a deterrent to using public transportation. A frequency of one bus every $15-20$ minutes was cited by a focus group participant as having a positive impact on their potential use of public transportation. Focus group participants who had used paratransit also were concerned with the travel time window that was either too long (i.e., waiting for service to arrive) or too short (i.e., not enough time to get to the service when at your door).

Figure 26 presents results to the question: "What one factor if changed would make public transit an option for you to use today?" It is evident that cost (i.e., free or low cost public transit services) and accessibility (i.e., closer to my home and easier to get on or off) are the two highest ranked factors to the 36 focus group participants who answered this question (eight declined). Four participants indicated that, despite any improvements of public transportation services they still would not use it. The perceived lack of personal safety has been cited as a factor seniors mention as a reason to avoid using transit. None of the focus group participants indicated that crime on local public transit services detracted from them

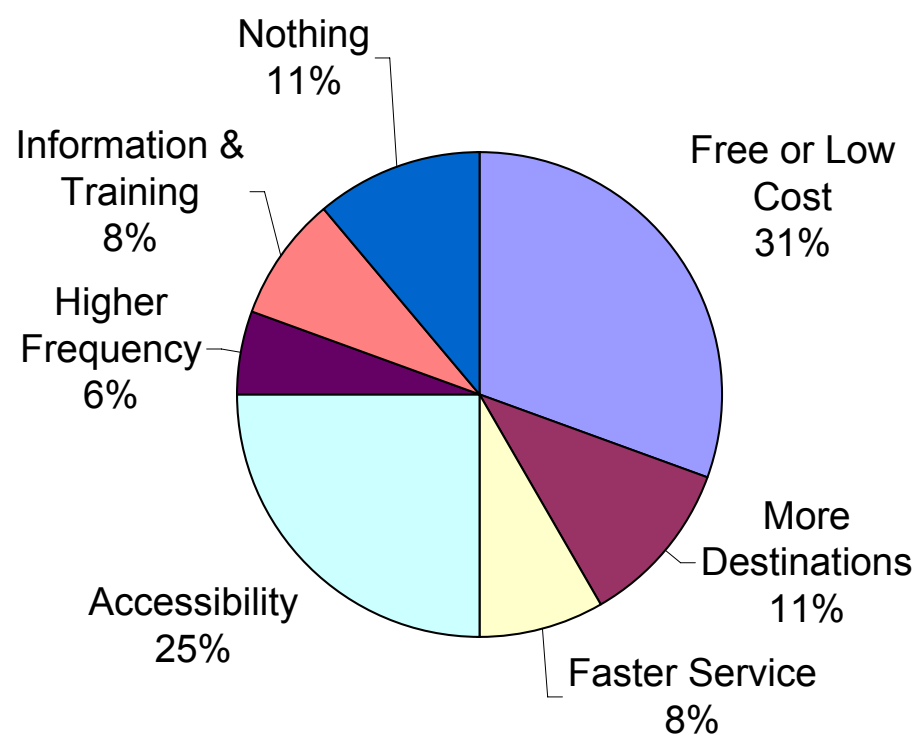

Figure 26 - Factors Enhancing Potential Use of Public Transportation 
using it; or on the other hand, improving the personal safety environment on local transportation services might induce them to use it.

\section{Fears or Concerns in Using Public Transit}

Focus group participants were asked to indicate their primary concern about using public transit. Responses (37) are presented in Figure 27. Service area (i.e., public transit does not go where I want to go) was the foremost factor giving rise to concern, followed by transit information (i.e., lack of information about public transit). These two factors are interrelated as the lack of knowledge about the public transit options in an area may be due to a lack of information about public transit in general. More information and training about using public transit may increase consideration of its use by seniors.

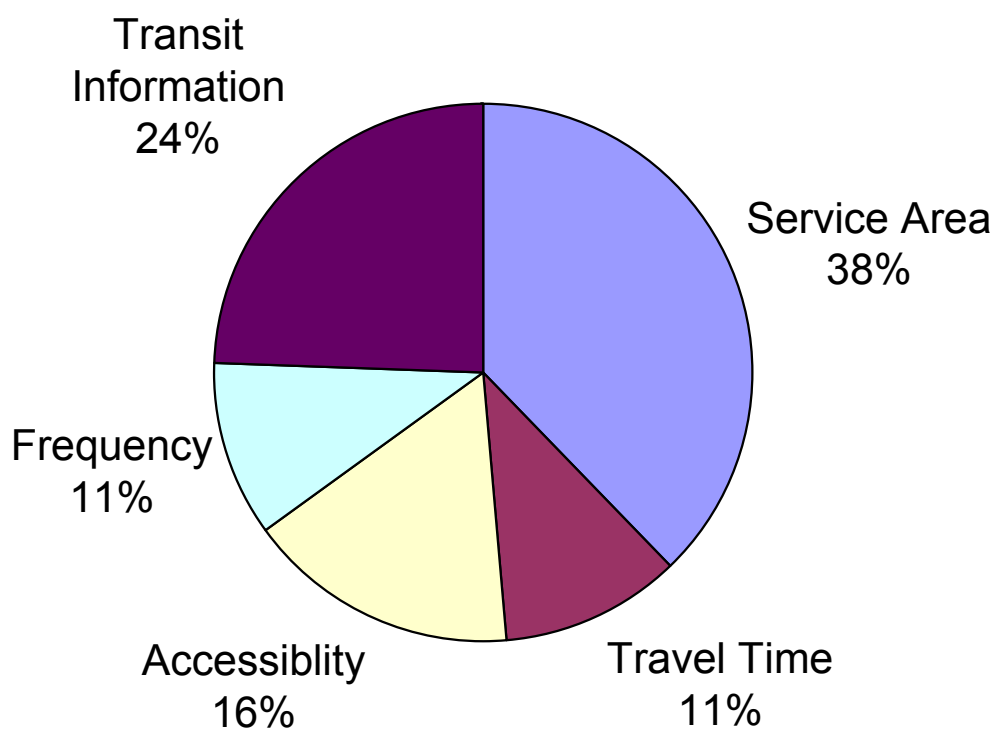

Figure 27 - Factors Influencing Concerns About Using Public Transit

\section{Retirement Relocation and Public Transit Accessibility}

Views were sought from focus group participants as to whether the availability of public transportation influenced the choice of retirement relocations. Reasons noted for relocation to Florida were to be closer to family, move with spouse, weather, medical condition, and natural environment. None of the responses indicated that the transportation environment in the receiving community played a part in influencing their move.

With respect to making moves at this stage in their lives for example, to be closer to family or improve access to public transportation responses varied from a reluctant "yes" to a hesitant "no." Some focus group participants indicated that, ideally, they would not want to 
relocate after being in their current environment for many years. Nevertheless, the thought of being some distance away from their grandchildren caused them to rethink their answers and resolve that they would go. In another case, one focus group participant responded to the prospect of having to relocate with one of her adult children that they would grab one of the kids and tell them that she has to have somebody (stay near them to meet their needs).

The importance of mobility in a new community is clearly evident in Figure 28. This figure indicates the responses $(n=40)$ of focus group participants who were asked to indicate the importance of access to public transit if they had to relocate to a new residential location. Not taking access to adult children for granted, it was noted in one discussion session that an adult child may not want his parents to relocate with them, possibly in order to minimize provision of services, including transportation. This possibility for some of the focus group participants supported their highest rating of the importance of access to public transportation as being extremely important.

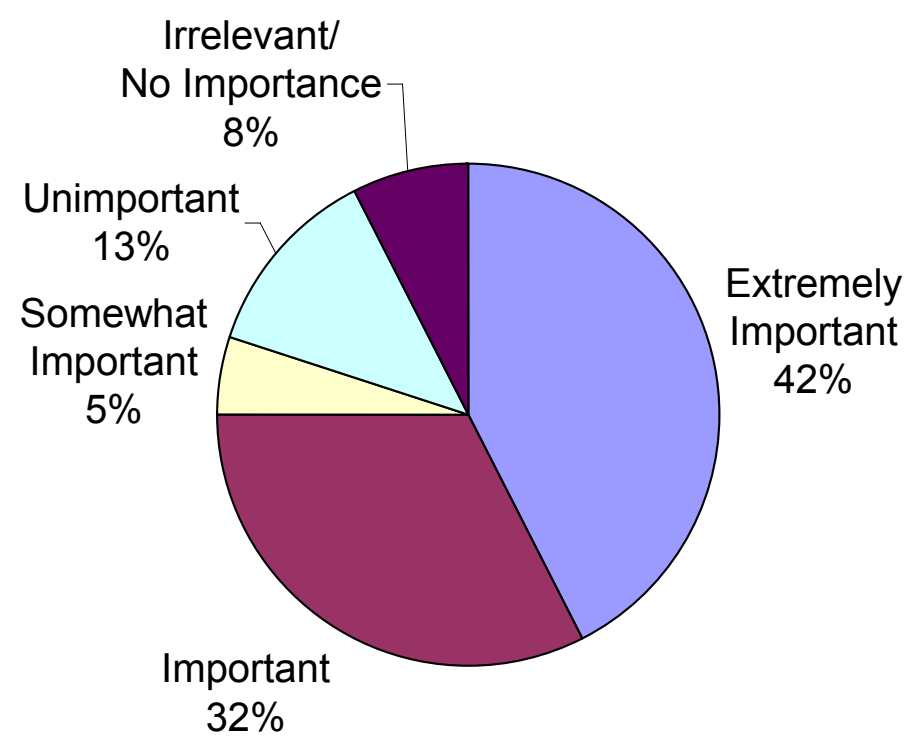

Figure 28 - Importance of Access to Public Transit if Having to Relocate

As to the use of public transportation in this new community, it would be the choice of last resort. As one focus group participant lamented, "Only if we had to, you know, if it was a necessity, if there was no other way." Again, familial relationships played a role in the response to this question. One focus group participant who stated that she would move to have better access to transportation also indicated that she was not on talking terms with one of her adult children who lived close by. 


\section{Viability of Using Public Transit in the Future}

Focus group participants were asked to give an indication as to the potential of public transportation to be considered as an option in meeting their transportation needs by answering the question: "Do you think that public transit is a viable option for you to use today?" Overall results presented in Table $8(n=42)$ indicated a 50:50 split, with 21 focus group participants indicating "yes" and 21 "no." Breaking down these results by driver type (i.e., former and current drivers), the responses were as follows:

Table 8 - Viability of Future Consideration of Public Transportation as a Transportation Alternative

\begin{tabular}{|l|c|c|c|}
\hline Driving Status & Yes & No & Total \\
\hline Current Drivers & $11(26 \%)$ & $15(36 \%)$ & 26 \\
\hline Former Drivers & $10(24 \%)$ & $6(14 \%)$ & 16 \\
\hline Total & $21(50 \%)$ & $21(50 \%)$ & 42 \\
\hline
\end{tabular}

These results indicate that, among current drivers, $15(60 \%)$ of the 26 focus group participants who responded felt that public transportation is not a viable transportation option for them. This result may have been influenced due to their non- or limited use, nonavailability or negative perceptions held about public transportation. A similar percentage $(62 \%)$ of former drivers (10 out of 16$)$ responded positively. Possible factors contributing to this result may have been due to this group investigating transportation options as former drivers and having had recent experience with using public transportation, coupled with a concomitant change of attitude towards this mode arising from their experience. Interpretation of the viability of public transportation by focus group participants in meeting their transportation needs may not, in reality, result in the actual use of this mode. Focus group participants may require a variety of interventions to be in place in order for them to use public transportation, some of which may be economically unviable for a transportation provider to implement for the market being served.

Chapter 5 synthesizes these findings as well as the information gleaned from the literature review and quantitative analysis into some overarching observations. 


\section{CHAPTER 5 - CONCLUSIONS AND RECOMMENDATIONS}

This chapter provides a variety of observations, findings, and recommendations resulting from the research described previously. The issues surrounding driving cessation and its impact on public transportation, particularly in the future, result in this being a very complex topic area. Thus, the observations and recommendations span a range of topical areas, some well beyond the traditional areas of interest of transportation planners. As one might expect, progress in medical care and treatments, improvements in technologies to mitigate the impacts of physical and mental decline, and changes in the social and cultural environment associated with a host of causes, including changes in the economy, are all likely to influence travel needs of the elderly population in the future. Nonetheless, some of these observations are relevant to those persons serving the mobility needs of today's elders as well as those involved in planning for the future or developing future research agendas.

The findings are organized into three sections. The first addresses factors associated with the potential demand for publicly provided or supported travel by the future elder population. The second addresses specific tactics and strategies that the public transportation industry can use to help better meet the needs of current and future elder travelers. The third addresses information and knowledge needs that will help us better understand, forecast, and respond to the needs of elder travelers.

\section{The Demand for Publicly Provided Elder Transportation}

Figures 29 and 30 are taken from Technical Memorandum One (Polzin \& Page 2005 ) and were developed to characterize various aspects of the decision frameworks that support, first, a process for quantifying the market potential for public transportation from ceased drivers, and second, a characterization of the individual decision process for travel decisionmaking by individuals. These frameworks provide structures for organizing thoughts about the findings from this research and identifying knowledge gaps.

Referring specifically to Figure 29, this graphic conceptualizes the composite profile of public transit market potential from an aging population perspective that may be created through accessing and analyzing a variety of data sources (represented by the separate layers in the graphic). Different types of information are each represented and characterized as a screen that helps to sort the overall target population into groupings based on their propensity to use public transportation. Thus, each layer of knowledge helps us to build an overall picture of the potential of various subsets of the older population to take advantage of fixed route public transportation services. A single data source which provides complete data/knowledge of seniors is currently not available; however, individual datasets may be analyzed to create a composite profile of seniors in order to understand the potential demand for public transportation from ceased drivers. In addition, the information base supports transit service design and marketing to enable it to most effectively respond 
to mobility needs of ceased drivers and helps to inform policy discussions relating to mobility needs of older ceased drivers and non-drivers. Much of the knowledge gleaned in this research fits into the second, third and forth boxes in this figure, with the greatest contribution in the areas shown in box 3 , Knowledge and attitudes about public transit.

1. Socio-demographic characteristics of older population (NHTS and BTS Surveys, Mature Driver database)

2. Travel options for older population (NHTS and BTS surveys)

3. Knowledge and attitudes about public transit (from focus groups)

4. Travel demands of older population (NHTS and BTS surveys)
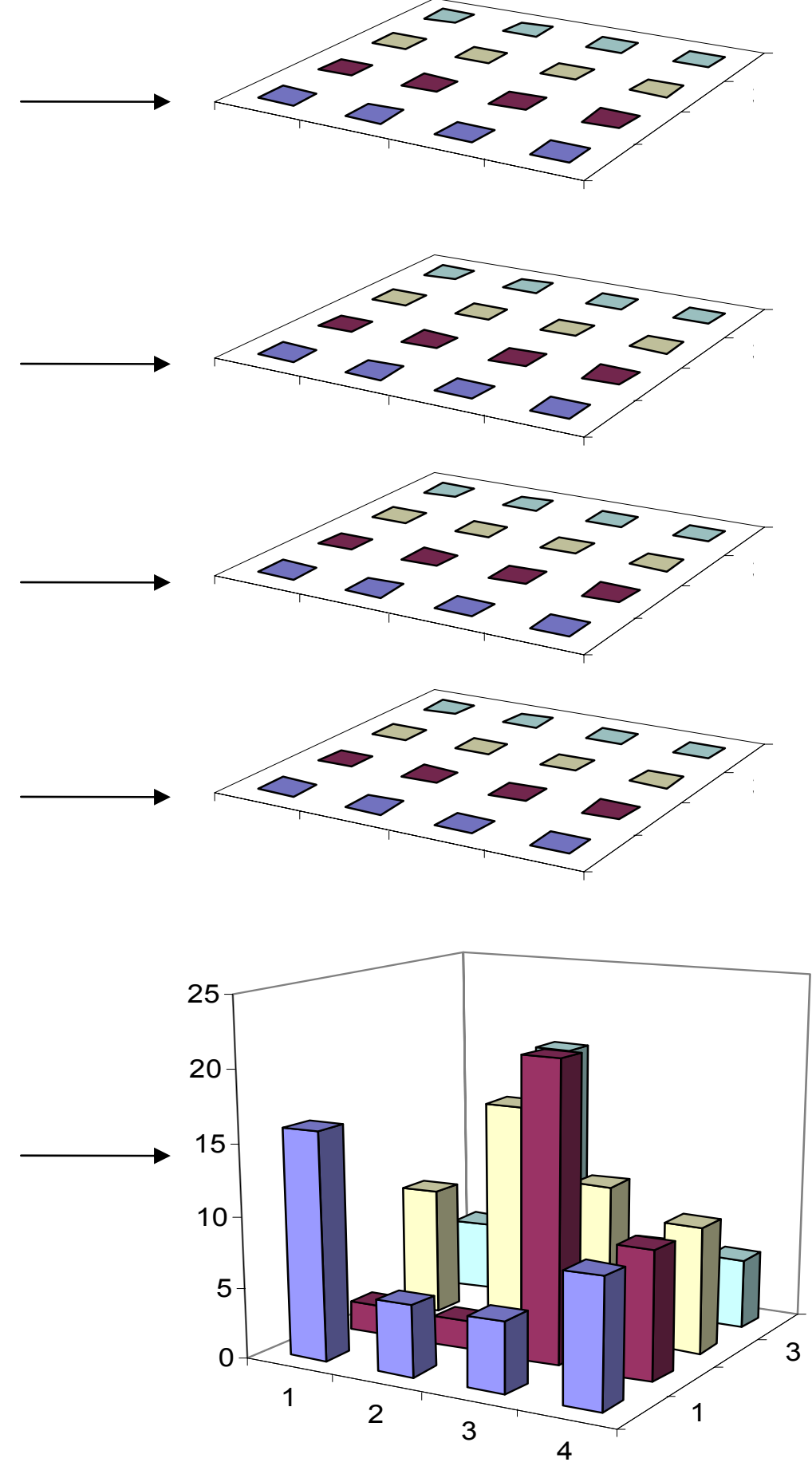

5. Public transit market potential profile

\section{.}


Figure 30 is a graphical representation of the decision making process one might use in characterizing the factors that go into decision making by older persons who are not able to drive. By itemizing the features of the travel options known to influence mode choice one is able to appreciate the characteristics of public transit services that would be considered by travelers in deciding if and how to travel.

\section{The Size of the Elder Market that May be Served by Public Transit}

The Transportation Research Board report "Estimating the Impacts of the Aging Population on Transit Ridership" (2006) provides a helpful summary of many of the demographic trends that will shape the overall size of the elder market. The fact that tomorrow's seniors are today's middle-aged adults provides constraints on the overall size of the market and provides some insight into the characteristics of the next generation of elder population. However, at the local level there is much greater uncertainty regarding the size and nature of the future elder population in any given transit service area.

\section{Will Seniors Live Near Good Transit?}

From the perspective of a transit agency and the potential transit market, the residential locations of the future senior population are of particular interest. The baby boomer generation has been characterized as suburban in concentration, and the historic tendency has been for elders to retire in place. This has suggested that the next generation of elders will be concentrated in suburban locations and, hence, are less likely to be in locations where traditional fixed route public transportation can provide the quality of service that most of these customers will demand. However, several other phenomena may influence the location concentration of the elder population. One of the most common driving restrictions that aging seniors place on themselves is to restrict their travel to areas with limited roadway congestion and with moderate-speed roadway facilities (i.e., in areas with arterial and local road networks but few highways or freeways). Thus, as suburbs, particularly in large urban areas, become congested, there may be a temptation for the seniors to relocate to the more peripheral areas. Similarly, to the extent that housing costs are higher in the vicinity of large urban areas, more peripheral locations might enable lower-cost housing and an opportunity for seniors to capture some of the home value appreciation that occurred during their lifetime.

The propensity of future seniors to relocate also may be influenced by the nature of their social interactions and relationships. The next generation of seniors is likely to have fewer children and fewer siblings than prior generations, to have relocated during their lifetimes, perhaps several times, to have divorced, and to have become accustomed to cell phone and internet communications to keep in touch with their network of friends; thus, they may be 


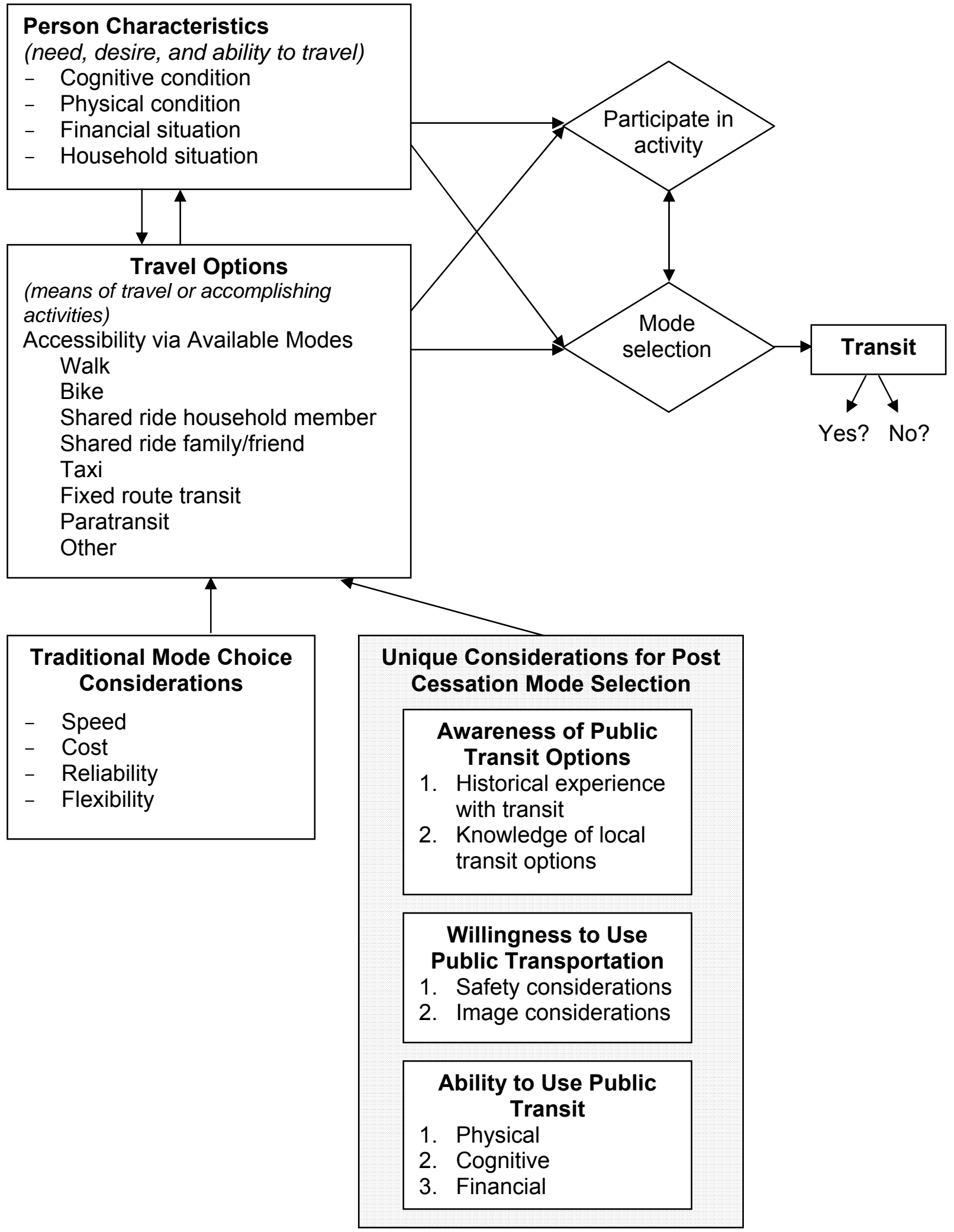

Figure 30 - The Decision on Using Public Transportation for Ceased Driver (Schematic of Older Traveler Travel Decision-Making) 
less strongly tied to an existing home and more likely to relocate in their senior years. Other differences between generations may also suggest a more mobile future senior population. For example, the average new-home size has increased over 50 percent in the past few decades.

The average new-home is now approximately 2500 square feet, and many of the next generation of elders live in large homes now. Similarly, the average household member is far less likely to have the skills and time to maintain a large property as they age. Thus, there may be a higher likelihood that future seniors living in larger properties will make household location changes as they progress through their senior years. The prospect of maintaining a larger, aging, single-family home is not likely to be appealing and may hasten relocation to smaller, newer, and condominium-type lifestyles where the demands of taking care of the property are lower. One is likely to see a large variance in behavior across the income spectrum.

Economic conditions will influence the flexibility and choices the next-generation of elderly will have in their lifestyle, housing, and location decisions. Low and moderate income households may have little choice but to remain in their current housing as they age. Concerns about the financial stability of Social Security and the prospect for a larger share of the retired population not having the security of defined-benefit retirement plans may result in a greater polarization of the wealth levels in future retirees. The lower income segment of the elder population is more likely to be in a position of desiring or needing public transportation options when they cease driving. To the extent that seniors move from low density suburbs to more urban environments, they are more likely to be located in the vicinity of higher quality transit services.

The migration of population to the west and south, combined with the general decline in public transportation use over the past several decades, will produce a situation where fewer of the next-generation of elders have grown up in locations with good public transportation service or have themselves been regular users of public transportation. While the growth of public transportation services has been strong in some of the western and southern areas that have experienced rapid population growth, there will, nonetheless, be a larger share of the future elder population that is not familiar with public transportation.

\section{To What Extent Will Family Mobility Options Exist?}

Perhaps the single most important issue in terms of public transportation demand will be the ability of future seniors to take advantage of family, household members, or friends as mobility providers. The focus groups revealed that the success of the driving cessation experience was often strongly influenced by the extent of family support in meeting mobility needs. Relying on a spouse or family members for mobility remains the most common and most favored option for persons who have ceased driving. The presence of a spouse, sibling, or other adult will be critical in determining the extent to which public transportation 
is desired or necessary. The changing socio-demographic environment is expected to result in more households were an elder non-driver does not have convenient private transportation options. The decline in average household size over the past few decades implies future generations are less likely to have siblings and children to help them, and it is more likely that they live more distant than was historically the case. This has potential significant ramifications to future senior mobility. Offsetting this trend is the prospect that higher female licensure rates of the next generation of elders provide the prospect that more households will have a licensed and able female member to help meet their own and their spouse's travel needs.

\section{Will Alternative Public Transit Services Help?}

While traditional urban fixed-route services may not be available to some suburban and exurban households, the public transportation industry may have other mobility products such as paratransit services that may meet the needs of some households. The Independent Transportation Network (ITNAmerica) is a non-profit transportation service for seniors headquartered in Portland, Maine, that provides "dignified and sustainable transportation services," using the automobile, to assist seniors. Volunteers operate vehicles and receive payment either by reimbursement at a rate of 25 cents per mile when carrying a passenger; or by accumulation of transportation credits based on miles driven when a passenger is not being carried. Transportation credits can also be earned by donating a vehicle. Users of ITNAmerica services pay a minimal fee by means of transportation credits that are deducted from an account. Transportation credits can be used by the account holder themselves and donated to low-income seniors or another family member. The ITNAmerica model is being implemented in several cities nationwide including Orlando and West Palm Beach. Other cities in Florida have also shown an interest in the ITNAmerica model. This type of service under public or private management may be an important contributor to senior mobility.

\section{Will Seniors Move to be Near Transit?}

The focus group sessions addressed the prospect that older drivers or those who have ceased driving might consider household relocation in order to provide greater access to public transportation. In the discussions, there was no evidence that access to public transportation had been considered as a factor in individual relocation decisions during their senior years. In numerous cases, individuals had moved because of deteriorating health, loss of a spouse, income constraints, or other factors related to aging; but in these cases their motivation was to be closer to siblings or children. None had moved to be in a location where transit was more readily available or where more services and amenities could be accessed via walking.

Proximity to public transportation does not appear to be a high-priority strategic consideration for elder relocation decisions. There is some evidence to suggest a probable 
sequence of moves to take advantage of transportation options; one might have persons choose a suburban or exurban location where driving was less stressful and of lower risk to be their place of residence during their younger senior (i.e., young-old) years. At the age of driving cessation, a more urban, perhaps multi-unit, household arrangement might become more attractive. For example, an individual over 80 may give up the suburban single-family home and perhaps the car and take up residence in an urban condo where walking or public transportation could meet their mobility needs. This sequence of moves may be logical from a mobility perspective but would have obvious implications in terms of costs, social relationships, and other quality-of-life considerations. In practical terms, the myriad factors that come into play in household location decision-making are such that transportation does not appear to rise to the top.

The passion for driving as long as possible could have policy implications in terms of development patterns, attitudes towards density, and related issues. For example, the current Florida cap on homestead property appreciation encourages individuals to stay in the same home as they age to avoid a significant increase in property taxes should they purchase a similarly valued property in another location. Thus, any desire to take advantage of better mobility options or even moving closer to someone who can help provide their mobility needs could have a financial consequence. The relatively high transaction cost of selling and buying a residence and the difficulty of getting insurance are other factors that might deter moving to improve access to transportation.

\section{Will Changing Elder Health Impact the Transit Market?}

The health of the senior population and the availability of technology aids to extend their driving years will influence the share of the elder population in need of post-driving cessation mobility options. A host of medical advances, including numerous drugs and compounds to preserve health, artificial joints, corrective surgeries and related advances, have extended both the number of years of active mobility and the average life expectancy. Even if medical progress were to cease today, the next-generation of elders would benefit from improved health. Continued improvement in a number of areas may result in some segments of the senior population being able to drive far longer. Areas such as vision, dementia and mental health, heart health, and others are associated with conditions that can lead to driving cessation. The same areas often are targets for new treatments and pharmaceuticals. Thus, significant progress or breakthroughs in any of these areas might enable longer driving tenure for aging seniors.

While the trend towards ever-improving health care has been widely acknowledged over the past generation, there is a growing awareness that other factors may intervene. Most notably, there is a growing concern that obesity has reached such a level that it may create burgeoning elder health care problems and reverse the trend of ever longer lives.

Depending on health-care trends, there may be situations where longer lives result in more persons reaching the point where the general overall decline in their functioning results in 
them needing to cease driving whereas, in prior generations, these persons might have passed away from heart attacks or other conditions that have since become treatable. New technologies are enabling more individuals to retain driving competency longer. Such vehicle features as emergency communications (OnStar type systems), cruise control, and heads-up dashboards, backup cameras, navigation systems, and warning systems to note proximity to obstacles may enable extended driving tenure. Alternative control systems for handicapped drivers are more prevalent as well and may extend the availability of auto travel to a larger share of the population. The influence of these positive changes may be offset by the prospect of a reduced willingness of seniors to drive in more congested and stressful driving environments associated with today's and anticipated future roadway conditions.

\section{Will Travel Rates Influence Overall Transit Demand?}

The demand for public transportation will be influenced not only by the size of the market segment that has public transit available and needs it but also by the trip rates of those individuals. Historically, the average number of trips that a person takes has grown over time, reflecting higher real incomes, growing auto availability, modest transportation cost, and the specialization in the economy resulting in more activities being carried out away from the home. There is speculation that the highly mobile baby boom generation will continue to be highly active in their senior years. If this expectation materializes for those individuals who depend on transit, it will create a higher demand for transit. There may be some subsets of the senior population, for example, those who reside in condominiums or apartments in dense urban areas with high quality transit services, who will have high levels of trip-making on public transportation. In general, however, conditions associated with the highest levels of trip-making are often conditions that result in other non-transit alternatives being available, which then renders public transit use less probable.

\section{Tactics and Strategies for Providing Transportation for the Elderly}

Based on observations from this research, there are several recommendations to public transportation providers that may assist them in positioning themselves to meet the needs of the current and future elder population. Public transportation providers must recognize that travelers frequently have options, and there are numerous considerations that travelers take into

"[We would use the bus] only if we had to, you know, if it was a necessity, if there was no other way."

Focus group comment account when making mode choice decisions. There are issues associated with both the reality of how public transportation services perform and the perception that travelers may have of public transit's performance. 
Numerous focus group respondents displayed a great deal of reluctance or resistance to using public transportation and perceived it as unviable in their situation. The challenge to transit will be in both communicating an accurate representation of the viability of its various services and delivering such that the image and awareness of public transportation becomes more positive.

Listed below are several features of public transportation service that impact its acceptability to elder travelers. Comments on how this feature might best accommodate the needs of elder travelers are noted. One way to think about transit service is to characterize it as a set of

\section{"I couldn't get on the bus if I had to ride a bus." \\ Focus group comment} vehicles and facilities utilized to deliver a service that has attributes of coverage (i.e., where it goes), frequency, and the span of hours over which the services operate. Each is discussed below.

Vehicles - Buses remained the predominant means of delivering public transportation service, and the accessibility of the vehicle is a significant consideration in its ability to accommodate older travelers. Vehicle accessibility refers to the ability of the patron to navigate the steps and/or ramp and use other equipment such as the fare box, vending machines, information systems, etc. Boarding the vehicle may be the biggest challenge for many elderly passengers; they may not have the strength or stamina to climb the stairs, may be reluctant or embarrassed to cause service delays to accommodate them, or may fear for their safety when boarding or alighting the bus.

Within the transportation planning community, there has been a perception by some that, as one loses certain physical or mental capabilities that cause them to quit driving; they would then transition to using public transportation. Depending upon the particular set of physical or mental functional shortcomings, it appears that many seniors consider using public transportation more challenging than driving or riding in a car. This is not always true, as vision constraints and slower reflexes-two of the more common conditions that contribute to driving cessation-may not preclude the use of traditional fixed-route transit services.

While well beyond the scope of this research, it would be useful to have a richer understanding of the specific physical and mental conditions that contribute to driving cessation and to similarly understand to what extent these conditions might influence the ability to use transit. With sufficient information on medical and functional mobility limitations, one might be able to more closely identify target markets of potential public transportation users among those who are ceasing to drive. This knowledge could make an important contribution to developing a more sophisticated forecast of future public transportation demand. It may be that the subset of those individuals who are ceasing driving but might be able to use fixed route transit services is a relatively small share of those who cease driving. 
Newer, low-floor vehicles and vehicles with ramp access provide significant improvement in vehicle accessibility for those with limited mobility. Uncrowded conditions and enforcement of designated seating areas for senior and disabled passengers also will contribute to the comfort levels for this market segment. Common sense design features such as simple-touse controls, sufficiently large fonts on signs and materials, signage and railings where appropriate, slip resistant flooring materials and other features are likely to make transit use more possible and comfortable for persons with mobility disadvantages.

Amenities and Facilities - As in the case of vehicles, common sense design of transit's

\section{"I could not walk a block to} public transportation. I am lucky to be able to walk to my car."

Focus group comment amenities and facilities to accommodate persons with mobility limitations can increase the probability that ceased driver's will take advantage of public transportation. Particularly important in Florida is the issue of access to bus stops. The high prevalence of roadways with no shoulders and no sidewalks results in many locations having less-than-desirable

bus stop access. Stops on sloped road shoulders in vicinity of ditches and drainage are not uncommon. The ability to navigate rough terrain or to use a walker or wheelchair in this environment is very problematic. Sensitivity on the part of operators, route deviation services, and additional initiatives to collaborate with general-purpose governments to improve bus stop location environments are among the tactics that can be helpful.

Target Geographic Areas for Routes - There is no compelling case that the elder population will concentrate in any particular geography. A larger share of the next generation of elders will have suburban residences, but what remains unclear is the extent that there may be some clustering patterns for elderly that would produce concentrations that could be targeted with transit service. Retirement-themed developments may continue to capture some concentration of elder retirees, but no single residential product appears to be in a dominant position. The economic health of the baby boomers as they approach retirement may influence retirement settlement patterns. If, as some predict, the baby boomers have financial struggles in retirement, it may lessen the prospect that they relocate from existing residential areas.

For retirees and elders in denser urban areas, traditional fixed-route transit services may be competitive transportation options. In areas with pedestrian-friendly urban environments, a relatively dense roadway and transit route network and sufficient population and activity densities to justify reasonably frequent transit service, fixed-route service options may respond to the travel needs of seniors who transition from driving. Alternatively, in suburban areas where transit service is less frequent and a pedestrian environment is less attractive, fixed-route transit may not be viable. Some seniors may find express services attractive if it enables them to avoid driving in unfamiliar, high-speed, or very congested conditions that 
might typify the downtown or other express service destinations. More likely, the potential of public transportation to meet the needs of non-drivers living in suburban areas will be dependent on the extent to which demand responsive or other customized services are available. Circulator services serving residential and service retail areas of suburban downtowns may be viable for discretionary trips of non-drivers, assuming access and egress to the bus stop at both ends of the trip are viable for the particular individual and trip.

A more substantial role for the public transit provider in suburban markets might be acting as a mobility resource for persons who are ceasing from driving. The transit agency might be in a position to coordinate and educate individuals about the range of mobility options beyond driving, including the range of existing products of fixed route, demand responsive, and carpool matching services. This role might be expanded to include coordination or information dissemination about other services available in an area. This might include coordinating ride sharing and chauffeuring services or providing information and referral to social service, faith-based, and other mobility providers.

There may be more opportunities in the future to explicitly link the provision of transit service with the provision of housing for elder populations. To the extent that there may be an expanded market for concentration of older populations within individual buildings or communities (like the developments that have targeted retired seniors in places like Florida and Arizona), there may be opportunities to coordinate or target transit services accordingly. If more future seniors do not have family members to rely on for mobility and instead depend on group living arrangements or social service support systems, there may be sufficient concentrations of individuals who have ceased driving to make public or private transit options more viable and cost effective.

Some of the research observations shed light on senior trip purpose preferences. One of the most challenging senior trip purposes is for health care. This trip purpose is often not discretionary in time or location. The traveler may be apprehensive and his condition for the return trip may be influenced by the nature of the treatment or service received, thus creating additional stress and uncertainty. The highly specialized nature of today's medical treatments soften results in trips being lengthy in order to access designated specialists who happened to fall on some health-care plan providers list. The medical treatment may well involve long waits and frequently referrals to labs, scanning centers, pharmacies, or other treatment facilities in a separate off-site location. This type of trip can be difficult to serve, even with paratransit services. Basic shopping trip purposes can be readily served with existing transit services; however, if there is a need for carrying numerous packages, it may weigh against the appeal of using public transit for these trips. Often seniors are actively involved in their faith, wishing to participate in worship, volunteer service, and socialization activities. In general, this trip purpose is not particularly well served by public transportation, as Sunday services are typically modest and often do not operate at hours that complement worship schedules. 
Temporal Pattern of Demand - Transit service schedules historically have been targeted to meeting peak-period travel demands. Rush hour provides the greatest opportunity for transit to attract a market and is a time when transit can provide value by reducing demands on crowded roadway facilities. Oftentimes, travel by seniors is targeted to the midday period in an effort to reduce the prospect of needing to be on the roads during the most congested periods. Transit service frequencies tend to be lower in the midday periods, which are prime travel periods for older travelers. While transit services tend to be modest in the evenings as well, this is not a particularly common travel time for seniors. Transit also generally has reduced service on weekends and holiday periods. These travel times are attractive travel times for older travelers.

\section{Information and Knowledge Needs to Support Improved Transportation for the Elderly}

The focus groups provided a wealth of information regarding insights into seniors' perceptions and attitudes towards public transportation. These observations have been used to develop recommendations on how public transportation can better communicate with seniors.

A number of a focus group individuals had historic working knowledge of public transportation attained when they were younger and lived in another city. In the future, given the overall decline in transit use over time, it is possible that a smaller share of the senior population will have any meaningful personal familiarity with transit use. Given that transit service levels have declined over the years for several of the respondents, their perception of today's transit is contrasted with what might have been more frequent or better service available when they were younger or when they lived in larger cities with higher levels of public transit service. Thus, their image is not always positive. Service frequency and access to service appeared to be the two most criticized characteristics, followed closely by fare levels. Service frequency and access are limited in many areas of Florida due to development patterns, resources, and related factors.

Absent a radical change in development patterns, it is unlikely that much of the residential area in Florida will be able to support the levels of transit service that would appear to be attractive to this population. For example, doubling transit service-a historically rare expansion of service-would, in many locations, result in doubling the frequency of service, perhaps going from 60 to 30 minute headways in the off-peak, but could not simultaneously result in a denser network of services and longer span of hours of operation. While this change would be beneficial, in all probability it would still be far from meeting the threshold levels of acceptable service. Walks of a block or less, 10- to 15-minute headways, and a 12-hour-per-day six plus day per week service schedule might be deemed sufficient to consider transit more seriously for those who are physically able to access public transportation. This level of service may be an order of magnitude greater than currently 
exists in much of Florida. While any service improvements are helpful, it is important for policymakers to understand the magnitude of change that would be required to come closer to meeting expectations of high quality transit service.

In many ways, while the motivations are slightly different, the desires of the senior population regarding service frequency and accessibility are similar to those for other groups. The ability to access services is critical to seniors, as health and physical condition often preclude them from traveling long distances. Similarly, waiting for vehicles is onerous, not because their time is valuable, but because exposure to the elements can have health or crime exposure risks for seniors. While seniors are less concerned about a fast trip, they are concerned about access to restroom facilities.

The perception of existing transit services held by many of the elderly is somewhat dated because their use is limited or they rely on second- or third-hand knowledge of the system that may be several years old. As such, they are not readily aware of changes and improvements that may have been implemented over the past few years. One example of this involved a wheelchair-bound individual who showed reluctance to use transit services due to the challenge of using lift-equipped fixed-route buses when, in fact, ramp equipped buses have been the norm for the past few years in this individual's service area.

The extent of knowledge about public transit service options appeared to be very limited in the focus group. There did not appear to be any motivation to learn about public transit options. There are some unique challenges in educating seniors regarding the availability of mobility options. A common phenomenon for paratransit services is the use of a plethora of social service, charitable, and other entities, as providers of service. Thus, there may not be a single centralized mobility coordinating function that an individual could use to fully understand mobility option availability, costs, eligibility requirements, hours of operation, service areas, etc., complicating the communication process. Those persons most in need of services are the same persons who are least likely to be in a position to be exposed to or receive the necessary knowledge to improve their own mobility. The focus group participants, by virtue of the fact that they were recruited through their membership in community-sponsored programs targeted to seniors, were perhaps better connected and may be more outgoing socially than some of their peers. Even among this group, several individuals were unaware of available services. One participant did not recognize that there was a bus stop immediately in front of the senior center, another was unaware of the community paratransit service provider, and several were unaware of services being available through local churches and other groups.

Unfortunately, the dissemination of information about mobility options is likely to be a laborintensive and, hence, expensive challenge. The range of issues and considerations that are important to individuals is such that person-to-person and face-to-face communications will probably be required for a large segment of the target audience. The prospects of using 
written materials or Web-disseminated information as a sole source of knowledge is likely to miss huge segments of this market. Interestingly, attitudes about technology such as cell phones and the Internet vary dramatically. Virtually every senior facility has a computer room, classes, and opportunities to learn electronic communications; however, only a modest share of persons currently take advantage of that technology, and many do not have it in their homes. Some participants were very proud of their interest in and ability to use the Internet and cell phones, while others were equally proud of not needing to use the Internet and cell phones, punctuating their reactions with comments like "I got along without it for 85 years and I don't need to learn it now!" Over time, the senior population will be more likely to have grown up in an era of cell phones and Internet communications and may be more likely to take advantage of those services to learn about access to mobility. However, the lowest income, most educationally disadvantaged segments of the population may still require more labor-intensive strategies for communication.

One obvious recommendation emanating from the focus group sessions was the need for the local providers of public transit and paratransit services to coordinate their outreach efforts for the senior population and perhaps use handout materials, video materials, and ideally senior center site visits to educate this target audience about mobility options. There is a policy dilemma associated with more proactive outreach to make seniors aware of publicly-supported (as well as private) mobility options. Not only is it expensive to provide outreach, but it may well create additional demand when resources are extremely limited already. While there may be strong public support for publicly-provided, life-preserving travel such as access to health care and grocery shopping; there is most probably a smaller constituency that is supportive of publicly-funded travel services to offer quality of life improving mobility such as social-recreation activities. Thus, there may be some conflicting opinions regarding aggressive dissemination and training on how to use publicly-provided mobility options.

While Florida has been a leader in the coordination of paratransit services, this has not resulted in a widely shared or standardized strategy for providing mobility information to users. For example, if over time it became well-known that by calling a special phone number (such as 1011) they could be connected with an individual who could provide them guidance in planning their travel, it might result in better access to and utilization of existing services. In that way, the benefits of a diverse range of mobility providers including public, private, and charitable entities, could be preserved, yet access to information could be standardized and simplified.

The most powerful strategy for educating seniors about public transportation options would be to provide face-to-face interactions or group site training on how to use services. In that way, individuals' questions and concerns about everything from fare payment, to route patterns to what to do in emergencies could be dealt with. This is more likely to provide a comfort level high enough to try using transit. Numerous other tactics, such as travel partner 
or buddy system, might also provide the level of support to overcome a reluctance to use public transportation.

Focus group participants who had used their local bus service (fixed route) were generally aware of how public transportation operated between their home and one or two destinations. They accepted that buses run on a schedule and that they may have to take more than one bus to get to where they wanted. Some focus group participants also were aware of one of several travel passes for seniors that enabled seniors to travel locally at lower cost. Despite the reduced rate, some focus group participants still found the rate charged unreasonable. While it may be difficult for many in the working population to understand, it is clear that even very modest fares are a burden influencing some attitudes toward using public transportation. This is not necessarily a judgment on the value they place on mobility but rather the financial reality for some seniors.

Considering the physical limitations of some seniors with respect to walking to and from transportation access points, one focus group participant commented that it was necessary to make sure that one knew where their stop was in relation to their ultimate destination. Local buses do not stop everywhere but rather at fixed locations along a route. It was, therefore, necessary to do some homework beforehand to determine how far one had to go to access public transportation and how far one had to walk after disembarking. The attitude of the person towards the segments of the trip before and after the line haul did impact their propensity to use public transportation. As one focus group participant indicated, "A bit of walking ain't gonna hurt." With respect to the perceived low service frequency, one focus group participant explained this to be due to the high numbers of persons with cars; running buses one after the other would not make sense, as there would be no person to ride the buses.

At two senior centers, a bus stop of the local bus operator was situated alongside the property. When inquiring if focus group participants at these two centers knew the name of the local bus operator or the number of the bus route that served their center, the majority indicated "no." On further inquiry, focus group participants were asked whether they had taken a fixed-route bus to their senior center at any time. All responded "no." The lack of awareness of local bus services at the majority of senior centers prompted asking whether the local bus operator had visited the center to inform seniors about local services. Again, the focus group participants responded "no." This response may not be indicative of a lack of outreach on the part of the local transit provider but may reflect the fact that such a program would need to be ongoing and invasive to register with a significant share of the senior center population. Indeed, at some of the senior centers, information brochures on local fixed-route and paratransit services were evident at the reception desk.

The local paratransit service (Sunshine Line) was used by several focus group participants between their home and their local senior center. Nevertheless, not all focus group 
participants knew of all the other potential destinations that the local paratransit could serve, e.g. a doctor's office. The use of paratransit by focus group participants for other trips was somewhat influenced by lack of knowledge, the operating regime, and the perceptions and experiences of others. With respect to the operating regime, it was indicated by several focus group participants (who may not have used the service personally) that they may not be able to get a ride back to their homes at the time that suited them, the drivers do not come to their door but sound the horn to indicate that the bus is waiting, and that there is a two-hour window for pickup, which makes it difficult to plan more than one activity in a day. These possible factors may have discouraged further investigation into the travel possibilities and operating regime of the local paratransit provider by focus group participants.

\section{Public Transportation's Role in Meeting Travel Needs for Ceased-Driving Seniors}

After reflecting on the extensive body of literature, the focus group meetings, the observations that were made from the data sources reviewed, and discussions among the project team, several summary observations were developed. Mobility for seniors, particularly those who have ceased driving, is obviously very important to an individual's quality of life and well-being. Currently, transit plays a modest overall role but is very important for those persons who do rely on it. Public transportation is not necessarily a logical and certainly not a first choice post-driving travel means. Most often, the conditions that lead to cease driving result in the person much preferring traveling as an auto passenger. This, of course, is dependent on there being someone or an entity that is able to provide driving services. While post-driving cessation seniors are frequently reluctant to be burdensome to others, the practical reality remains that few find themselves in a situation where fixed-route transit services are a viable option. Paratransit services or other demand responses services, while far more appealing because they eliminate the access, egress, and outdoor wait time challenges have availability, cost, and eligibility constraints that often make them unattractive.

Looking ahead, there is no compelling evidence to suggest dramatic changes in transit service levels, land-use development patterns, service delivery costs, or other attributes that will dramatically alter travel preferences and opportunities for aging baby boomers. However, there could be incremental changes over the next several decades in both land use patterns and service supply levels. In addition, there may be opportunities to leverage technologies to improve productivity of paratransit services, to make continued progress in improving the accessibility of all the vehicles and bus stops in the urban environment, and to improve the ability to communicate with passengers in scheduling travel. These changes are likely to be incremental in nature and will not overcome the challenge of resource intensiveness of providing services to those who cannot rely on themselves, family members, or friends to provide transportation services. 
The public policy question will be to determine the extent of resource commitment that should be directed toward meeting the mobility needs of seniors unable to provide for themselves. While there is certainly political will to ensure safety-net services to provide for medical and sustenance trips for those in need, this may be a far cry from providing qualityof-life enhancing services or increasing the prospect that high quality public transit services can begin to attract a larger share of trips from persons who might otherwise rely on family or friends for mobility. There is, no doubt, a strong consensus on the desire to find more effective and cost efficient ways to serve the travel needs of older persons, but there is far less consensus regarding the extent of public resources that should be spent to attract more trips into the realm of public responsibility.

Irrespective of local policy and resource allocation priorities, some strategies are attractive:

1. Provide mobility information through a single group or entity in an urban area. This would be a logical first step to help seniors become aware of the opportunities for mobility support. While Florida has been aggressive in the coordination of mobility providers, this tactic is more intended to move toward a standardized information resource. Such a resource might help individuals deal with the plethora of mobility providers and the dynamics that exist in various programs and services.

2. Continue progress in adapting vehicles and facilities to more readily accommodate older travelers. This will contribute to greater acceptance of public transportation options.

3. Explore additional roles for the local transit providers in terms of meeting overall mobility needs of older travelers. This may include absorbing the information resource function noted above or it may include such strategies as sponsoring strategies, such as the Independent Transportation Network program described previously. These strategies might recognize that personalized transportation is both most attractive to the person needing mobility and ultimately more cost-effective in all but highly urbanized environments.

4. Monitor trends in driving cessation and senior mobility as part of local public transportation planning functions. Local entities should keep attuned to evolving trends and be in a position to take advantage of ideas and prepare to meet future needs. This responsibility is not unique to the individual agencies but a responsibility of the profession as well.

\section{What We Don't Know}

In carrying out this research, it was observed that there was an extreme level of interest but a lack of quantitative information regarding certain aspects of driving cessation and elder travel. Most notably was the lack of robust data on the share of the population that goes through the driving cessation process. It appears that much of the population passes away without going through an extended period of ceased driving but otherwise reasonable health and desire to travel. There is no rigorous mapping of which health conditions might 
preclude driving but would otherwise enable the individual to take advantage of fixed-route or curb-to-curb or door-to-door transit services. In many instances, the condition that precludes driving also precludes using fixed-route transit services and perhaps using any transit services. The research team will explore this issue through additional analysis of various data sets as part of a dissertation research project. Well beyond that work, however, a more sophisticated mapping of healthcare conditions and functional mobility might enable quantitative evaluation of the share of the ceased-driving population that could serve as a target market for public transportation.

Similarly, there is a need for additional work in exploring the probable locations of residence of the future senior population. A number of socio-demographic trends hint that the historic practice of retiring in place may not be as pronounced for baby boomers. It will be interesting to see if the role of the family changes for future generations of seniors. The extent that friends, faith-based organizations, or other partnerships step in to pick up responsibilities previously handled by an older person's family could determine the need for more substantial government intervention to meet the mobility needs of the post-driving seniors.

Finally, additional work to determine the most effective and efficient strategies for meeting elderly travel needs when they are not able to be met by family would prove useful. It is inevitable that social service agencies will continue to have a significant and perhaps growing role in meeting these travel needs. In light of the relatively high cost of customized services, it will be important to understand the most effective strategies, management plans, technologies, and policies to ensure that the most and best service possible can be delivered with the resources the public is willing to commit. 


\section{REFERENCES}

2004 Florida Statutes. Title XXIII Motor Vehicles. Chapter 322 Drivers' Licenses.

http://www.leg.state.fl.us/statutes/index.cfm?mode=View\%20Statutes\&SubMenu= 1\&App_mode=Display_Statute\&Search_String=\&URL=CH0322/Sec18.HTM

AAA (2005). Senior Licensing Laws. AAA Public Affairs

http://www.aaapublicaffairs.com/Assets/Files/20061301546440.

StateSeniorLicensingLaws.doc

Adler, G., Rottunda, S., Kuskowski, M. (1999). Dementia and Driving: Perceptions and Changing Habits. Clinical Gerontologist, Volume 20, Issue 2, pp. 23-34.

Auto Spectator (2005). Older Patients Don't Talk About Driving Ability During Medical Visits, AAA Survey of Medical Professional Finds. Article dated 24 October 2005.

Bauer, M.J. \& Rottunda, S. (2003). Older Women and Driving Cessation. Qualitative Social Work, Volume 2, pp. 309-325.

Berger, J.T. \& Rosner, F. (2000). Ethical Challenges Posed by Dementia and Driving. Journal of Clinical Ethics, Winter; Volume 11, Issue 4, pp. 304-8.

Burkhardt, J.E. (1999). Mobility Changes: their Nature, Effects, and Meaning for Elders who Reduce or Cease Driving. Transportation Research Record No. 167, pp. 1118.

Burkhardt, J.E., Berger, A.M., \& McGavock, A.T. (1998). The Mobility Consequences of the Reduction or Cessation of Driving by Older Women. In Women's Travel Issues: Proceedings from the Second Conference (Federal Highway Administration Publication FHWA-PL-97-024, pp. 439-454). Washington, DC: U.S. Department of Transportation, Federal Highway Administration.

Campbell, M.K., Bush, T.L., \& Hale, W.E. (1993). Medical Conditions Associated with Driving Cessation in Community-Dwelling, Ambulatory Elders. Journal Gerontology, Volume 48, Issue 4, pp. S230-4.

Carr, D.B. (2000). The Older Adult Driver. American Family Physician, Volume 61, Issue 1, pp. 141-146.

Cobb, R.W. \& Coughlin, J.F. (1997). Regulating Older Drivers: How are the States Coping? Journal of Aging and Social Policy, Volume 9, Issue 4, pp. 71-87.

Coley, M. (2001). Older Driver Relicensing Laws: The State of the States. The Public Policy and Aging Report, Volume 11, No. 4.

Coughlin, J.F. (2001). Beyond Health and Retirement: Placing Transportation on the Aging Policy Agenda. MIT AgeLab.

http://www.subnet.nga.org/ci/assets/BeyondHealthRetirement.pdf

Coughlin, J.F. \& Lacombe, A. (1997). Ten Myths about Transportation for the Elderly. Transportation Quarterly, Volume 51, Issue 1, ENO Transportation Foundation Inc., pp. 91-100.

Cutler, S.J., \& Coward, R.T. (1992). Availability of Personal Transportation in Households of Elders: Age, Gender, and Residence Differences. The Gerontologist, Volume 32, Issue 1, pp. 77-81. 
Dellinger, A.M., Sehgal, M., Sleet, D.A., Barrett-Connor, E. (2001). Driving Cessation: What Older Former Drivers Tell Us. Journal of the American Geriatrics Society, Volume 49, Issue 4, pp. 431.

Evans, E.L. Influences On Mobility Among Non-Driving Older Americans (2001). Personal Travel: The Long and Short of It Conference Proceedings June 28-July 1, 1999. Washington, D.C. Transportation Research Circular Number E-C026.

Fields, J. \& Casper, L.M. (2001). America's Families and Living Arrangements Population Characteristics. U.S. Census Bureau, Washington DC. http://www.census.gov/prod/2001pubs/p20-537.pdf

Foley, D.J., Heimovitz, H.K., Guralnik, J.M., \& Brock, D.B. (2002). Driving Life Expectancy of Persons Aged 70 years and Older in the United States. American Journal of Public Health, Volume 92, Issue 8, pp. 1284-9.

Forrest, K.Y., Bunker, C.H., Songer, T.J., Coben, J.H., \& Cauley, J.A. (1997). Driving Patterns and Medical Conditions in Older Women. Journal of the American Geriatric Society, Volume 45, Issue 10, pp. 1214-8.

Freedman, M.L. \& Freedman, D.L. (1996). Should Alzheimer's Disease Patients be Allowed to Drive? A Medical, Legal, and Ethical Dilemma. Journal of the American Geriatric Society, Volume 44, Issue 7, pp. 876-7.

Freund, B. \& Szinovacz, M. (2002). Effects of Cognition on Driving Involvement Among the Oldest Old: Variations by Gender and Alternative Transportation Opportunities. The Gerontologist, Volume 42, pp. 621-633.

Freund, K. Surviving Without Driving - Policy Options for Safe and Sustainable Senior Mobility. (2004) Transportation Policy for an Aging Society - Keeping Older Americans on the Move. Transportation in an Aging Society A Decade of Experience Technical Papers and Reports from a Conference November 7-9, 1999 Bethesda, Maryland. Transportation Research Board Washington, DC.

Frey, W.H. (2003). Boomers and Seniors in the Suburbs: Aging Patterns In Census 2000. Brookings Census 2000 Series, Washington D.C.: Brookings Institute - Center on Urban \& Metropolitan Policy.

Friedland, R.P. (1997). Strategies for Driving Cessation in Alzheimer Disease. Alzheimer Disease Association Disorders, Volume 11, Supplement \#1, pp. 73-5. Gilley, D.W., Wilson, R.S., Bennett, D.A., Stebbins, G.T., Bernard, B.A., Whalen, M.E., \& Fox J.H. (1991). Cessation of Driving and Unsafe Motor Vehicle Operation by Dementia Patients. Archives of Internal Medicine, Volume 151, No. 5.

Goldstein, A. \& Damon, B. (1993). We the American...Elderly. U.S. Department of Commerce Economics and Statistics Administration - Bureau of the Census. Washington, D.C. http://www.census.gov/apsd/wepeople/we-9.pdf

Haas, W.H., III \& Serow, W.J. (1993). Amenity Migration Process: A Model and Preliminary Evidence. The Gerontologist, Volume 33, pp. 212-220.

Harpine, C.J., McNeil, J.M., \& Lamas, E.J. (1990). Current Population Reports: Series P70, No. 19. The Need for Personal Assistance with Everyday Activities: Recipients and Caregivers. U.S. Government Printing Office, Washington, DC. 
Hartford Financial Services Group (2000). At the Crossroads - A Guide to Alzheimer's Disease, Dementia \& Driving. Hartford, CT.

Hebert, K., Martin-Cook, K., Svetlik, D.A., \& Weiner, M.F. (2002). Caregiver DecisionMaking and Driving: What We Say versus What We Do. Clinical Gerontologist, Volume 26, Issue 1.

Hobbs, F.B. \& Damon, B.L. (1996). 65+ in the United States. Current Population Reports: Special Studies. Report P23-190. U.S. Government Printing Office, Washington, DC.

Horowitz, A., Boerner, K., \& Reinhardt, J. P. (2002). Psychosocial Aspects of Driving Transitions in Elders with Low Vision. Gerontechnology, Volume 1, Issue 4, pp. 262-273.

Insurance Institute for Highway Safety (2001). Special Issues: Older Drivers, Volume 36,

No. 8. http://www.hwysafety.org/sr/pdfs/sr3608.pdf

Insurance Institute for Highway Safety (2005). Fatality Facts 2004: Older People. http://www.hwysafety.org/research/fatality_facts/pdfs/olderpeople.pdf

Janke, M.K. (1994). Age-related Disabilities that may Impair Driving and their Assessment. Sacramento: California State Department of Motor Vehicles, National Highway Safety Administration.

Jett, K., Tappen, R.M., \& Rosselli, M. (2005). Imposed versus involved: Different Strategies to Effect Driving Cessation in Cognitively Impaired Older Adults. Geriatric Nursing, Volume 26, Issue 2, pp. 111-6.

Kington, R., Reuben, D., Rogowski, J., \& Lillard, L. (1994). Sociodemographic and Health Factors in Driving Patterns After 50 Years of Age. American Journal of Public Health, Volume 84, Issue No. 8, pp. 1327-1329.

Kostyniuk, L.P., \& Shope, J.T. (2003). Driving and Alternatives: Older Drivers in Michigan. Journal of Safety Research, Volume 34, Issue 4, pp. 407-414.

Kostyniuk, L.P., Shope, J.T., \& Molnar L.J. (2000). Reduction and Cessation of Driving among Older Drivers in Michigan: Final Report. University of Michigan Transportation Research Institute. Report Number UMTRI-2000-06.

Lange, J.E. \& McKnight, A.J. (1996). Age-Based Road Test Policy Evaluation. Transportation Research Record. Volume 1550. pp. 81-87. Washington, DC.

Levy, D.T. (1995). The Relationship of Age and State License Renewal Policies to Driving Licensure Rates. Accident Analysis and Prevention, Volume 27, Issue 4, pp. 461467.

Longino, C.F. Jr. \& Bradley, D.E. (2003). A First Look at Retirement Migration Trends in 2000. Gerontologist, Volume 43, Issue 6, pp. 904-7.

Longino, C.F. Jr. (1995). Retirement Migration in America, Vacation Publications. Houston TX.

Longino, C.F. Jr., Jackson, D.J., Zimmerman, R.S., \& Bradsher, J.E. (1991). The Second Move: Health and Geographic Mobility. Journal of Gerontology: Social Sciences, Volume 46, pp. S218-S244. 
Longino, C.F. Jr., Perzynski, A.T., Stoller, E.P. (2002). Pandora's Briefcase: Unpacking the Retirement Migration Decision. Research on Aging, Volume 24, Issue 1, pp. 29-49.

Marottoli, R.A., Mendes de Leon, C.F.M., Glass, T.A., Williams C.S., Cooney, L.M., Jr. \& Berkman L.F. (2000). Consequences of Driving Cessation: Decreased Out-ofHome Activity Levels. Journal of Gerontology Series B Psychology Science Social Science, Volume 55, pp. 334-340.

McKnight, J. (2003). The Freedom of the Open Road: Driving and Older Adults.

Generations. The Journal of the American Society on Aging, Volume 27, No. 2, pp. $25-3$.

Messinger-Rapport, B.J. \& Rader, E. (2000). High Risk on the Highway: How to Identify and Treat the Impaired Older Driver. Geriatrics, Volume 55, No. 10, pp. 32-45

Molnar, L.J. \& Eby, D.W. (2005). A Brief Look at Driver License Renewal Policies in the United States. Public Policy \& Aging Report. National Academy on an Aging Society, Volume 15, Issue 2, pp. 1, 13-17.

Morrisey, M.A. \& Grabowski, D.C. (2004). State Motor Vehicle Law and Older Drivers. Health Economics, Volume 14, Issue 4, pp. 407-419. John Wiley \& Sons, Ltd.

Nelson, D.E., Sacks, J.J., \& Chorba, T.L. (1992). Required Vision Testing for Older Drivers. New England Journal of Medicine, Volume 326, pp. 1784-1785.

Office of Highway Policy Information - Federal Highway Administration (2001). Highway Statistics 2000. Licensed drivers, by State, Sex, and Age Group Table DL-22. http://www.fhwa.dot.gov/ohim/hs00/pdf/dl22.pdf

Office of Highway Policy Information - Federal Highway Administration (2004). Highway Statistics 2003. http://www.fhwa.dot.gov/policy/ohim/hs03/index.htm

Owsley, C., Ball, K., McGwin, G., Sloane, M.E., Roenker, D.L., White, M.F., \& Overley, T. (1998). Visual Processing Impairment and Risk of Motor Vehicle Crash Among Older Adults. Journal of the American Medical Association, Volume 279, No. 14.

Persson, D. (1993). The Elderly Driver: Deciding when to Stop. Gerontologist, Volume 33, Issue 1, pp. 88-91.

Polzin, S. \& Page, O. (2005). Technical Memorandum One-Transit Use Viability Among Older Drivers Losing Driving Privileges. National Center for Transit Research. Tampa, FL. http://www.nctr.usf.edu/publications.htm

Rock, S.M. (1998). Impact from Changes in Illinois Drivers License Renewal Requirements for Older Drivers. Accident Analysis and Prevention, Volume 30, Issue 1, pp. 69-74. Elsevier Science Limited.

Rosenbloom, S. (2003). Older Drivers. Should We Test Them Off the Road? Access, Number 23, pp. 8-13. University of California Transportation Center.

Rosenbloom, S. (1993). Transportation Needs of the Elderly Population. Clinics in Geriatric Medicine, Volume 9, Number 2, pp. 297-310. 
Rosenbloom, S. (2004). Mobility of the Elderly: Good News and Bad News.

Transportation in an Aging Society A Decade of Experience Technical Papers and

Reports from a Conference November 7-9, 1999 Bethesda, Maryland,

Transportation Research Board Washington, DC.

Satariano, W.A., MacLeod, K.E., Cohn, T.E. \& Ragland, D.R. (2004). Problems With

Vision Associated Limitations or Avoidance of Driving in Older Populations. The

Journals of Gerontology Series B: Psychological Sciences and Social Sciences,

Volume 59, pp. S281-S286.

Sauls. S., Zeller, R., Klein, D.F., \& Grosz. M.J. (2001). Final Report for the Mature

Operator Database Project Florida Department of Transportation Grant Number

FT-01-24-08-01 Contract AJ587. Department of Highway Safety and Motor

Vehicles - Division of Driver Licenses. Tallahassee, FL.

Schiamberg, L.B. \& McKinney, K.G. (2003). Factors Influencing Expectations to Move or

Age in Place at Retirement Among 40- to 65-Year-Olds. Journal of Applied

Gerontology, Volume 22, Issue 1, pp. 19-41.

Shope, J.T. (2003). What Does Giving Up Driving Mean to Older Drivers, and Why Is It

So Difficult? Generations. The Journal of the American Society on Aging, Volume

27, Issue 2, pp. 57-59.

Stamatiadis, N., Agent, K.R., \& Rideway, M. (2003). Driver License Renewal for the

Elderly: A Case Study. The Journal of Applied Gerontology, Volume 22, Issue 1, pp. 42-56.

Stanfield, R. (1996). Aging of America. National Journal, Volume 7, Issue 20, pp. 15781583.

Staplin, L. \& Freund, K. (2005). Public and Private Policy Initiatives to Move Seniors

Forward. Public Policy \& Aging Report. National Academy on an Aging Society,

Volume 15, Issue 2, pp. 1, 3-5.

Stewart, R., Moore, M., Marks, R., May, F., and others. (1993). Driving Cessation in the

Elderly: An Analysis of Symptoms, Diseases, and Medications. Journal of

Geriatric Drug Therapy, Volume 8, Issue 2, pp. 45-60.

Straight, A. (1997). Community Transportation Survey Research Report. AARP Public

Policy Institute. http://assets.aarp.org/rgcenter/il/d16603_commtran.pdf

Taylor, B.D. \& Tripodes, S. (2001). The Effects of Driving Cessation on the Elderly with

Dementia and their Caregivers. Accident Analysis \& Prevention, Volume 33, pp.

519-528.

Transportation Research Board (2005). Safe Mobility for Older Americans - Report of the

Committee for the Conference on Transportation in an Aging Society.

Transportation Research Board. Washington DC.

http://www.trb.org/publications/conf/CPW2.pdf

Trobe, J.D., Waller, P.F., Cook-Flannagan, C.A., Teshima, S.M., \& Bieliauskas, L.A. (1996). Crashes and Violations Among Drivers with Alzheimer Disease. Archives of Neurology, Volume 53, Issue 5, pp. 411-416. American Medical Association, Chicago, IL. 
U.S. Census Bureau (2005). DP-1. Profile of General Demographic Characteristics: 2000. Census Bureau. http://www.census.gov/census2000/states/us.html

U.S. Census Bureau (2005). U.S. Interim Projections by Age, Sex, Race, and Hispanic Origin. U.S. Census Bureau, Population Division, Population Projections Branch http://www.census.gov/population/projections/SummaryTabB3.xls

U.S. Department of Transportation \& Bureau of Transportation Statistics (2003). NHTS 2001 Highlights Report. BTS03-0. Washington DC.

U.S. Department of Transportation (2004). 2001 National Household Travel Survey User's Guide Version 3 - National Sample with Add-Ons. Washington DC. http://nhts.ornl.gov/2001/usersguide/index.shtml

Victoria Transport Policy Institute (2006). Transportation Demand Encyclopedia http://www.vtpi.org/tdm/index.php (accessed April 2006)

Waldorf, B. (2001). Anticipated Mode Choice Following Driving Cessation. European Research in Regional Science, Volume 11, pp. 22-40.

Waller, P.F. (1991). The Older Driver. Human Factors, Volume 33, No. 5, pp. 499-505.

Walser, N. (1991). When to Hang up the Keys - Aged Drivers. Harvard Health Letter. http://www.findarticles.com/p/articles/mi_m1585/is_n1_v17/ai_11514877

Wang, C. \& Carr, D. (2004). Older Driver Safety: A Report from the Older Drivers Project. Journal of the American Geriatric Society, Volume 52, pp. 143-9.

Yassuda, M.S., Wilson, J.J., \& von Mering, O. (1997). Driving Cessation: The Perspective of Senior Drivers. Educational Gerontology, Volume 23, Issue 6, pp. 525-538. 


\section{APPENDIX A: FOCUS GROUP SESSION ADVERTISEMENT}




\section{Drivers and Ex-Drivers...........!!!}

Are you an ex-driver? Have you stopped driving permanently during the last 15 years? Do you still drive but drive less now than you did 5 years ago? If you have answered yes to any of these questions we would like to speak with you.

The Center for Urban Transportation Research at the University of South Florida will be conducting small group discussions at this senior center during the month of J anuary 2006. The research team would like to understand how you travel locally when you do not drive or drive less.

Would you like to share your experiences with us? Volunteers are needed-you or your friends are invited. Aftendance at one session (no more than two hours) is all that is involved.

Refreshments will be provided.

Discussion Group will be held at the XXXX Senior Center

Friday $27^{\text {th }}$ January 2006, $10-11.30$ am

Interested .....?

To register - Please call XXXX: 999-999-9999

(Monday to Friday $10 \mathrm{am}$ to $3 \mathrm{pm}$ ) 


\section{APPENDIX B: FOCUS GROUP SESSION STRUCTURE}




\section{SENIOR TRAVEL BEHAVIOR \\ PARTICIPANT INTERVIEW GUIDE}

\section{FACILITATOR ROLE}

- Welcome and expressions of gratitude

- Explanation of research project

- Signing of consent forms

- Ensure participation from all

- Manage conversation; one person speaks and no one dominates

- Inform participants of digital recording

\section{DESIRED OUTCOMES}

- Assess how participants have altered driving habit/behaviors as a result of lost driving privileges

- Assess why participants have altered driving habits/behaviors

- Identify how participants are satisfying life's needs absent driving privileges

- Identify changes in familial relationships in response to lost driving privileges

- Identify system-specific features of public transportation services that attract participants who have lost driving privileges.

- Identify system-specific features of public transportation services that detract participants who have lost driving privileges.

\section{INTERVIEW “GUIDE”}

- Why did you stop driving?

- How did you know it was time to stop driving?

- How has your life changed since you stopped driving?

o Positives?

o Negatives?

- How do you feel about not driving?

- Now that you've stopped driving, how do you get around?

- How has public transportation helped you since you quit driving?

- Why don't you use public transportation more frequently?

- How have your family members or friends helped you since you quit driving?

- Additional comments?

\section{CLOSURE}

- Post-interview questionnaire.

- Extend gratitude and explain next steps. 


\section{APPENDIX C: FOCUS GROUP QUESTIONNAIRE - FORMER DRIVERS}




\section{TRANSIT USE VIABILITY OF SENIORS LOSING DRIVING PRIVILEGES}

(Persons who have permanently stopped driving)

This study is about senior travel behavior, how do you get from home to the grocery store, or pharmacy and back home again? We will ask you questions about how you travel locally. We don't require your name and will not be selling you anything and your responses will remain confidential.

\section{Questions about your driving status}

1. How many years had you driven at the time when you stopped?

more than 40 years

21 to 40 years

6 to 20 years

1 to 5 years

2. Do you hold a valid drivers license issued by any state in the U.S.?

Yes (go to question 3)

No (go to question 4)

3. In which year will your current driver's license expire?

2006

2007 to 2008

2009 to 2010

2011 or later

Questions about when you permanently stopped driving

4. Which year did you stop driving?

1989 or before

between 1990 and 1999

between 2000 and 2002

between 2003 and 2005 
5. Which was the primary factor that influenced you to stop driving? (check one response only)

License revoked

Health reasons

Financial reasons

Personal discomfort with driving

Family pressure

Other

6. Since the time that you stopped driving till now have you used public transit (e.g., Hartline Bus, Sunshine Line, Trolley) for any local trip, i.e., from your home to the grocery store or doctor?

Yes

No

\section{Questions about transportation}

7. Which transportation mode do you currently use for the majority of your local trips? (check one response only)

$\square \quad$ Car passenger (where someone else is driving)

Public transit (i.e., Hartline Bus, Sunshine Line, Trolley)

Walk

Other

8. What one factor gives you concern about using public transit? (check one response only)

Being worried about the expense of using public transit

$\square \quad$ Public transit does not go where I want to go

Public transit takes too long to get to where I want to go

Getting to and traveling on public transit is difficult

Public transit is not available when I need to travel

Being worried about crime on public transit 
$\square \quad$ Lack of information about public transit

9. What one factor if changed would make public transit an option for you to use today? (check one response only)

Free or low cost public transit services

Many more destinations (i.e., it goes to where I want to go)

Faster service (i.e., takes a short time to where I want to go)

Accessibility (i.e., closer to my home and easier to get on or off)

Higher frequency of services

Visible personal safety and security measures, e.g. transit police

More information and training about using public transit

Nothing - I still would not use public transit despite improvements

\section{Questions about you and your household}

10. Total number of persons in your household (including yourself)?

11. Total number of persons with drivers licenses in your household (including yourself)?

12. Total number of vehicles in your household

13. Who normally drives the car (the majority of the time) in your household? (check one response only)

Spouse/partner/significant other

Someone else (other than spouse/partner/significant other)

Not driven at all

A car is not available in my household to drive 
14. Who would be your first choice in assisting you with transportation if you needed it? (check one response only)

$\square \quad$ Spouse/significant other

Adult children

Other relative (e.g., son-in-law or grandchild related to you)

Friend/neighbor/volunteer (unrelated to you)

Caretaker/Hired-help (not a taxi)

No one else

\section{Questions about You}

15. Gender

Male

Female

16. Are you?

Between 55 years and 64 years of age

Between 65 years and 74 years of age

Between 75 years and 84 years of age

Above 85 years of age

17. What is your race or ethnic heritage?

White non-Hispanic

African American/Black non-Hispanic

Hispanic of any Race

Other

18. Which of the following best describes your annual household income in 2005?

Up to $\$ 30,000$

Over $\$ 30,000$ 
19. If you had to relocate to another residential location this year how important would access to public transit be to you? (check one response only)

$\square \quad$ Extremely important

Important

Somewhat important

Unimportant

Irrelevant/no importance

20. Do you think that public transit (e.g., Hartline Bus, Sunshine Line, Trolley) is a viable transportation alternative for you to use today?

$\square \quad$ Yes

No

There is a possibility that we would like to follow up later this year on your travel experiences, would this be OK with you?

$\square \quad$ Yes

$\square \quad$ No

Name

Contact Number

Thank you!!! 


\section{APPENDIX D: FOCUS GROUP QUESTIONNAIRE - CURRENT DRIVERS}




\section{TRANSIT USE VIABILITY OF SENIORS LOSING DRIVING PRIVILEGES (Persons who have reduced their driving exposure)}

This study is about senior travel behavior, how do you get from home to the grocery store, or pharmacy and back home again? We will ask you questions about how you travel locally. We don't require your name and will not be selling you anything and your responses will remain confidential.

\section{Questions about your driving status}

1. How many years have you driven to date?

more than 40 years

21 to 40 years

6 to 20 years

1 to 5 years

2. Do you hold a valid drivers license issued by any state in the U.S.? Yes (go to question 3)

No (go to question 4)

3. In which year will your current driver's license expire?

2006

2007 to 2008

2009 to 2010

2011 or later

4. Are you currently driving a car for at least one trip per week?

Yes

No 


\section{Questions about transportation}

5. Which transportation mode do you currently use for the majority of your local trips? (check one response only)

Drive myself (in a personally operated vehicle)

Car passenger (where someone else is driving)

Public transit (i.e., Hartline Bus, Sunshine Line, Trolley)

Other

6. What one factor gives you concern about using public transit? (check one response only)

$\square \quad$ Being worried about the expense of using public transit

Public transit does not go where I want to go

Public transit takes too long to get to where I want to go

Getting to and traveling on public transit is difficult

Public transit is not available when I need to travel

Being worried about crime on public transit

Lack of information about public transit

7. What one factor if changed would make public transit an option for you to use today? (check one response only)

Free or low cost public transit services

Many more destinations (i.e., it goes to where I want to go)

Faster service (i.e., takes a short time to where I want to go)

Accessibility (i.e., closer to my home and easier to get on or off)

Higher frequency of services

Visible personal safety and security measures, e.g. transit police

More information and training about using public transit

Nothing - I still would not use public transit despite improvements 


\section{Questions about you and your household}

8. Total number of persons in your household (including yourself)?

9. Total number of persons with drivers licenses in your household (including yourself)? ........

10. Total number of vehicles in your household ........

11. Who normally drives the car in your household?

Yourself

Spouse/partner/significant other

Someone else (other than spouse/partner/significant other)

Not driven at all

12. Who would be your first choice in assisting you with transportation if you needed it? (check one only)

$\square \quad$ Spouse/significant other

Adult children

Other relative (e.g., son-in-law or grandchild related to you)

Friend/neighbor/volunteer (unrelated to you)

Caretaker/Hired-help (not a taxi)

No one else

\section{Questions about You}

13. Gender

Male

Female

14. Are you?

Between 55 years and 64 years of age

Between 65 years and 74 years of age 
$\square \quad$ Between 75 years and 84 years of age
Above 85 years of age

15. What is your race or ethnic heritage?

White non-Hispanic

African American/Black non-Hispanic

Hispanic of any Race

Other

16. Which of the following best describes your annual household income in 2005?

$\square \quad$ Up to $\$ 30,000$

$\square \quad$ Over $\$ 30,000$

17. If you had to relocate to another residential location this year how important would access to public transit be to you? (check one response only)

$\square \quad$ Extremely important

Important

Somewhat important

Unimportant

Irrelevant/no importance

18. In the past 12 months have you considered that you may have to stop driving at some time in the future?

$\square \quad$ Yes

No 
19. Do you think that public transit (i.e., Hartline Bus, Sunshine Line, Trolley) is a viable transportation alternative for you to use today?

$\square \quad$ Yes

$\square \quad$ No

There is a possibility that we would like to follow up later this year on your travel experiences, would this be OK with you?

$\square \quad$ Yes

$\square \quad$ No

Name

Contact Number

Thank you!!! 